\title{
An acoustic survey of zoophagic bats on islands in the Kimberley, Western Australia, including data on the echolocation ecology, organisation and habitat relationships of regional communities
}

\author{
N.L. McKenzie ${ }^{1}$ and R.D. Bullen ${ }^{2}$ \\ ${ }^{1}$ Department of Environment and Conservation, Science Division, PO Box 51, Wanneroo, Western \\ Australia 6946, Australia. \\ 243 Murray Drive, Hillarys, Western Australia 6025, Australia. \\ Email: normm@dec.wa.gov.au
}

\begin{abstract}
Bat ultrasound was recorded on 30 of the in-shore islands along the Northern Kimberley coast as part of a biological survey to assess their conservation potential as microcosms of the region's biodiversity. Species were identified from their search-mode echolocation call sequences using a call library based (mainly) on two variables: the frequency maintained for the greatest number of cycles $\left(F_{\text {peakc }}\right)$ and sharpness quotient $(Q)$. Populations of 20 of the 21 species that comprise the Northern Kimberley region's zoophagic bat fauna are now known to occur on these islands, an average of $8 \pm 0.6$ (S.E.) species per island.
\end{abstract}

The Kimberley has two compositionally distinct bat communities, one occupying landward environments and the other occupying mangroves. Both were represented on the islands. In each community, the search-mode calls of syntopic species were dispersed in spectral space, with few showing more than peripheral overlap in their spectral variables $\left(Q\right.$ and $\left.F_{\text {peakc }}\right)$. Their different call designs were functionally appropriate to differences in (1) foraging niche predicted from empirical data on species' flight capabilities and foraging behaviours, and (2) airframe variables related to flight performance and control. These observations imply a niche-assembly model of metacommunity structure. Pleistocene climatic fluctuations and habitat filtering also appear to have influenced metacommunity structure at regional scales. However, nestedness was observed in assemblage composition that could be explained by environmental factors, implying the influence of environmental controls. The richest bat assemblages were recorded on the most mesic of the large inshore islands with cavernous landscapes and permanent pools.

Comparison with surrounding regions revealed a diversity-productivity model of faunal structure, with an organisation that conforms to the specialisation hypothesis. Six islands, including their mangrove stands, are identified as priorities for conservation.

KEYWORDS: bat, echolocation, $F$ Q, metacommunity, species composition, habitat relationships

\section{INTRODUCTION}

Effective conservation depends on detailed species inventory, extensive knowledge of species natural history and an understanding of the factors that regulate composition point-to-point across landscapes (e.g. Leibold et al. 2010). Comprehensive bat lists are available for most bioregions of Western Australia (WA) (e.g. Burbidge et al. 2008), but site composition data are rare on the Kimberley mainland (e.g. McKenzie and Rolfe 1986), and there are none from its islands. Where such data are available from mainland Australia, analyses have revealed a diversity-productivity model of community structure (Nijs and Roy 2000), the most arid regions having species-poor faunas (McKenzie et al. 2002). In these communities, cooccurring species occupy different foraging niches, 
but environmental factors influence turnover in species composition across landscapes (e.g. Crome and Richards 1988; McKenzie and Start 1989; Milne et al. 2005b; McKenzie and Bullen 2009). For the bats in these communities, foraging method is as tightly coupled to aspects of their echolocation call structure as it is to their flight morphology (McKenzie and Bullen 2003; Bullen and McKenzie 2009), and search-mode calls are useful for acoustic identification of species (Bullen and McKenzie 2002a; McKenzie and Bullen 2009).

There are no published assemblage data with which to assess the organisation of bat faunas on Australia's continental islands, despite the importance of these islands as conservation arks (Nias et al. 2010). The Kimberley's inshore islands extend from Sunday Island in King Sound to Adolphus Island in Cambridge Gulf (Figure 1) and, in terms of their climate, geology and biogeographical history, belong to the Northern Kimberley bioregion (e.g. Gibson and McKenzie 2012). Of the 24 species of echolocating bats listed for the Kimberley, 21 are known from the Northern Kimberley (Burbidge et al. 2008; Armstrong 2011). Prior to this study, however, available data on the region's island bat faunas was fragmentary, as it was gleaned from opportunistic collections made during a few brief visits over the last 40 years by zoologists carrying out general vertebrate surveys (e.g. McKenzie et al. 1978; Friend et al. 1991; McKenzie et al. 1995; How et al. 2006). The richest list was from Koolan Island, where iron ore has been mined since the 1960s (McKenzie et al. 1995). Except for Cockatoo, a small island adjacent to Koolan, the rest of these islands are uninhabited and seldom visited.

This study is part of a biodiversity survey of Kimberley islands (Gibson and McKenzie 2012). In this paper we also report the results of our fieldwork on the adjacent mainland that aimed to document assemblage composition at a range of locations scattered throughout the Kimberley, characterise and differentiate the search-mode echolocation calls of Kimberley bat species, and develop a call library. Herein, a call is defined as a single pulse of sound emitted as part of an echolocation call sequence. Next, using this library, we identify bat call sequences recorded on the 30 Northern Kimberley islands sampled during the acoustic survey and, after incorporating specimen records, display the composition of the island faunas in terms of species co-occurrence patterns, then explore these patterns in terms of environmental factors.

Finally, in assessing the composition of Kimberley bat assemblages, we integrate habitat and metacommunity paradigms (e.g. Armstrong 2005). To provide context on aspects of metacommunity structure at regional scales (Leibold et al. 2010), avoiding the assumption that species respond only to environmental controls and not to interactions with other species, biogeographic history, phylogenetic relationships and/or habitat filters, we:

1. document the foraging niches of Kimberley bats in terms of differences in their flight capabilities, airframe designs, foraging microhabitats and foraging strategies;

2. consider the implications of Pleistocene climatic fluctuations for the Kimberley fauna; and

3. examine species geographical ranges for gaps and limits that might indicate habitat filtering.

Since observations on species foraging niche are scarce for most Australian bats, our field program focused on collecting these data, and we report them in detail.

\section{METHODS}

\section{STUDY AREA}

The Kimberley is divided into five geomorphically distinctive bioregions (Figure 1). The most mesic of these, the Northern Kimberley, has an area of $82,540 \mathrm{~km}^{2}$ and encompasses hot tropical sub-humid near-coastal as well as inland landscapes. Average annual rainfall ranges from $1500 \mathrm{~mm}$ in the northwest to $800 \mathrm{~mm}$ in the south-east and is locally reliable, while average temperatures range from a daily maximum of $32.8^{\circ} \mathrm{C}$ in January to a night-time minimum of 14.8 in July. The region is drained by seasonally active river systems fringed by tall trees that form riparian forests, and permanent pools are common. Its landscapes support tree steppe, woodlands and open forests on undulating hill-country with broad valleys and on rugged boulder country associated with extensive ranges, plateaux and uplands dissected by gorges. Tree hollows and caverns are common. Patches of rainforest are scattered through the region and extensive mangrove forests fringe estuaries, embayments and broad macro-tidal mudflats between steep headlands on its otherwise rocky shoreline. Its rugged sunken coastline is deeply embayed and fringed by more than 2,500 recognisable islands, 145 of which exceed 100 ha, and 20 exceed 1000 ha. Augustus, the largest, is 18,990 ha. These islands extend from King Sound in the bioregion's south-west to Cambridge Gulf on its eastern edge, and provide microcosms of the Northern Kimberley's geological, topographic, climatic (coastal) and vegetative diversity (e.g. Gibson and McKenzie 2012).

\section{KIMBERLEY BAT COMMUNITIES}

The Kimberley bat fauna comprises six families and a total of 27 species (Table 1). All but one of 


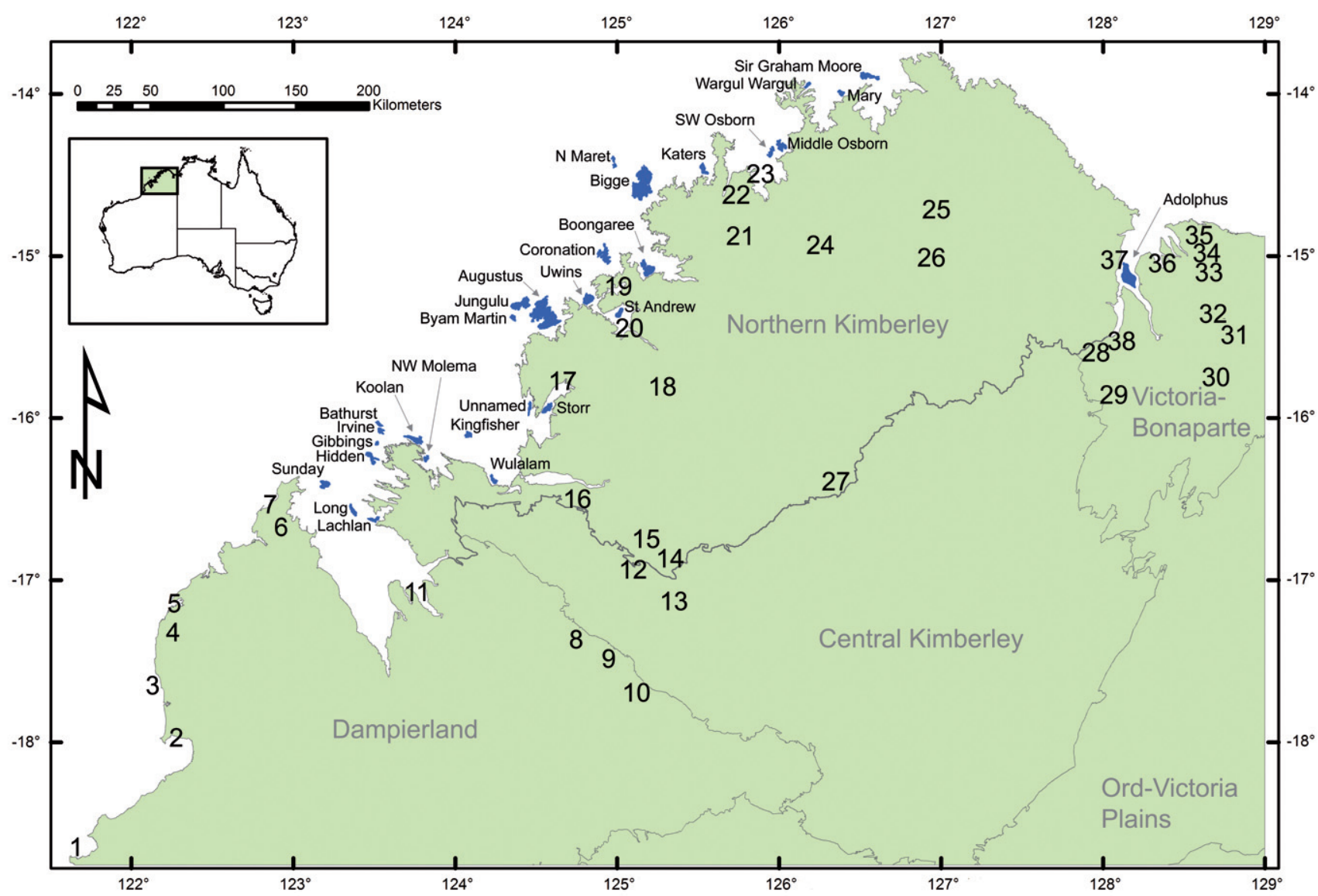

FIGURE 1 The Northern Kimberley biogeographic region (outlined in bold) showing the boundaries of other Kimberley bioregions (Environment Australia 2000), the 38 mainland localities (Table 2) and the islands sampled for bats.

these families (Pteropodidae, three species) are zoophagic and use echolocation to forage. The pteropodid species are phytophagic and do not use echolocation. Several sources of data were used to compile bat lists for each of the five bioregions that comprise the Kimberley, including Lumsden et al. (2005), Burbidge et al. (2008), Armstrong (2011) and the specimen registers of Australian museums (OZCAM 2011). For these lists, specific decisions were made on the following species records:

1. We excluded some early records that are still listed under their old names in the Australian Museum (AM) and Western Australian Museum (WAM) registers. These include specimens of Scotorepens greyii from Dampierland and Ord-Victoria Plains that are listed as Scotorepens balstoni caprenus (e.g. AM04469) and several S. sanborni specimens that are still listed as S. greyii (e.g. AM22044). Following the taxonomic revision (Kitchener and Caputi 1985), the genus name was automatically updated (from Nycticeius to Scotorepens), but not the species names.

2. We excluded two species (Tadarida australis and Vespadelus finlaysoni) that are common throughout adjacent desert regions and penetrate the southern (arid) periphery of the Kimberley to the extent of the red desert sand dune fields, i.e. the southern parts of the OrdVictoria Plains and Dampierland bioregions. Data on their geographic distributions were provided in Bullen and McKenzie (2005) and Kitchener et al. (1987), respectively.

3. We excluded two Northern Territory species that could occur in the Victoria-Bonaparte bioregion in WA (Taphozous kapalgensis and Pipistrellus adamsi - see Lumsden et al. 2005), but have not been confirmed despite several subsequent bat surveys of the area.

4. We excluded an AM record of Nyctophilus walkeri (AM25502) from Ord Victoria Plains that was collected in September 1989 by Harry Parnaby at a site on Bell Creek $3 \mathrm{~km}$ south of Bell Gorge $\left(17^{\circ} 01^{\prime} \mathrm{S}, 125^{\circ} 14^{\prime} \mathrm{E}\right)$ in the Northern Kimberley (Harry Parnaby, pers. comm.).

5. We excluded a single Hipposideros stenotis record labelled just 'Derby', but with no other information (WAM M36730 from May 1992). 
Three sources of data were used to compile lists of the echolocating bats known from localities scattered throughout the four Kimberley bioregions that approach the coast (Dampierland, Northern Kimberley, Central Kimberley and VictoriaBonaparte - Figure 1): the specimen register at the WAM, mammal survey records collected during Kimberley field work over the last 38 years (i.e. McKenzie et al. 1975, 1977, 1978, 1995; Kitchener et al. 1981; McKenzie 1983; McKenzie and Rolfe 1986; Lumsden et al. 2005), and species captured during recent field work, particularly the mainland work required to build a bat call library for this project. Localities each included a typical landscape mosaic and were up to $15 \mathrm{~km}$ in radius (i.e. within an hour's commuting-range for all species), akin to the $50 \mathrm{~km}^{2}$ sites used by Presley et al. (2009) for their assessment of metacommunity structure in Paraguayan bats. Mangrove localities excluded records from adjacent habitats, and were treated separately if the mangrove patches were more than $15 \mathrm{~km}$ apart.

The analysis package PATN (Belbin 1995) was

TABLE 1 Kimberley bat fauna (from Burbidge et al. 2008). Nomenclature follows Van Dyck and Strahan (2008). Families = (E)mballonuridae, (H)ipposideridae, (Mi)niopteridae, (Me)gadermatidae, (M)olossidae, (P)teropodidae and two vespertilionid sub-families (N)yctophilinae and (V)espertilioninae.

\begin{tabular}{lll} 
Family & Species & Code \\
\hline $\mathrm{V}$ & Chalinolobus gouldii (Gray, 1841) & $\mathrm{Cg}$ \\
$\mathrm{M}$ & Chaerephon jobensis (Miller, 1902) & $\mathrm{Cj}$ \\
$\mathrm{V}$ & Chalinolobus nigrogriseus (Gould, 1856) & $\mathrm{Cn}$ \\
$\mathrm{H}$ & Hipposideros ater Templeton, 1848 & $\mathrm{Ha}$ \\
$\mathrm{H}$ & Hipposideros stenotis Thomas, 1913 & $\mathrm{Hs}$ \\
$\mathrm{V}$ & Myotis macropus Gould, 1855 & $\mathrm{Ma}$ \\
$\mathrm{M}$ & Mormopterus beccarii Peters, 1881 & $\mathrm{Mb}$ \\
$\mathrm{Me}$ & Macroderma gigas (Dobson, 1880) & $\mathrm{Mg}$ \\
$\mathrm{P}$ & Macroglossus minimus (Geoffroy, 1810) & $\mathrm{Mm}$ \\
$\mathrm{M}$ & Mormopterus loriae cobourgiana Johnson, 1959 & $\mathrm{Ml}$ \\
$\mathrm{Mi}$ & Miniopterus schreibersii orianae ${ }^{\mathrm{b}}$ Thomas, 1922 & $\mathrm{Ms}$ \\
$\mathrm{N}$ & Nyctophilus arnhemensis Johnson, 1959 & $\mathrm{Na}$ \\
$\mathrm{N}$ & Nyctophilus daedalus Thomas, 1915 & $\mathrm{Nd}$ \\
$\mathrm{N}$ & Nyctophilus geoffroyi pallescens ${ }^{\mathrm{c}}$ Thomas, 1913 & $\mathrm{Ng}$ \\
$\mathrm{N}$ & Nyctophilus walkeri Thomas, 1892 & $\mathrm{Nw}$ \\
$\mathrm{V}$ & Pipistrellus westralis Koopman, 1984 & $\mathrm{Pw}$ \\
$\mathrm{P}$ & Pteropus scapulatus Peters, 1862 & $\mathrm{Ps}$ \\
$\mathrm{P}$ & Pteropus alecto Temminck, 1837 & $\mathrm{Pa}$ \\
$\mathrm{H}$ & Rhinonicteris aurantius Gray, 1845 & $\mathrm{Ra}$ \\
$\mathrm{E}$ & Saccolaimus flaviventris (Peters, 1867) & $\mathrm{Sf}$ \\
$\mathrm{V}$ & Scotorepens greyii (Gray, 1843) & $\mathrm{Sg}$ \\
$\mathrm{V}$ & Scotorepens sanborni (Troughton, 1937) & $\mathrm{Ss}$ \\
$\mathrm{M}$ & Tadarida australis (Gray, 1838) & $\mathrm{Ta}$ \\
$\mathrm{E}$ & Taphozous georgianus Thomas, 1915 & $\mathrm{Tg}$ \\
$\mathrm{V}$ & Vespadelus caurinus (Thomas, 1914) & $\mathrm{Vc}$ \\
$\mathrm{V}$ & Vespadelus finlaysoni (Kitchener, Caputi and Jones, 1987) & $\mathrm{Vf}$ \\
$\mathrm{V}$ & Vespadelus douglasorum (Kitchener, 1976) & $\mathrm{Vd}$ \\
\hline & & \\
\hline
\end{tabular}

\footnotetext{
a Herein abbreviated to 'Mormopterus loriae' b Herein abbreviated to 'Miniopterus schreibersii'
}

c Herein abbreviated to 'Nyctophilus geoffroyi' 
used to expose patterns of species composition and species co-occurrence in the mainland data matrix (presence/absence data). The Czekanowski measure was used to compare the localities according to their species similarities and Two-step (Belbin 1980) was used to determine the quantitative relationships between species in terms of their co-occurrences. Flexible UPGMA (unweighted pair-group mean averaging; Sneath and Sokal 1973; Belbin 1995), with the clustering parameter (Beta) set to -0.1, was used to derive classification dendrograms from the locality and species dissimilarity matrices, then the data matrix was reordered accordingly. ANOSIM (Clarke and Green 1988) was used to test if there was a significant difference in the $F$-ratio of the association values between/within classification groups, compared with 100 iterations in which localities and species were randomly re-allocated between groups.

\section{REFERENCE CALL LIBRARY}

Search-mode call data were collected from freeflying bats that: (1) we could identify in-flight while their echolocation calls were being recorded (Macroderma gigas and Saccolaimus flaviventris) and (2) had been captured in mist nets or bat traps set over pools, in riparian woodlands, in mangroves or across the entrances of caves at a variety of Kimberley mainland locations (Table 2), then identified and released on-site within two hours with bioluminescent tags (Buchler 1976) and recorded on subsequent passes [the external character used to distinguish $S$. greyii from $S$. sanborni is described in Appendix 9]. Captured bats were released into open air-spaces well clear of obstructions such as trees and shrubs. During recording, the detector microphone was hand-held and orientated towards the bat. Most data were derived from calls emitted 10-15 s after release; calls recorded less than $3 \mathrm{~s}$ after release were ignored (Parsons and Szewszak 2009). We excluded sequences if echolocation calls by more than one individual were present in the sequence (i.e. calls were out-of-phase or irregularly over-packed relative to the species wing beat frequency; Bullen and McKenzie 2002b).

The call sequences were recorded using the frequency-division function of Anabat II ultrasound detectors (Titley Electronics, Australia), set to a frequency division ratio of 16 . Frequencydivision in these detectors involves Zero-crossing and is known to operate on the strongest harmonic present, normally the fundamental harmonic (Parsons et al. 2000). They ouput a quasi-square wave that represents the frequency of every 16th cycle in the call, eliminating cycle amplitude but not frequency, so the number of cycles at each frequency can be estimated for the call. We recognise that frequency changes that occur during the intervening 15 cycles (the time it takes for the frequency-division detector to output one cycle) cannot be detected at all, so frequency-divided calls that had been reduced to less than 10 cycles were excluded from the library $[10 \mathrm{~ms} @ 15 \mathrm{kHz}=150$ cycles $=9.4$ cycles after division (150/16); 5 ms @ 30 kHz; 2.5 ms @ 60 kHz]. Such short calls were often of poor quality (e.g. clipped because of the detector sensitivity threshold chosen), or were not search mode calls.

Output was stored directly as linear PCM WAVE files on an Olympus LS10 digital recorder set to a sample rate of $44.1 \mathrm{kHz}$ at a bit-depth of 16 . A Sony Minidisc recorder (MZ-N510) in SP-mono mode $(9.1 \mathrm{kHz}, 16 \mathrm{bit})$ was used for some of the early recordings (made between 2003 and 2008, see Appendix 1) but, given the division factor (16) applied to the input signal, Nyquist criteria allows that this sampling rate should accurately reproduce sounds of up to $73 \mathrm{kHz}(=9.1 \times 0.5 \times 16)$. Only three species in the WA bat fauna have search mode call frequencies higher than this. They are the three leaf-nosed bats and use distinctive FM-CF-FM calls at quite different frequencies $(H$. stenotis $\approx 103 \mathrm{kHz}$, Rhinonicteris aurantia $\approx 115 \mathrm{kHz}$ and $H$. ater $\approx 160$ $\mathrm{kHz}$; Churchill 2008). Recordings made prior to 2003 were stored on Metal IV cassette tapes using a Sony Walkman Professional (WMD6C) tape recorder.

COOL EDIT 2000, now 'Adobe Audition 2' (Adobe Systems, USA), was used to display call sequences in spectral view. Since bats flap their wings in a narrow range of frequencies $(7-12 \mathrm{~Hz})$ (Schnitzler et al. 1987; Bullen and McKenzie 2002b), call repetition rates could be used to distinguish periods of 'search mode' (as opposed to 'approach and interception') (Kalko and Schnitzler 1993, 1998; McKenzie and Bullen 2003) in sequences recorded from all free-flying bats except leaf-nosed bats and $M$. gigas. The time between successive search mode calls is an integer multiple ( $\mathrm{x} 1, \times 2 \ldots \times 6$ etc.) of wing beat frequency (McKenzie and Bullen 2003). Measurement was restricted to clean search-mode calls (except for the leaf-nosed bats), defined as calls from sequential sets emitted at a rate of no more than one call per wing-beat and with a welldefined shape that was not even partly masked by background noise or echo. All discernable leafnosed bat calls were measured.

When applied to a square wave, fast-Fourier transformation (FFT) sums the number of cycles at each frequency. Two spectral attributes were calculated by using COOL EDIT 2000 to carry out a 2048-point FFT (Blackmann-Harris window) on each selected call, and display its frequency spectrum (as a line-graph showing the number of cycles at each frequency in the call's strongest 
TABLE 2 Kimberley mainland locality data, including centroid co-ordinates and locality average radius. Codes prefixed ' $M$ ' are mangrove locations.

Locality number and name

Code $\begin{array}{ccc}\text { Latitude } & \text { Longitude } & \text { av } \\ \left({ }^{\circ} \mathrm{S}\right) & \left({ }^{\circ} \mathrm{E}\right) & \begin{array}{c}\text { Radius } \\ (\mathrm{km})\end{array}\end{array}$

\begin{tabular}{|c|c|c|c|c|c|}
\hline 1 & Cape Bossut mangroves & M Bos & -18.6124 & 121.7171 & 10.6 \\
\hline 2 & Broome mangroves & M Brm & -17.9718 & 122.3068 & 4.5 \\
\hline 3 & Barred Creek mangroves & M Bar & -17.6640 & 122.1964 & 0.9 \\
\hline 4 & Coulomb & Coul & -17.3333 & 122.0944 & 7.3 \\
\hline 5 & Coulomb mangroves & M Coul & -17.2667 & 122.1889 & 1.7 \\
\hline 6 & Pender & Pen & -16.6889 & 122.8486 & 7.1 \\
\hline 7 & Pender mangroves & M Pen & -16.6174 & 122.9313 & 13.6 \\
\hline 8 & Barker Gorge & Bark & -17.2642 & 124.7271 & 0.7 \\
\hline 9 & Winjana Gorge & Winj & -17.4176 & 124.9774 & 2.1 \\
\hline 10 & Tunnel Creek & Tunl & -17.6082 & 125.1458 & 0.1 \\
\hline 11 & Point Torment mangroves & M Torm & -17.1964 & 123.6478 & 8.3 \\
\hline 12 & Mt Hart & HART & -16.8186 & 124.9289 & 1.5 \\
\hline 13 & Milliwindi Track & Mili & -17.1828 & 125.2550 & 0.2 \\
\hline 14 & Bell Creek east & eBEL & -17.0606 & 125.2556 & 6.0 \\
\hline 15 & Bell Creek west & wBEL & -17.0058 & 125.2174 & 1.3 \\
\hline 16 & Rainforest 19/2 & $\mathrm{R} 19 / 2$ & -16.4586 & 124.8458 & 0.3 \\
\hline 17 & Barlee Impediment mangroves & M Barle & -15.7786 & 124.7028 & 2.1 \\
\hline 18 & Prince Regent south & sPR & -15.7917 & 125.3083 & 0.5 \\
\hline 19 & Prince Regent west & $\mathrm{wPR}$ & -15.3096 & 125.0047 & 5.3 \\
\hline 20 & St George Basin mangroves & M SGB & -15.4626 & 125.0632 & 2.3 \\
\hline 21 & Mitchell Plateau south & sMP & -14.8572 & 125.7710 & 5.3 \\
\hline 22 & Mitchell Plateau north & nMP & -14.5847 & 125.7615 & 6.8 \\
\hline 23 & Mitchell Plateau mangroves & M MP & -14.5739 & 125.8360 & 0.8 \\
\hline 24 & Mitchell Plateau east & eMP & -15.0163 & 126.1651 & 9.4 \\
\hline 25 & Drysdale north & $\mathrm{nDR}$ & -14.7347 & 126.9679 & 6.4 \\
\hline 26 & Drysdale south & sDR & -14.9931 & 126.9199 & 18.5 \\
\hline 27 & Hann River & Han & -16.5131 & 126.3550 & 0.3 \\
\hline 28 & Pentecost mangroves & M Pcst & -15.6447 & 127.8781 & 0.5 \\
\hline 29 & Kununurra west & wKN & -15.9247 & 128.0519 & 7.9 \\
\hline 30 & Kununurra & KN & -15.7826 & 128.7114 & 4.1 \\
\hline 31 & Cave Spring Range & CAV & -15.4678 & 128.8613 & 4.8 \\
\hline 32 & Ningbing Range south & sNi & -15.2669 & 128.6738 & 2.0 \\
\hline 33 & Ningbing Range central & $\mathrm{cNi}$ & -15.0751 & 128.6210 & 1.7 \\
\hline 34 & Ningbing Range 8-mile & $8 \mathrm{Ni}$ & -14.9785 & 128.6004 & 0.7 \\
\hline 35 & Ningbing Range north & $\mathrm{nNi}$ & -14.9172 & 128.5751 & 1.7 \\
\hline 36 & Cambridge Gulf east mangroves & M Fals & -15.1136 & 128.3849 & 13.7 \\
\hline 37 & Black Cliff Point mangroves & M Blak & -15.0364 & 128.1008 & 0.3 \\
\hline 38 & Wyndham mangroves & M Wyn & -15.4135 & 128.1435 & 13.6 \\
\hline
\end{tabular}


harmonic; see Figure 2 in McKenzie and Bullen 2009). The frequency that was maintained for the greatest number of cycles $\left(F_{\text {peak }}\right)$, and its sharpness quotient $\left(Q=F_{\text {peak }}\right.$ /width of $F_{\text {peak } C}$, Laverghetta 1981), were determined from the frequency spectrum. $Q$ measures fineness-of-tuning: the width of the frequency band that accumulates most of the cycles in the call. Because of the noise levels associated with field recordings, $Q$ was calculated at $50 \%$ of the cycle-count at $F_{\text {peakc }}$. This is equivalent to 6 $\mathrm{dB}$ below peak from the FFT (i.e. $Q 6 d B$, hereafter referred to as $Q$ ), rather than the $Q 10 d B$ typically used under laboratory conditions when assessing frequency tuning properties (e.g. of auditory neurones; Casseday and Covey 1992).

When interpreting the FFT result, it is important to know if the Anabat detector's quasi-square wave output retains enough of the original signal's frequency content to yield the same $F_{\text {peak }}$ and $Q$ values as frequency-division detectors that retain the waveform of the strongest harmonic, such as the D940 (Pettersson Electronik, Uppsala Sweden). The D940 replaces every 10 cycles in the original wave train with a single cycle that has their combined wavelength but similar average shape. Using both detectors, calls by a representative sub-set of Kimberley bats were recorded over six nights along Bell Creek $\left(17^{\circ} 04^{\prime} \mathrm{S}, 125^{\circ} 15^{\prime} \mathrm{E}\right)$ and near Derby $\left(17^{\circ} 18^{\prime} \mathrm{S}, 123^{\circ} 38^{\prime} \mathrm{E}\right)$ in September 2010 . The D940 and the Anabat II bat detectors were fixed to a wooden frame so that they were parallel and about $60 \mathrm{~cm}$ apart, with their frequency-divided outputs (/16 for the Anabat; /10 for the D940) feeding into the 'left' and 'right' channels, respectively, of an Olympus LS10 digital recorder. The recording was saved as 16 bit 'linear PCM wave' files with a audio sampling rate of $44.1 \mathrm{kHz}$, as specified above. For the comparative analysis, $F_{\text {peak }}$ and $Q$ values were measured on each search-mode call for which both detectors simultaneously yielded a clean signal. By 'clean', we mean that the recorded call, when viewed as a spectrogram, was above the level of background noise and not masked or distorted by an echo, dropouts or reverberation.

\section{EMPIRICAL DATA ON FORAGING NICHE FOR METACOMMUNITY ANALYSIS}

Two measures of niche were documented, usual foraging microhabitat and usual foraging strategy. These data were compiled from observations made by the authors during a program of Kimberley field work over the last 18 years, and supplemented from relevant literature. Observations were made with a spotlight, in the glow of a floodlight or at dusk, or when bats returned to forage nearby after being released carrying chemiluminescent tags ('Cyalume'). They were recorded if the bat was seen to be foraging or if its 'search-approach- interception' echolocation sequences were detected. Nearly half of the microhabitat data came from observations we made while recording ultrasound sequences emitted by bats of known identity. The data were collected to provide a basis for assessing the influence of metacommunity interactions on assemblage composition.

Assignment of a bat to a foraging microhabitat depended on differences in the degree of air-space clutter (Schnitzler and Kalko 1998) at the point where the free-flying bat was first recorded. The proportion of observations in each microhabitat was used as a measure of airspace clutter in the preferred foraging habitat. Microhabitat definitions follow McKenzie et al. (2002), and were modified from McKenzie and Rolfe (1986):

1. Open airspaces more than $5 \mathrm{~m}$ above or beside canopies, cliffs, hill-slopes or hilltops (OC).

2. Semi-open airspaces a few metres above ( $>2$ but $<5 \mathrm{~m}$ ) the top of the canopy or bare hills (AC).

3. Semi-cluttered airspaces within a few metres $(>2)$ of the sides and underside of the canopy or rock faces $(\mathrm{BS} / \mathrm{O})$.

4. Airspaces within $2 \mathrm{~m}$ of foliage, bark, rock faces, ground or surface of pools (BS/A).

5. Cluttered airspaces between boulders, tree trunks, branches and among foliage in stands of vegetation (IS).

Species were assigned to one of five foraging strategies by integrating data on flight speeds and foraging behaviours (including turn capabilities) such as those reported in Bullen and McKenzie (2001), McKenzie et al. (2002) and McKenzie and Bullen (2009). In those studies, we used turn capability to rate species airframes in terms of agility, mode horizontal free-flight speed as an approximation of foraging speed, and documented foraging behaviours (either observed during fieldwork, or reported for the same species elsewhere). Strategy definitions follow Bullen and McKenzie (2001, 2004) and were modified from Norberg and Rayner (1987):

1. Interception. Fast, straight interception of airborne insect prey, neither agile nor manoeuvrable flight (I).

2. Surface. Involves manoeuvrable but not agile flight. Species glean prey while flying to conform with vertically as well as horizontally arrayed clutter (shrubs, boulders, trees, rock faces, etc.). Two classes were recognised: Surface-3D $\left(\mathrm{S}_{3 \mathrm{D}}\right)$ species fly at medium to low speeds and use both pitching and rolling manoeuvres, whereas Surface-2D $\left(\mathrm{S}_{2 \mathrm{D}}\right)$ species fly at low speeds, but most manoeuvres have a lateral orientation (rolling very gently or 
skidding). Both classes include 'slow hawking' against clutter and 'gleaning' in clutter, as well as 'ambushing' which involves sallying from a perch into open or semi-cluttered air spaces, or onto the ground, and has also been called 'perch-hunting'.

3. Air-superiority. Agile foraging, designed to outmanoeuvre airborne prey at medium to high speeds. Again, two classes were recognised: agile species that foraged in open airspaces $\left(\mathrm{A}_{\mathrm{O}}\right)$ and highly agile species of semi-cluttered to cluttered air spaces $\left(\mathrm{A}_{\mathrm{H}}\right)$.

Flight speeds were measured from passing bats, either at dusk as they foraged around vegetation or departed their roosts in caves or abandoned mines, or at night if they were partially illuminated using a $12-\mathrm{V}$ neon floodlight ('Versa-Light' by Burn-Brite Lights, Australia). In such situations they were subsequently identified from their ultrasound sequences. The speeds were measured using a hand-held K-band radar unit (Dopplershift meter model TS3, supplied by Municipal Electronics, U.S.A.), calibrated for a speed range of 1-28 m sec-1 (4-100 kph). Additional flight speed data were measured from bats released in the field within a few hours of capture that were carrying bioluminescent tags or were released the next morning in daylight. In this case, subadults, pregnant females and animals with scarred wings were excluded, as was the period while bats accelerated from rest. All readings for a species were pooled. Mode rather than average speed values were used for our analysis because the readings did not have normal distributions even when pooled by species. Like airframes in general (Torenbeek 1976), bats favour at least two characteristic flight speeds, representing different points along their velocity-power curve that are functionally efficient for sustained activities such as foraging and commuting (e.g. Speakman and Thomas 2003; Grodzinski et al. 2009). The authors' data relating mode speed to foraging behaviour are the subject of a separate study. Speed data from individuals captured in the adjacent Ord-Victoria and Dampierland bioregions were incorporated to increase sample sizes for most species.

Measurements taken from live, adult nonpregnant bats from tropical WA (from the Kimberley unless otherwise specified), with their flight surfaces fully extended in accordance with the methods published in Bullen and McKenzie (2001), were used to calculate various airframe parameters related to flight capability and foraging niche (e.g. Bullen and McKenzie 2001, 2004, 2007, 2009; Bullen et al. 2009):

1. Aspect ratio $(A R)$, wing loading $(W L)-$ longitudinal flight performance and stability, related to usual foraging microhabitat.

2. Tail-ear area ratio (TEAR) and ear canard type, as well as flight- and heart-muscle mass ratios, which determine airframe agility and control, and reflect foraging strategy and roost preference.

\section{ACOUSTIC SURVEY}

A total of 30 islands were sampled using Anabat II ultrasound detectors placed at ground level. The detector's microphone was orientated within $30^{\circ}$ of vertical. During the 2007 to 2010 dry seasons, four sites were sampled on the seven largest islands (i.e. two sites near each of two campsites), two sites on 18 islands (i.e. one campsite) and one site on one island. A single site was resampled on 15 of these islands during the wet season. One island (Glauert) was sampled at a single site during the wet season. During the dry season of 2011, additional sites were sampled on Bathurst (1 site), Gibbings (2 sites) and Irvine (5 sites). The site, recording system used and sampling data for the 30 islands visited are provided in Appendix 2.

Sites were not randomly arrayed. Excluding repeats, most of the 87 sites sampled were in or within $100 \mathrm{~m}$ of savanna woodlands (49 sites) and/or rainforest (24 sites), often with fresh water pools of varying size and permanence (26 sites) or mangroves (29 sites) within $100 \mathrm{~m}$, and usually in or within $300 \mathrm{~m}$ of rugged boulder country with crevices and caves (66 sites). It is important to note that sample sites were paired geographically; the two sites associated with each island campsite were usually less than $500 \mathrm{~m}$ apart because they had to be within walking distance of one another (see Gibson and McKenzie 2012). Given the mobility of most bats, this meant that sites near the same camp could not be analysed as independent samples even though they were positioned in very different habitats.

At each site, echolocation calls emitted by passing bats were recorded for an average of $2.5 \mathrm{~h}$ from late dusk, (we averaged 3.3 recording nights, totalling $8.3 \mathrm{~h}$, per island excluding the more prolonged Bathurst and Irvine recording sessions; Appendix 2). Repeated sampling depended on logistical opportunities offered by a trapping program that focused on non-volant mammals and reptiles, a constraint that precluded (1) a more systematic sampling regime for bats and (2) any multivariate statistical analysis requiring a balanced sampling design. For this reason, analysis of habitat-use was confined to species presence/absence data at the islands that were sampled for two or more recording sessions, and the relative abundance of detections and issues of seasonality were ignored (Gannon et al. 2003; Meyer et al. 2011). Overall 
sampling efficiency for species was assessed using both the Chao2 (Chao 1987) and the incidencebased ICE (Lee and Chao 1994) estimators in the EstimateS software (Colwell 2006).

$F_{\text {peak }}$ and $Q$ values were determined for several of the search-mode calls comprising sequences in the recordings, and identified to species using the reference call library in conjunction with associated call duration and repetition-rate data measured from the sequence. The call library (discussed earlier) comprised a scatterplot of $F_{\text {peakc }}$ v. $Q$, as well as a table summarising call attribute values for species, such as duration and repetition rate. We ignored calls that did not meet the clarity, duration and sequence repetition rate criteria used in compiling the library. Unknown calls that plotted on the periphery of a call cluster in the library scatterplot were identified only if they were in continuous sequence with calls that fell within the cluster. Unknown calls that plotted in an area of overlap between two species were not identified unless they were in continuous sequence with calls that fell in an area of the cluster that was outside of the overlap.

\section{HABITAT ASSOCIATIONS}

This analysis assumes that spatial distribution reflects an underlying correlation with environmental factors (Austin 1991; Clarke 1993), '... a habitat paradigm' (Armstrong 2005), and treats metacommunity relationships (e.g. microhabitat and resource availability hypotheses, sensu Hernandez et al. (2005) and Leibold et al. (2004)) as second order effects at regional scales. Because we do not yet have an explicit model to provide an explanatory framework for our results, our interpretation of this inherently exploratory design was based on deductive logic (Oksanen 2001; Dickman and Crowther 2008) and, as no experimental or mensurative design has been implemented to construct a null hypothesis (Austin and McKenzie 1988), alternative hypotheses are not excluded. Inferential statistics are used to test patterns observed in the empirical data.

Patterns of species composition and species co-occurrence in the island data matrix (species presence/absence) were exposed using the analyses procedures in PATN (Belbin 1995), described earlier. North Maret and Glauert Islands were only sampled for a single evening, so they were excluded from the analysis to reduce 'noise' associated with undersampling (e.g. Fischer et al. 2009). Dimensionality of the island and species dissimilarity matrices was reduced using Semistrong Hybrid scaling (with 100 iterations, a minimum stress differential of 0.005 , and 100 random starts). Patterns overt in the resulting three dimensional scatterplots were assessed statistically (below) in terms of island and species attributes (Table 3). These attributes were chosen because they were likely to influence microbat distributions and assemblage composition, either directly or indirectly, and also on the basis that they were not highly intercorrelated (Kendall Tau <0.6). On these criteria, we retained 'isothermality' and 'annual average precipitation' (generated for the islands using ANUCLIM; McMahon et al. 1995). Temperature and rainfall attributes have direct effects on the ecophysiology of many mammal species (e.g. Prosser and Brown 1961; McNab 1980; Spicer and Gaston 1999; Meynard and Quinn 2007). Attributes such as riparian development (combining availability of freshwater and presence of complex riverine vegetation), as well as distance to well-developed mangrove, rainforest, savanna and cave country, were recorded on-site or derived from Google Earth ${ }^{\mathrm{TM}}$. Their biological relevance for Australian microbats has been well documented (e.g. McKenzie and Rolfe 1986; Lumsden and Bennett 1995; Law et al. 1998; McKenzie and Muir 2000; Young and Ford 2000; Williams and Dickman 2004; Milne et al. 2005a, b; McKenzie and Bullen 2009). Atmospheric conditions were not included in the analysis because we did not sample on cold or windy nights, or during wet season storms. Species attributes assessed include habitat preference, roost type, whether the species' original geographical range was restricted to high rainfall regions or extended into more arid regions as well, and an array of behavioural, airframe and echolocation call attributes related to their foraging ecology (e.g. Burbidge et al. 2008; Van Dyck and Strahan 2008; Bullen and McKenzie 2004, 2009; McKenzie and Bullen 2009).

Correlations with these island and species attributes were determined by principal component analysis (PCC in PATN; Belbin 1995) and significance assessed using Monte-Carlo simulation involving 1000 iterations of randomly re-distributing attribute values against the objects (islands or species). Partial mantel tests from the computer package PASSAGE (Rosenberg and Anderson 2011) were used to assess the influence of spatial structure (e.g. Diniz-Filho et al. 2003) on the composition of island faunas. Distance matrices (Gower, from PATN) representing each of the island environmental attributes were compared to the species dissimilarity matrix for the islands (Czekanowski measure) while the matrix representing the Euclidean distance apart $(\mathrm{km})$ for all pairs of islands was held constant. The significance of the mantel correlations was tested using 999 randomisations. 
Island Attributes

Rainforest (distance to a well developed patch):

$0=$ no substantial patches on or adjacent to island

$1=$ small $(<2$ ha) patches $<1 \mathrm{~km}$ from site

$2=$ substantial patches $<1 \mathrm{~km}$ from site or small patch at site

$3=$ substantial patches sampled

Mangrove Proximity (distance to a well developed patch):

$0=$ no substantial patches on or adjacent to island

$1=$ small $(<4$ ha) patches $<1 \mathrm{~km}$ from site

$2=$ substantial patches $<1 \mathrm{~km}$ from site or small patch at site

$3=$ substantial patches sampled

Cave Country (distance to ranges/heavy scree with crevices):

$0=$ no substantial areas on or adjacent to island

$1=$ small areas $<1 \mathrm{~km}$ from site

$2=$ substantial areas $<1 \mathrm{~km}$ from site or small area at site

$3=$ substantial area sampled

Area (of island)

Isothermality

Average Annual Precipitation

Riparian Development (combinations of freshwater availability and vegetation complexity):

$3=$ permanent pool with riverine woodland/forest sampled

2 = permanent pool sampled, but no riverine vegetation

$1=$ ephemeral pool at site or permanent pool

$<1 \mathrm{~km}$ from site, but without riverine vegetation

$0=$ no permanent pools or riverine vegetation on island

Sampling Effort: $\log _{10}$ (minutes of ultrasound recording $X$ number of visits to island by bat biologists)

Distance to the mainland coast (sum island chain gaps to represent the likelihood of animals flying there from the mainland)

Distance to River Mouth ( $1=$ in a major mainland river mouth; 5 = remote from a river mouth)

Number of species (zoophagic bats)

\section{Species Attributes}

Clim (driest edge of range, from Burbidge et al. 2008):

$4=$ restricted to high rainfall regions of Australia

$3=$ high and moderate rainfall regions

$2=$ high, moderate and semi-arid regions

$1=$ high, moderate, semiarid and arid regions

Roost:

$0=$ tree hollow or foliage only

$1=$ tree $/$ foliage or rock crevice

$2=$ cave twilight zone

3 = deep cave only

Mangrove:

$1=$ landward habitats only

$2=$ catholic

$3=$ mangrove only

Riparian:

$1=$ not restricted to riparian habitat

$2=$ usually encountered in riparian habitat

$3=$ almost always

Usual Foraging Strategy (empirical categorisation of foraging behaviour, ordered in terms of agility)

Microhab (airspace clutter in usual foraging microhabitat)

Mode flight speed

TEAR (a measure of the airframe's ability to generate/sustain lateral acceleration)

$A R$ (airframe aspect ratio), WL (airframe wing loading)

$Q$ (sharpness quotient of search mode echolocation call)

$F_{\text {peakc }}$ (search mode echolocation call frequency at peak cycles)

Phylogeny (relatedness, based on a phylogenetic tree simplified from Teeling et al. 2005, p. 580)

Heart-muscle mass ratio, a measure of aerobic capacity

(Bullen and McKenzie 2009)

Flight-muscle mass class (Bullen and McKenzie 2004):

$1=(\mathrm{L})$ ow energy

$2=(\mathrm{G})$ eneral energy

$3=(\mathrm{H})$ igh energy 


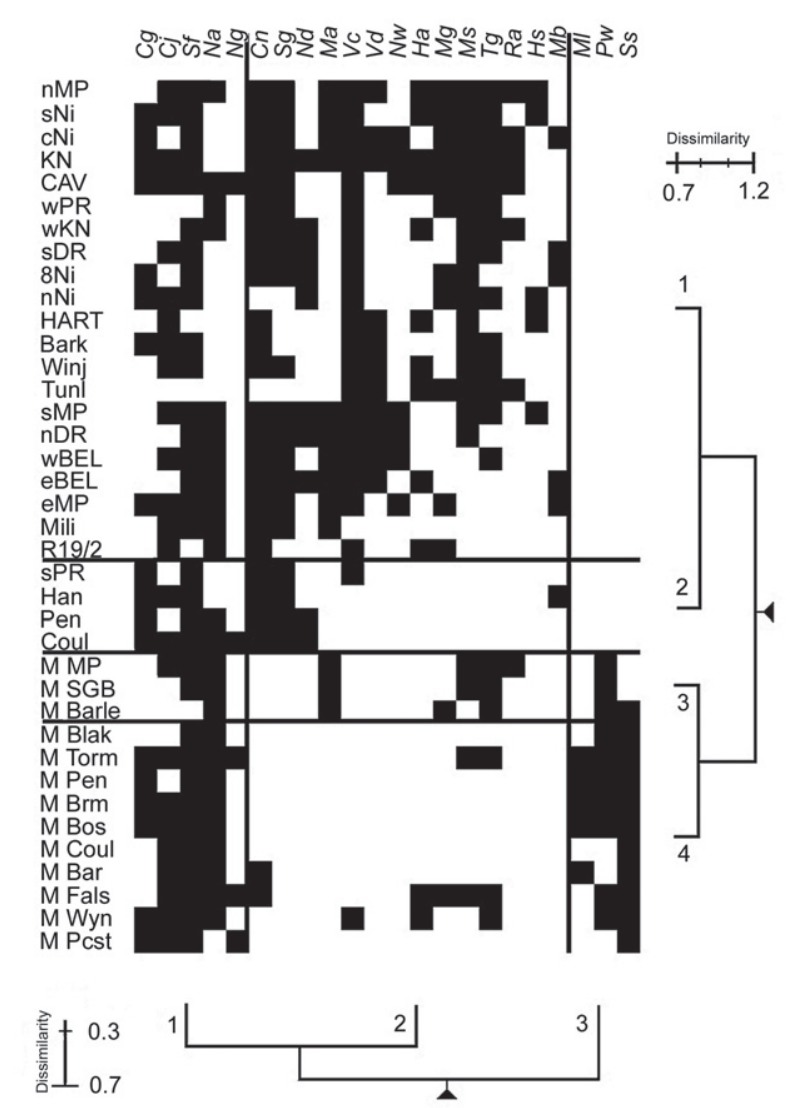

FIGURE 2 The mainland assemblage matrix reordered according to the classification analyses. Classification partition structure is displayed to the fourgroup level for localities and to the three-group level for species. Two communities are revealed: one occupying landward environments and the other the mangroves. Locality data are shown in Table 2.

\section{RESULTS}

\section{KIMBERLEY BAT COMMUNITIES}

Lists of the echolocating bats known from localities across the Kimberley mainland (Table 2) were compiled as a presence-absence matrix (38 localities $x 22$ species). When species were classified according to their co-occurrences at localities, the dendrogram's partition structure could be interpreted to the 3-group level in terms of known habitat associations and roost preferences of their component species across their wider distributions in Australia (Figure 2):

1. Five species that are widespread in the region, and roost in or on trees and also occur in mangroves (e.g. McKenzie and Rolfe 1986; Van Dyck and Strahan 2008).
2. Fourteen species, comprising nine that roost in caves and/or crevices associated with rocky habitats, one that forages along waterways through rocky habitats but roosts under foliage rather than in caves (e.g. N. walkeri, Churchill et al. 2008), and four tree-roosting species that are usually recorded along watercourses (Chalinolobus nigrogriseus, S. greyii, Nyctophilus daedalus and Mormopterus beccarii). Six of these 14 are not known from mangroves (S. greyii, $N$. daedalus, N. walkeri, Vespadelus douglasorum, H. stenotis and M. beccarii).

3. Three species that are mangrove specialists in Western Australia (Pipistrellus westralis, M. loriae and Scotorepens sanborni). All have mesic tropical distributions elsewhere in Australia where they occur in rainforests, monsoon forests and/or riparian zones as well as mangrove communities (McKenzie and Rolfe 1986; Van Dyck and Strahan 2008).

At this level, an ANOSIM test showed that association distances between species in different partitions were significantly greater than the distances between species in the same partition $($ real- $\mathrm{F}=2.3$, best $-\mathrm{F}=1.6, \%$ randomised $>$ real $=0$ ).

When localities were classified in terms of their species composition, two communities were revealed: one occupied the landward environments and the other occupied mangroves (Figure 2; '2-group ANOSIM' real-F $=1.6$, best-F $=1.1, \%$ randomised $>$ real $=0$ ). In this paper, we use the term 'landward' to encompass the Kimberley's terrestrial, aquatic and riparian environments, but not marine inter-tidal ecosystems such as mangroves. This dendrogram's partition structure could be interpreted down to the 4-group level (ANOSIM real-F $=1.6$, best- $\mathrm{F}=1.2, \%$ randomised $>$ real $=0$ ):

1. Landward localities that included cave-country as well as well-developed riparian zones characterised by permanent pools. These were the most specious localities; as well as treeroosting bats such as $S$. flaviventris, M. beccarii and $N$. walkeri, these locations showed high site occupancy by obligate cave dwellers (e.g. H. ater, M. gigas, T. georgianus and R. aurantia).

2. Landward localities with well-developed riparian zones characterised by permanent pools, but little or no cavernous country.

3. The three mangrove localities with the highest rainfall ( $>1100 \mathrm{~mm}$ average annual rainfall).

4. Mangrove localities in drier parts of the Kimberley $(<800 \mathrm{~mm})$.

The Kimberley fauna includes three species that are restricted to mangroves as well as at 
a.

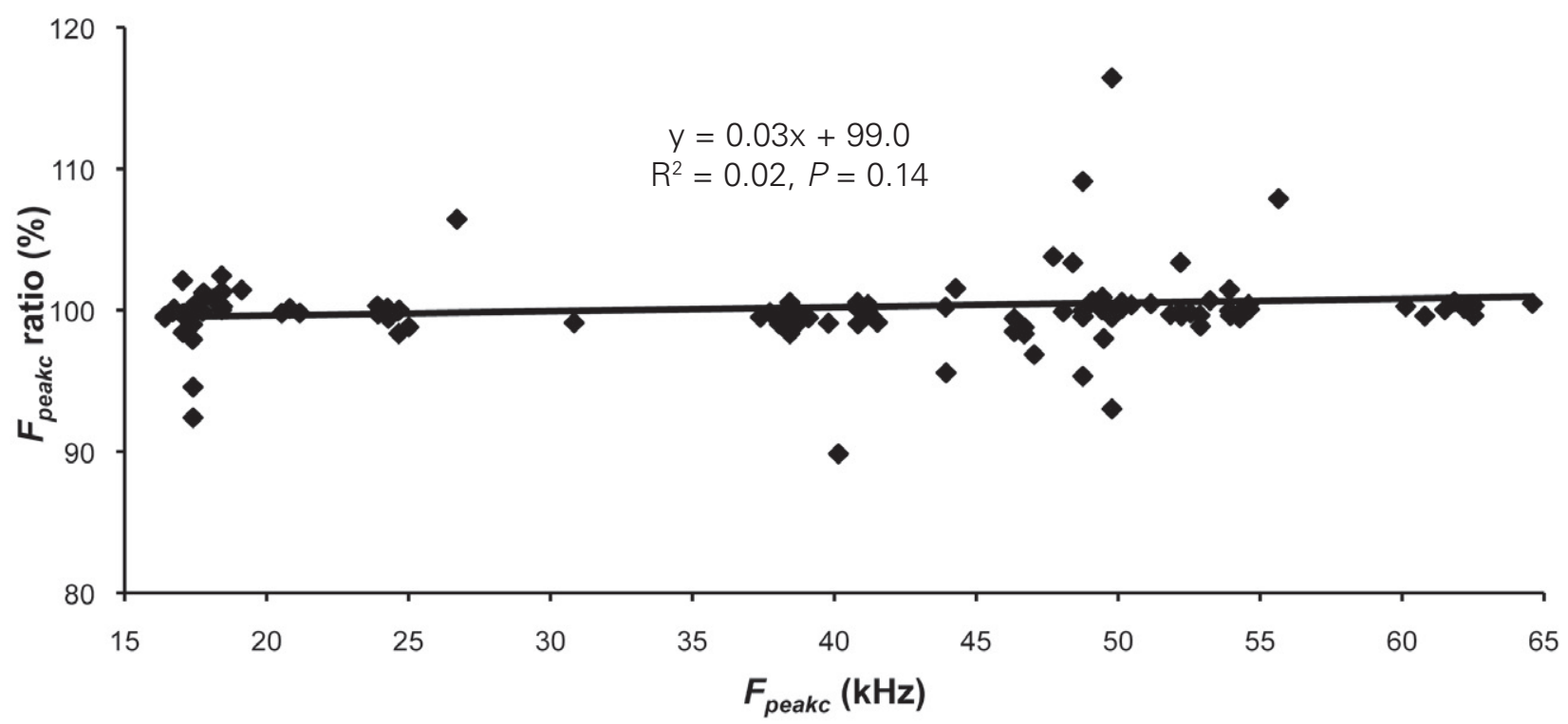

b.

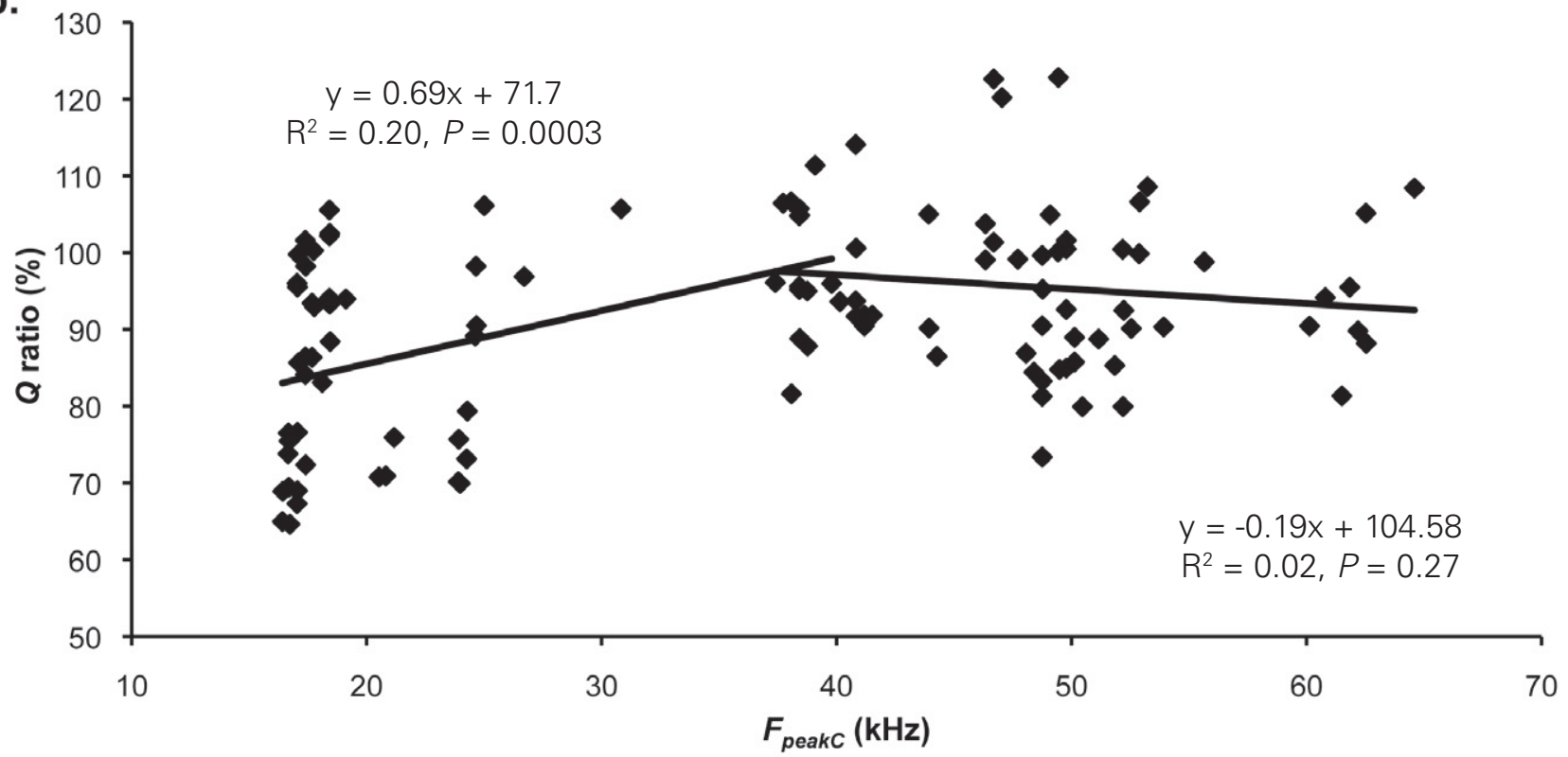

FIGURE 3 Comparison of (a) $F_{\text {peakc }}$ and (b) $Q$-values derived from Anabat II and D940 bat detectors. The 116 clean search-mode calls plotted (total of 13 species) were recorded simultaneously by feeding the output of the detectors into the left and right channels of an Olympus LS10 digital stereo recorder (see Appendix 3 for data). We measured an average of 4.2 (S.E. $=0.7)$ passes per species at an average of $1.8($ S.E. $=0.2)$ calls per pass.

least four (M. beccarii, N. daedalus, S. greyii and V. douglasorum; Figure 2) that have not been recorded in mangrove stands despite considerable survey effort (e.g. McKenzie and Rolfe 1986; McKenzie et al. 1995; WAM specimen register, authors' unpublished data). The three mangrove specialists (M. loriae, S. sanborni and P. westralis) are replaced by closely-related allopatric species in the region's landward environments (M. beccarii, S. greyii and $V$. douglasorum). Thus, the fauna forms two compositionally distinct communities - one comprises up to 16 species and occupies mangroves while the other comprises up to 19 species and occupies landward environments.

The ICE and Chao 2 procedures in EstimateS both produced an estimate of 19 species from 
the 25 localities in landward environments. These indicated that no further species would be added after the 16th locality. The empirical survey results were $100 \%$ of the estimation (of 19 species). Chao2 estimated 16 species, but 17 by ICE, for the 13 mangrove localities for which vouchered assemblage lists are available, with no further species predicted to be added after the 13th locality. Again the empirical result was $100 \%$ of the estimated richness. Both terrestrial and mangrove accumulation curves were asymptotic.

The nestedness temperature calculator (Atmar and Patterson 1995) was used to assess whether the species lists from localities were likely to represent sub-sets of a single community rather than random draws from the regional species pool. The landward and mangrove matrices were both strongly nested $(T=31.7$ and 27.2 , respectively, $P<<$ 0.0001 in both cases). BINMATNEST (RodriguezGirones and Santamaria 2006) confirmed these nestedness results (null model 3, $T=29.9$ and 24.9, $P$ $<0.008$ in both cases).

Species comprising the landward and mangrove communities in each of the Kimberley's five biogeographic regions are listed in Table 4. These data have been updated from McKenzie and Rolfe (1986) using vouchered specimen records in the WAM and AM in combination with other recent survey records (see Methods).

\section{CALL SPECTRAL CHARACTERISTICS}

Table 5 summarises search-mode echolocation call characteristics of 22 of the 24 species $(6$ families) known from the Kimberley, data derived by analysing signal output from the Anabat II ultrasound detector. The other two species ( $T$. australis and $V$. finlaysoni) are excluded from our analyses because, while they are widespread in the adjacent Great Sandy Desert and Pilbara bioregions to the south, they only penetrate the Kimberley's arid southern periphery. This table includes statistics on the number of individual bats and calls used for characterisation. The three leaf-nosed bats in the Kimberley fauna used 'constant frequency' (CF) calls of much higher frequency and sharpness quotient than the other species, all of which used 'frequency modulated' calls (FM) of relatively short duty-cycle.

Analysis of 116 clean search-mode calls (13 species; average $8.2 \pm 0.6$ calls per species) (see Figure 3 and Appendix 3) revealed that the different wave-shapes, output by two different frequency-division bat detectors (clipped from the Anabat, unclipped from the D940), had little (if any) affect although, below $30 \mathrm{kHz}, Q$-values from the D940 averaged $10-15 \%$ higher so a correction factor needed to be applied. When compared to the call library (see below), the values for $F_{\text {peakc }}$ and $Q$ for the individual calls were sufficiently consistent from both detectors to yield the same species identification and correct niche assignments in all but one case: two individual calls in a sequence by Miniopterus schreibersii were miss-assigned to $P$. westralis using the D940 output. None of the other 36 call sequences was miss-assigned (Appendix 3).

\section{REFERENCE CALL LIBRARY}

Earlier in this paper we showed that three of the species are restricted to the mangrove stands scattered along the coast $(M$. loriae, $P$. westralis and $S$. sanborni) being replaced by closely related allopatric counterpart species in the region's landward environments (M. beccarii, $V$. douglasorum and $S$. greyii, respectively). For clarity, the spectral characteristics of species comprising these two compositionally distinct communities have been considered separately, even though they share a majority of species.

Figures $4 \mathrm{a}$ and $4 \mathrm{c}$ plot $F_{\text {peakc }}$ against $Q$ for reference search-mode calls by the 18 echolocating species found in the Northern Kimberley's landward environments. They show that searchmode sequences by 17 of the 18 species could be identified using a combination of $F_{\text {peakc }}$ and $Q$, provided that (1) the sequence included calls that plotted in neither an overlap zone nor outside of a species cluster, and (2) call repetition-rate, complexity and/or duration were invoked to distinguish $M$. gigas from Myotis macropus and Nyctophilus arnhemensis (Table 5). The exception is $N$. arnhemensis which was too similar to $N$. daedalus to be resolved. Nyctophilus geoffroyi is not known from the Northern Kimberley bioregion, and excluded from Figure 4.

Macroderma gigas has a surface foraging strategy with two modes. It perches in vegetation to ambush passing prey (either on the ground or in the air), and it also gleans surfaces such as the ground while in flight (e.g. Churchill 2008; Appendix 4). Its inflight echolocation calls occupy the spectral spaces of M. macropus and N. arnhemensis, and overlap the low $-Q$ calls of $S$. greyii, S. sanborni and $C$. nigrogriseus (Figure 4a). However, unlike the other species using the same frequency band, M. gigas calls were complex in terms of frequency when displayed in time domain (W-, M-, N- or U-shaped FM, or stepped CF - see Figure 6b in McKenzie and Bullen 2009), and usually irregularly spaced call-tocall in sequences (Figure 5a). Where sequences were regular, the call repetition-rate corresponded to their relatively low wing-beat frequency $(6.96 \pm 0.71$ $\mathrm{Hz}$; Bullen and McKenzie 2002b) compared to other bats using the same spectral space. The call complexity distinguished them from the searchmode calls of all other species. Our reference calls were recorded in two separate contexts: 
TABLE $4 \quad$ Kimberley bat community lists updated from McKenzie and Rolfe (1986) as a result of subsequent museum accessions and field survey work, including this study (NK = Northern Kimberley, VB = VictoriaBonaparte, $\mathrm{DL}=$ Dampierland, $\mathrm{CK}=$ Central Kimberley, OVP = Ord Victoria Plains, $\mathrm{L}=$ landward, $\mathrm{M}=$ mangrove). Species codes are listed in Table 1.

NK $\quad$ VBa $^{a}$

DL

$\mathrm{DL}$

CK

OVP

Species

L M

L M

L M

L

$\mathrm{L}$

\begin{tabular}{|c|c|c|c|c|c|c|c|c|}
\hline$C g$ & $X^{b}$ & & $X$ & $X$ & $X$ & $X$ & $X$ & $\bar{X}$ \\
\hline$C j$ & $x$ & $X$ & $x$ & $X$ & $x$ & $X$ & $X$ & $x$ \\
\hline $\mathrm{Cn}$ & $x$ & $X$ & $x$ & $X$ & $x$ & $X$ & $X$ & $x$ \\
\hline $\mathrm{Ha}$ & $x$ & $x$ & $x$ & $x$ & $x$ & & $x$ & $x$ \\
\hline Hs & $x$ & & $x$ & & & & & $x$ \\
\hline$M a$ & $x$ & $X$ & $x$ & & & & & $x$ \\
\hline$M b$ & $x$ & & $x$ & & $x$ & & $X$ & $x$ \\
\hline$M g$ & $x$ & $X$ & $X$ & $X$ & $x$ & & $X$ & $x$ \\
\hline $\mathrm{Ml}$ & & $X^{c}$ & & & & $x$ & & \\
\hline Ms & $x$ & $X$ & $X$ & $x$ & $x$ & & $x$ & $x$ \\
\hline $\mathrm{Na}$ & $x$ & $X$ & $x$ & $X$ & $x$ & $X$ & $X$ & $x$ \\
\hline $\mathrm{Nd}$ & $x$ & & $x$ & & $x$ & & $X$ & $x$ \\
\hline $\mathrm{Ng}$ & d & & $x$ & $x$ & $x$ & $x$ & $X^{e}$ & $x$ \\
\hline$N w$ & $x$ & & $x$ & & & & & $x$ \\
\hline$P w$ & & $X$ & & $X$ & & $X$ & & \\
\hline$R a$ & $x$ & $x$ & $x$ & & $x$ & & $X$ & $x$ \\
\hline$S f$ & $x$ & $X$ & $X$ & $X$ & $x$ & $X$ & $X$ & $x$ \\
\hline$S g$ & $x$ & & $x$ & & $x$ & & $x$ & $x$ \\
\hline Ss & & $X$ & & $x$ & & $x$ & & \\
\hline $\mathrm{Ta}$ & & & & & $\mathrm{f}$ & $\mathrm{f}$ & & \\
\hline $\mathrm{Tg}$ & $x$ & $X$ & $x$ & $X$ & $x$ & $X$ & $x$ & $x$ \\
\hline$V_{c}$ & $x$ & $x$ & $x$ & & $x$ & & $X$ & $x$ \\
\hline$V f$ & & & & & $\mathrm{f}$ & & & $\mathrm{f}$ \\
\hline \multirow[t]{2}{*}{$V d$} & $x$ & & $X$ & & $x$ & & $x$ & $x$ \\
\hline & 18 & 14 & 19 & 12 & 16 & 10 & 16 & $1 \mathrm{C}$ \\
\hline$P_{S}$ & $X$ & $X$ & $X$ & $X$ & $X$ & $X$ & $X$ & $x$ \\
\hline $\mathrm{Pa}$ & $x$ & $x$ & $x$ & $X$ & $x$ & $X$ & $x$ & $x$ \\
\hline$M m$ & $x$ & $X$ & $x$ & & $x$ & $X$ & & \\
\hline
\end{tabular}

a Excludes tentative call identifications of Taphozous kapalgensis (Lumsden et al. 2005) from the Victoria-Bonaparte bioregion in WA.

b Although widespread throughout the rest of the Kimberley, there are no reliable records of C. gouldii from near-coastal

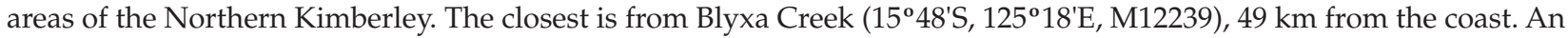
early echolocation-based record from Koolan Island (McKenzie et al. 1995) has been reassessed using the call library compiled during this project and is more likely to be M. loriae.

c Mormopterus loriae was recorded only from three islands on the south-western periphery of the Northern Kimberley bioregion, adjacent to Dampierland (Koolan, Lachlan and Sunday; Figure 1).

d The only Northern Kimberley specimen of N. geoffroyi (WAM M51030, collected in 1920 from 'Drysdale River WA') has been lost. The identification, by Glauert, pre-dated the description of N. arnhemensis Johnson, 1959. Consequently, it is more parsimonious to assign the record to the widespread long-eared bat of similar size, N. arnhemensis.

e AM M04621 (August 1970), AM M22117 (September 1989).

f Excludes two species that are widespread in the adjacent Great Sandy Desert and Pilbara bioregions to the south, and penetrate the Kimberley's southern (arid) periphery: T. australis and V. finlaysoni; V. finlaysoni extends into central Dampierland where it is replace by its mesic counterpart $V$. douglasorum. 


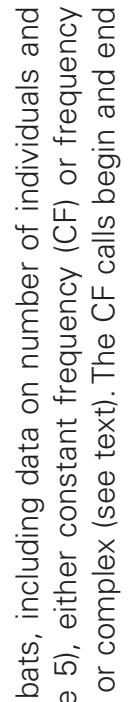

贾䨔

立过茎

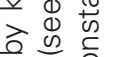

030

나에

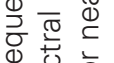

ब

क्ष के के

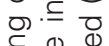

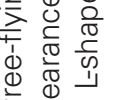

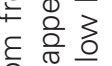

尖

잉

这孪

is 웅 $\frac{\pi}{\infty}$

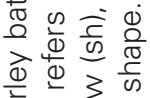

远 的

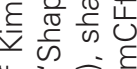

पे

is $\frac{1}{0} \frac{0}{0} \frac{1}{0}$

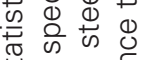

ஸ)

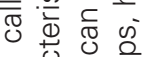

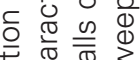

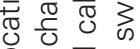

응 이닌

至

\& 80.

는 这 $\frac{\pi}{5}$ 흥

丳

눌

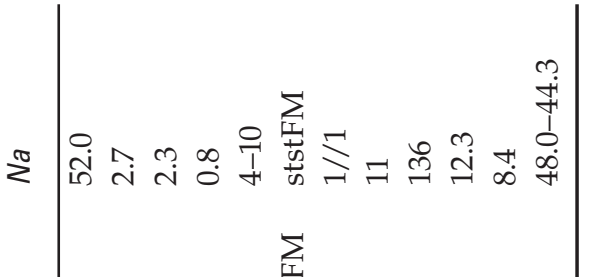

$\sum_{\text {至 }}$

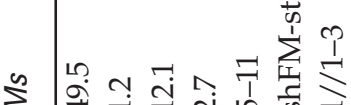

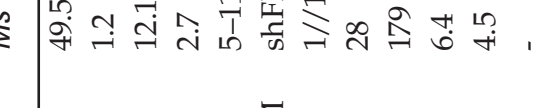

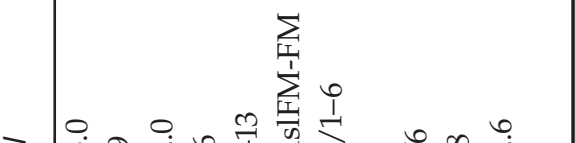

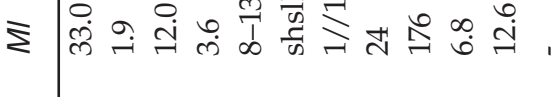

$\sum_{i}$

I

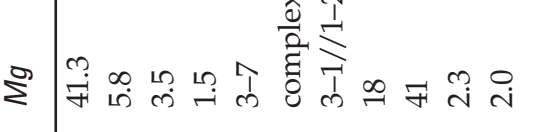

s)

岂

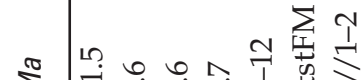

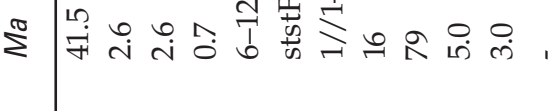

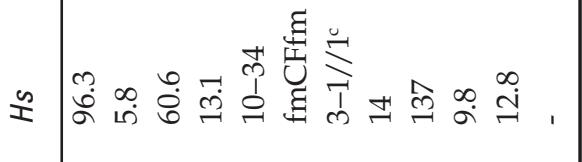

『

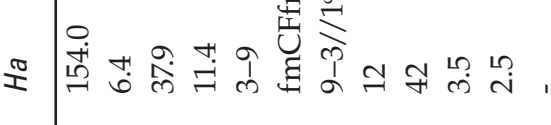

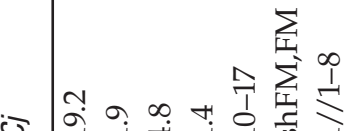

u

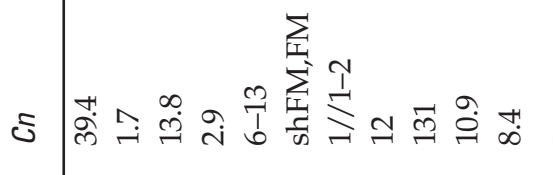

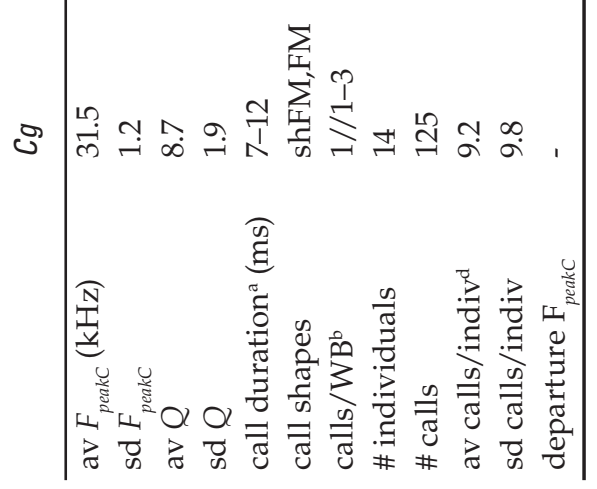

S

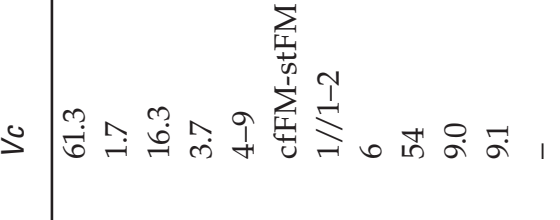

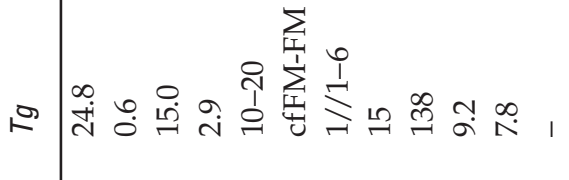

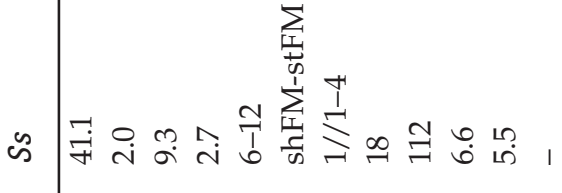

m

岂

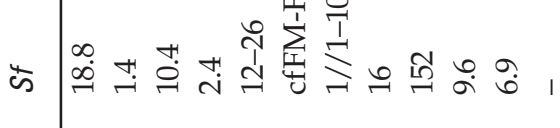

\&

उ

之人

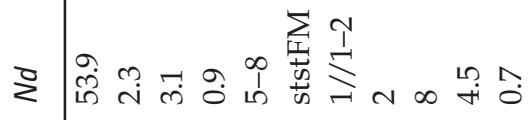

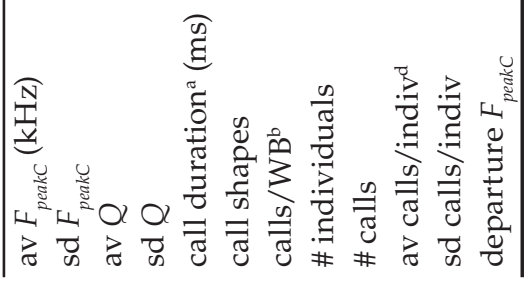

के

ஓे

ฮี

డ్

농

बें

$\sum_{0.0}^{0.5}$

눅워

仓声矛

离

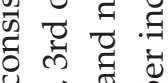

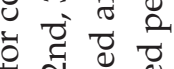

$3>\pi$

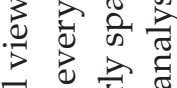

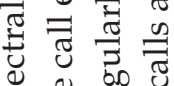

की

ธี .

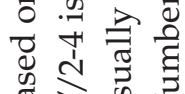


a.

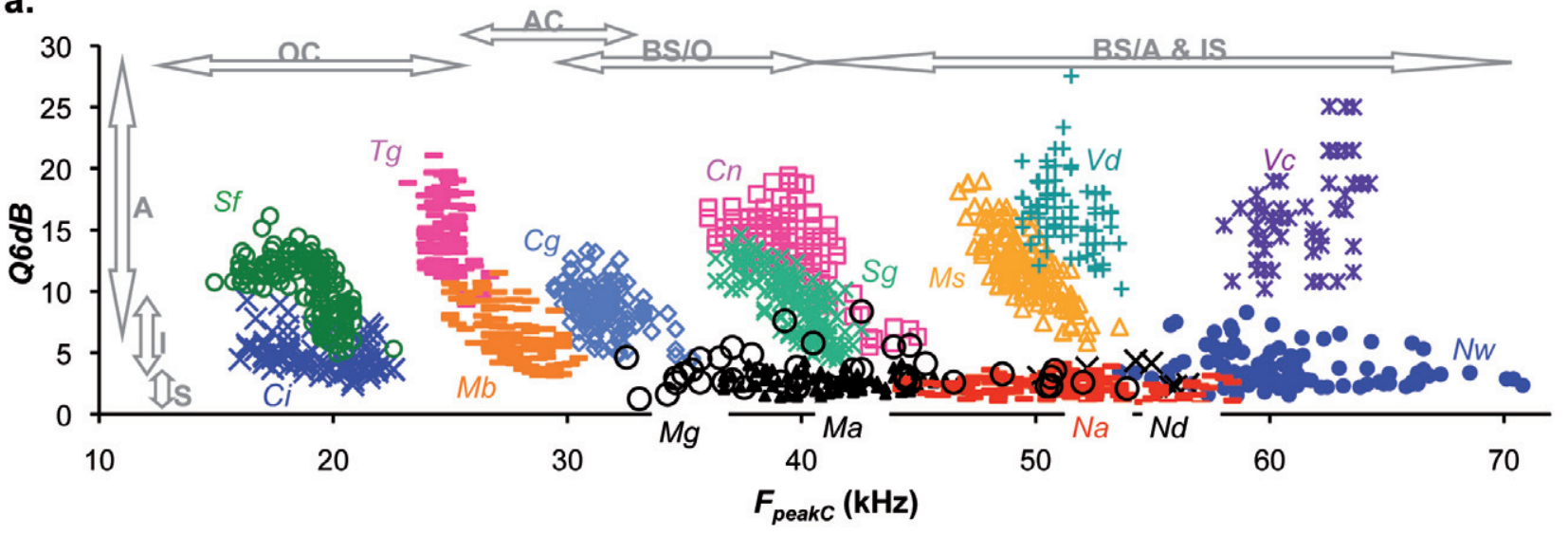

b.

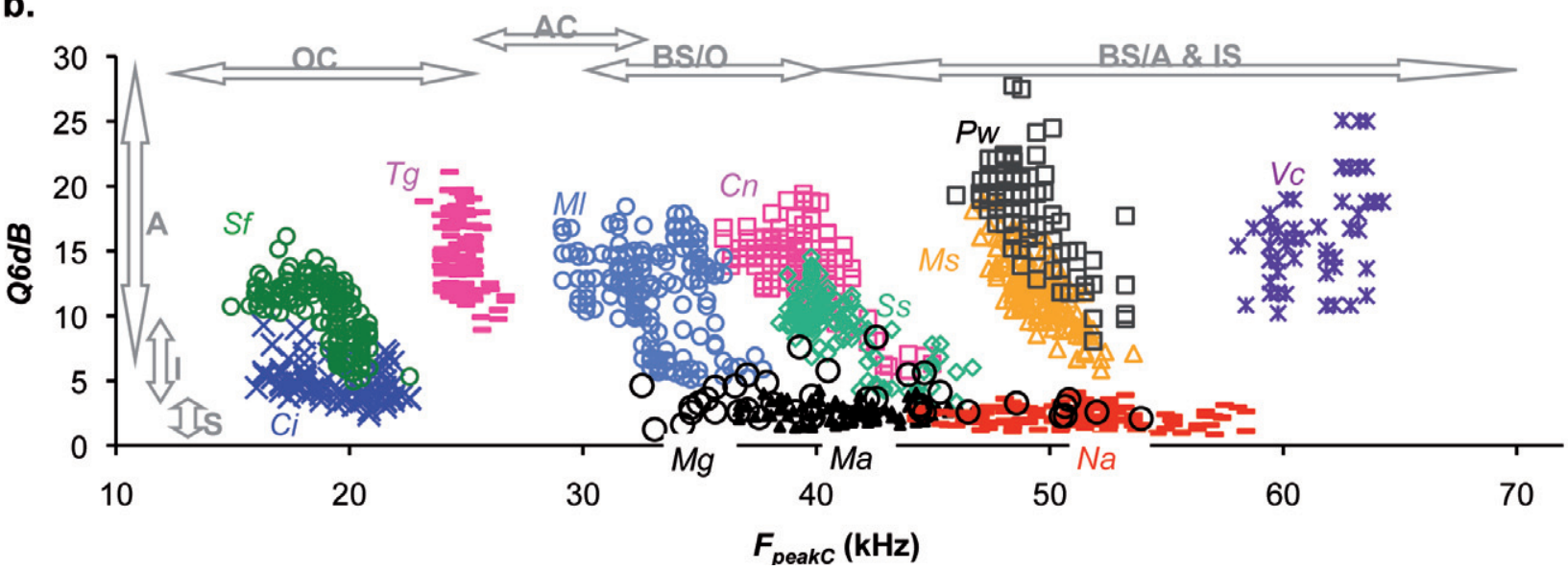

c.

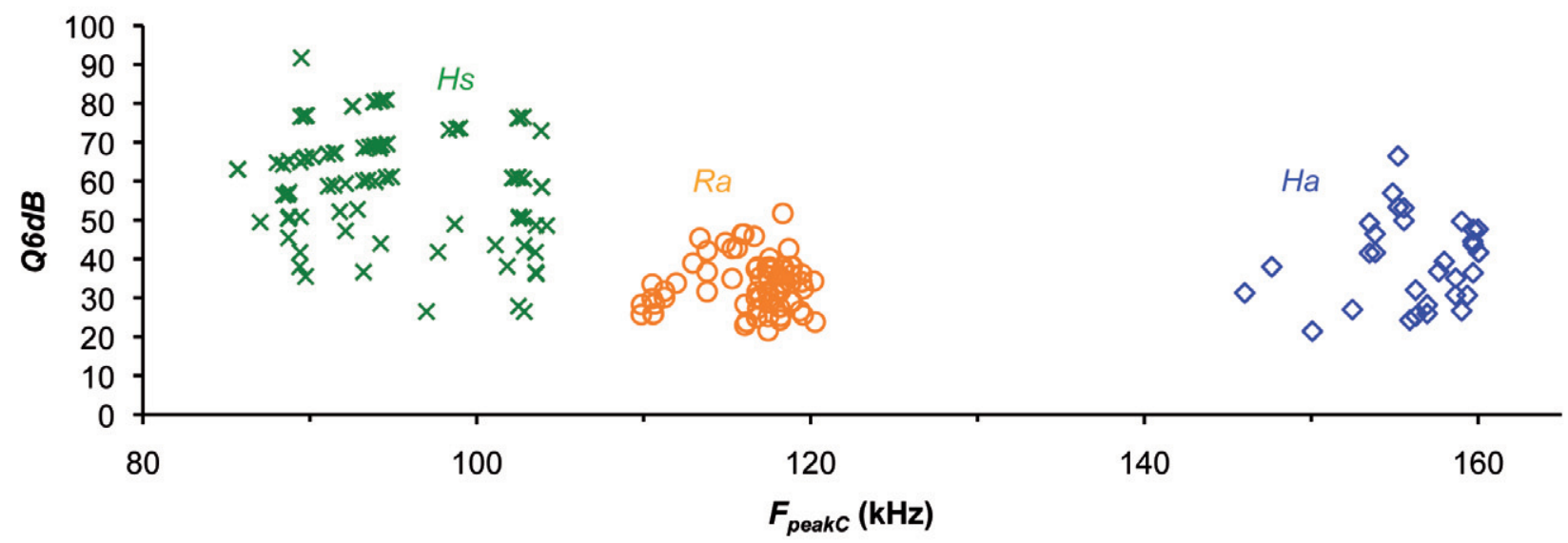

FIGURE 4 Scatterplot of $F_{\text {peakc }}$ versus $Q$ of the strongest harmonic in reference search-mode echolocation calls by ( $a$ and $c$ ) the 18 species found in the Northern Kimberley's landward environments, and (b and c) the 14 species found in its mangrove environments. Species codes comprise the first letter of the genus and species names (see Table 1). Sample sizes are provided in Table 5. Microhabitat and foraging strategy categories from Tables 6 and 7 are superimposed.

1. Recordings of flying M. gigas observed just after leaving a cave (Kununurra Bat Cave 154' $10^{\circ} \mathrm{S}$, $128^{\circ} 39^{\prime} 06^{\prime} \mathrm{E}$; Tunnel Creek $17^{\circ} 36^{\prime} 30^{\prime} \mathrm{S}, 125^{\circ} 08^{\prime} 45^{\prime} \mathrm{E}$; Ningbing Range Cave $\left.14^{\circ} 56^{\prime} 20^{\prime} S, 128^{\circ} 35^{\prime} 04^{\prime} \mathrm{E}\right)$ after dark, or foraging with a Cyalume tag, included brief $(<8 \mathrm{~ms})$, low $Q(<6)$ calls with peak frequencies between 34 and $55 \mathrm{kHz}$ (labelled ' $M g^{\prime}$ in Figure 4), with complexity as described above.

2. Recordings of $M$. gigas observed flying or perching in cave entrances and within roosts at Tunnel Creek included occasional prolonged (11-23 ms), usually low $Q(2.6-5.5)$, stepped-CF and complex FM calls with peak frequencies 


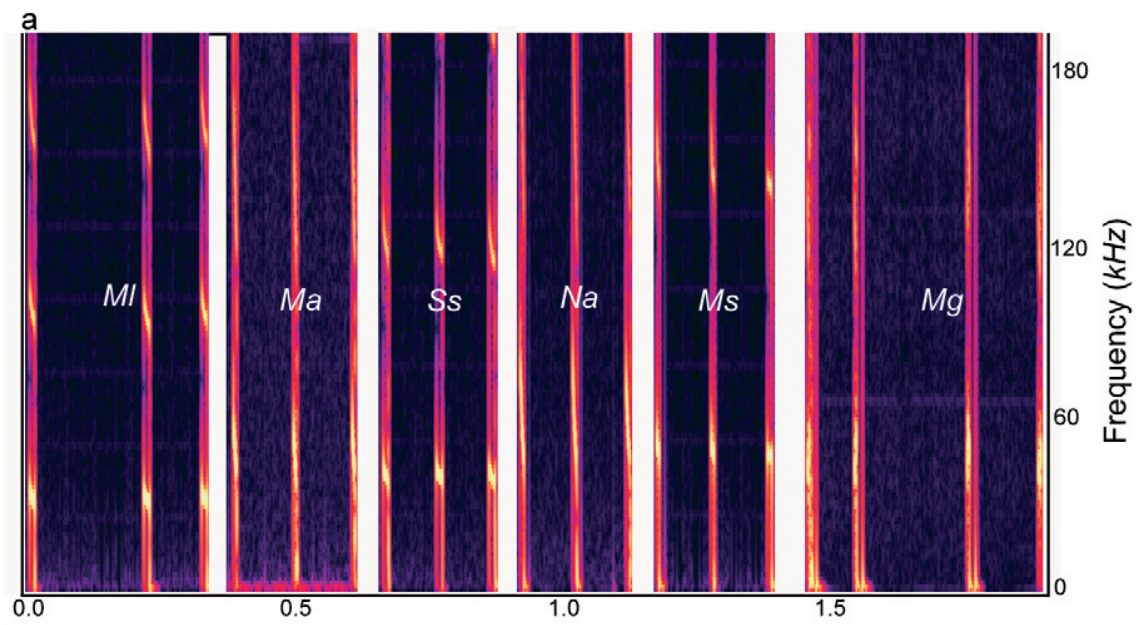

Time (sec)

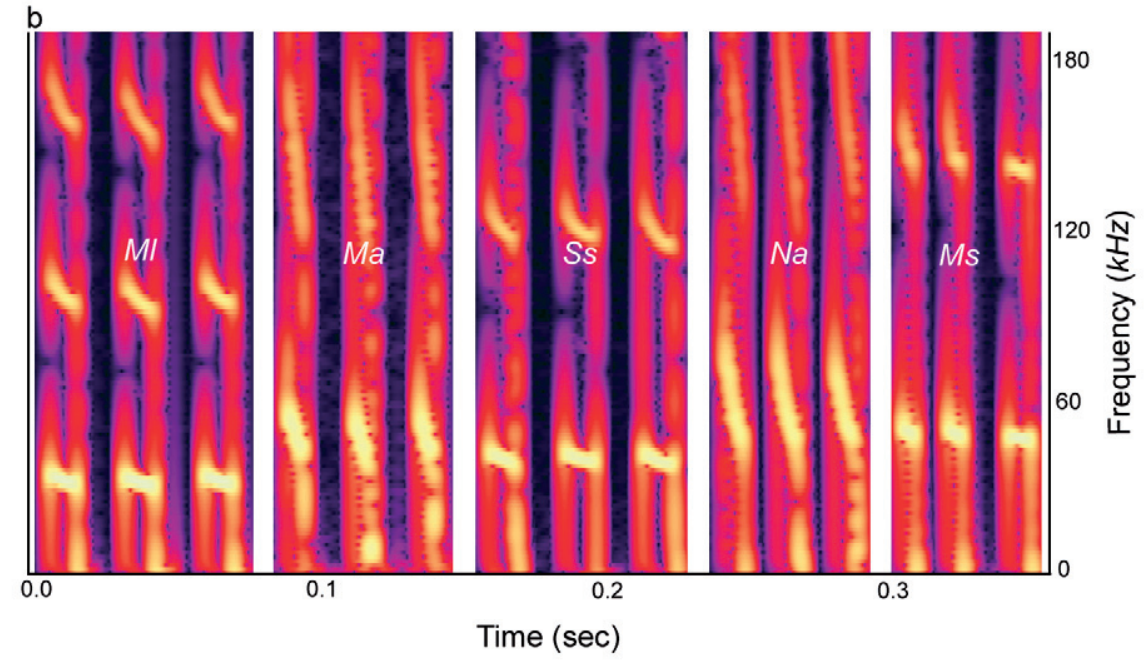

FIGURE 5 Search-mode call sequences in time domain by $M$. gigas and other Kimberley species that use the same frequency band. (a) Sections from sequences by Kimberley M. loriae, M. macropus, S. sanborni, N. arnhemensis and M. schreibersii, showing their typically steady call repetition rates tied to their wing-beat frequency (one call every wingbeat, or every second wing-beat etc.), compared to characteristically irregular call-repetition rates of M. gigas. (b) Close-up views of calls shown in (a) with the spacing between calls removed.

between 32 and $44 \mathrm{kHz}$ (not plotted in Figure 4). Call duration and complexity are sufficient for diagnosis, being greater than any recorded for other species using the same spectral niche.

In addition, $M$. gigas sequences often included characteristic sub-sequences of audible chitter-calls (see Figure 6a in McKenzie and Bullen 2009), and described by Churchill (2008) as 'distinctive twitter'. Examples of the call structure of other species that use the same frequency band as $M$. gigas are displayed in Figure 5b. Kimberley M. gigas also emit the loud audible 'chirping sounds' described by Kulzer et al. (1984).

While additional call attributes were not needed to separate any of the 14 species known to forage in Northern Kimberley mangroves (Figures $4 \mathrm{~b}$ and c), they were required to separate some additional species that forage in the mangroves of the adjacent Dampierland and Victoria-Bonaparte bioregions:

- Nyctophilus echolocation sequences can include occasional calls or call-series that are outside the species normal frequency-range (termed 'departure sub-sequences' by Bullen and McKenzie 2002a; McKenzie and Bullen 2009). These had to be ignored to separate $N$. arnhemensis from $N$. geoffroyi sequences (see Figure 6).

- Two call characteristics were useful in resolving 
the spectral overlap between Mormopterus loriae and Chalinolobus gouldii (Figures 4a and b) in Dampierland mangroves. Mormopterus loriae sequences often include calls with $Q$ values well above 14.0 (the upper limit for $C$. gouldii), and calls with higher $F_{\text {peakc }}$ values at any given $Q$ value. Individually, its calls had a narrower bandwidth $\left(F_{\min }\right.$ to $F_{\max }$ range and less curvilinear shape in time domain) for any given $F_{\text {peakc }}$ value (Milne 2002). Chalinolobus gouldii is not known from coastal areas of the Northern Kimberley and M. loriae is only known from its south-western periphery (King Sound, Figure 1).

More than $35 \%$ of the C. gouldii and M. loriae reference library calls are in the area of overlap between these species; overlap proportions between other species couplets (see Figure 4) are provided below.

\section{EMPIRICAL DATA ON FORAGING NICHE}

Clear patterns in microhabitat use emerged from the observational data (Table 6), which allowed species to be compared in terms of the airspace clutter they encountered in their usual foraging microhabitat. At the two extremes, T. georgianus, S. flaviventris and Chaerephon jobensis hunted in open airspaces well clear of obstructions, while the leaf- nosed bats as well as Nyctophilus spp and Vespadelus caurinus hunted in very cluttered airspaces, close to surfaces (BS/A and IS, Table 6). The remaining species hunted in various intermediate levels of clutter, except for $M$. beccarii which used three classes frequently, and M. loriae, its allopatric congeneric, which used all four.

Data on species foraging strategies are presented in Table 7, ordered according to agility (the species' ability to generate and sustain lateral force vectors). The assignments reflect available observations on flight speed, foraging behaviour and turn capability, and data on flight-muscle, heart-muscle mass ratios and ear canard type. High agility requires small, stiffened ears with a three-dimensional profile (Bullen and McKenzie 2009), large flight muscles and a muscular heart (Bullen and McKenzie 2004). Preferred roost data is included in the table because cave roosts appear to mitigate the need for a large heart muscle otherwise required by bats with an agile foraging strategy (e.g. T. georgianus, R. aurantia and M. schreibersii see Bullen et al. 2009). The three species with an agile foraging strategy, despite only moderate flight musculature, are all confined to highly productive habitats $-V$. douglasorum is confined to riparian environments, while $P$. westralis and $M$. loriae are confined to mangroves.
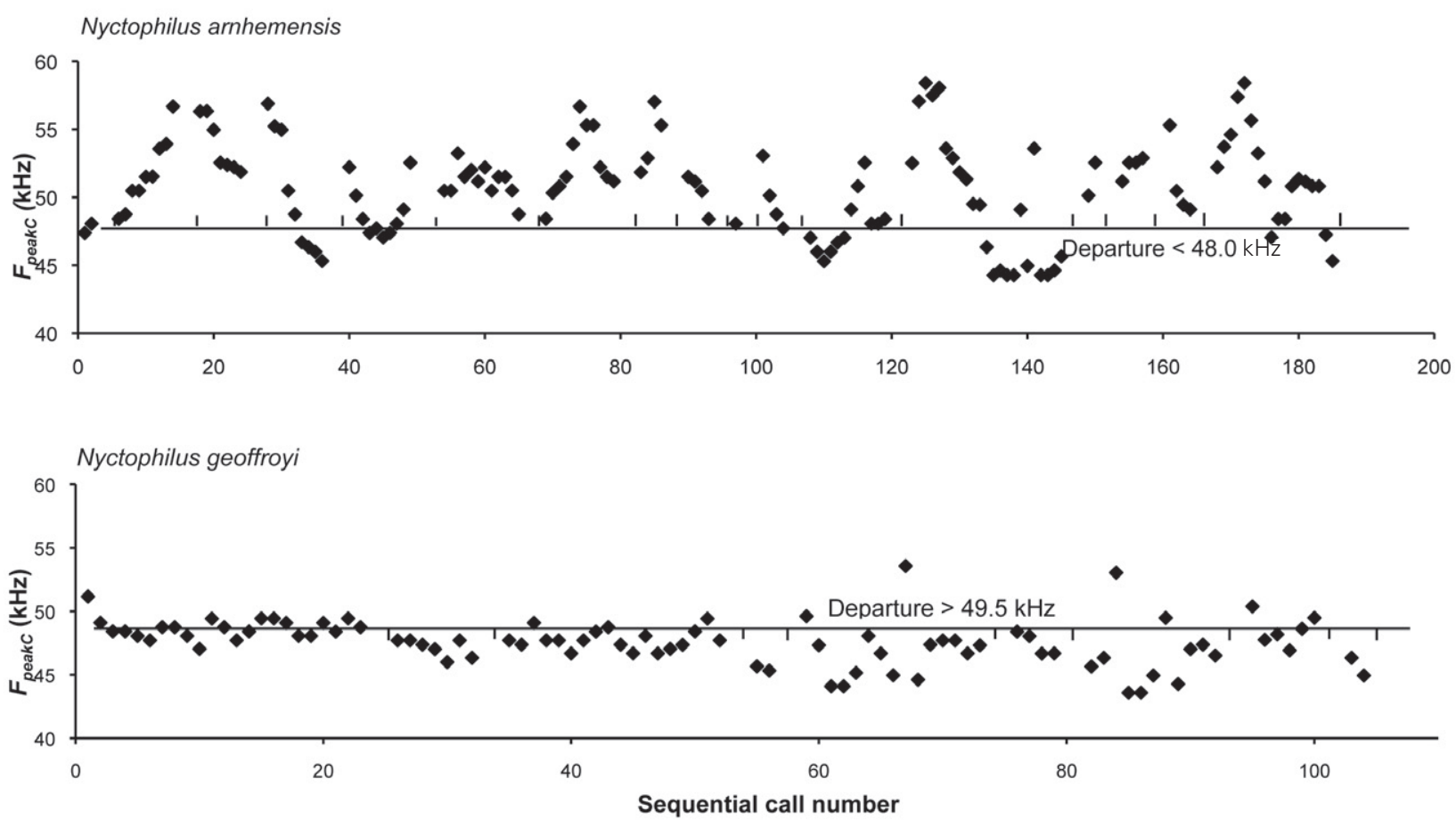

FIGURE 6 Search-mode sequence data for $N$. arnhemensis and $N$. geoffroyi. Individual bat sequences are separated by spaces. The horizontal line represents the arbitrary boundary used to distinguish between the normal and the departure sub-sequences for species recognition. Individual dots represent the $F_{\text {peakc }}$ value of each call within a sequence. 
Taken together, the data on agility, flight speed and ear canard type are consistent with published foraging strategies from elsewhere, as well as our field observations of foraging behaviours. Even moderately agile turns (Agility class 5 in Table 7) performed at high flight speeds $\left(>7 \mathrm{~m} \mathrm{sec}^{-1}\right)$ imply an air superiority strategy and are consistent with field observations of the relevant species outturning their prey (Appendix 4). Species observed to intercept their prey show high flight speeds, do not turn abruptly, and have 'cruising' canard ears (type-1). Bat species with a 'surface' foraging strategy $\left(\mathrm{S}_{\mathrm{a}^{\prime}} \mathrm{S}_{2 \mathrm{D}}\right.$ or $\mathrm{S}_{3 \mathrm{D}}$ in Table 7) have either type3 or type- 4 ears (Bullen and McKenzie 2009), use turns of moderate to low agility, and fly slowly, with the slowest (Hipposideros ater and H. stenotis) having the lowest agility rating. Exceptions were the large predator (M. gigas, $120 \mathrm{~g}$ ), which has the highest wing loading of all the surface strategists (13.5 v. 4.7-5.5 $\mathrm{N} \mathrm{m}^{-2}$ ) and consequently needs proportionally higher flight speed to generate sufficient lift even for level flight, and M. loriae, which has a dual-mode airframe (Bullen and McKenzie 2002b, 2004, 2007, 2009).

Bat airframe parameter values related to flight performance and control are provided in Table 8 (measurements are in Appendix 5). The relationships of 'Clutter' to ' $A R$ and $W L$ ' and 'Strategy' to TEAR are tight (Figures 7a and $7 \mathrm{~d}$, respectively) and functionally appropriate (Bullen and McKenzie 2007, 2009). Provided the leaf-nosed bats are excluded, these foraging niche measures

TABLE $6 \quad$ Foraging microhabitats of Kimberley bats.

Usual Foraging Microhabitats ${ }^{\mathrm{a}}$

\begin{tabular}{|c|c|c|c|c|c|c|c|c|c|}
\hline Species & OC & $\mathrm{AC}$ & $\mathrm{BS} / 0$ & $\mathrm{BS} / \mathrm{A}$ & IS & Clutter ${ }^{\mathrm{b}}$ & Microhabitat Specificity ${ }^{\mathrm{c}}$ & $n^{d}$ & $N$ \\
\hline$\overline{T g}$ & 55 & 5 & & & & 1.1 & 0.40 & 60 & 57 \\
\hline$S f$ & 80 & 7 & 2 & & & 1.1 & 0.39 & 89 & 84 \\
\hline$C j$ & 101 & 32 & 1 & & & 1.3 & 0.33 & 134 & 104 \\
\hline$M b$ & 6 & 11 & 6 & & & 2.0 & 0.20 & 23 & 23 \\
\hline$M l$ & 53 & 129 & 108 & 12 & & 2.3 & 0.19 & 302 & 255 \\
\hline $\mathrm{Cg}$ & & 8 & 56 & 3 & & 2.9 & 0.36 & 67 & 67 \\
\hline$S g$ & & 7 & 72 & 6 & & 3.0 & 0.36 & 85 & 85 \\
\hline $\mathrm{Cn}$ & & 4 & 91 & 12 & & 3.1 & 0.37 & 107 & 107 \\
\hline$M g$ & & 4 & 38 & 22 & & 3.3 & 0.26 & 64 & 64 \\
\hline Ss & & 1 & 65 & 33 & 3 & 3.4 & 0.28 & 102 & 97 \\
\hline Ms & & 3 & 33 & 48 & & 3.5 & 0.27 & 84 & 84 \\
\hline$M a$ & & & 21 & 26 & & $3.6^{\mathrm{e}}$ & 0.28 & 47 & 42 \\
\hline$P w$ & & 2 & 10 & 38 & 4 & 3.8 & 0.29 & 54 & 51 \\
\hline$N w$ & & & 4 & 19 & & 3.8 & 0.36 & 23 & 21 \\
\hline$V d$ & & & 4 & 20 & & 3.8 & 0.36 & 24 & 22 \\
\hline$R a$ & & & 4 & 22 & 3 & 4.0 & 0.32 & 29 & 22 \\
\hline$V c$ & & & 2 & 62 & & 4.0 & 0.43 & 64 & 61 \\
\hline $\mathrm{Nd}$ & & & & 14 & 1 & 4.1 & 0.41 & 15 & 15 \\
\hline $\mathrm{Ng}$ & & & 2 & 39 & 11 & 4.2 & 0.32 & 52 & 49 \\
\hline Hs & & & & 6 & 4 & 4.4 & 0.28 & 10 & 10 \\
\hline $\mathrm{Ha}$ & & & & 17 & 15 & 4.5 & 0.27 & 32 & 32 \\
\hline $\mathrm{Na}$ & & & 1 & 69 & 77 & 4.5 & 0.27 & 147 & 147 \\
\hline
\end{tabular}

${ }^{\text {a }}$ Microhabitat codes are explained in Methods.

${ }^{\mathrm{b}}$ Each microhabitat was assigned to an ordinal clutter value from 1 (OC) to 5 (IS). Thus the average clutter value for $M$. loriae $=((53 \times 1)+(129 \times 2)+(108 \times 3)+(12 \times 4)+(0 \times 5)) /(53+129+108+12+0)=2.3$

c The standard deviation of the proportion of observations in each microhabitat class.

d $n=$ number of observations, $N=$ numbers of individuals.

e But water has a flat surface so BS/A is less cluttered for this species. 


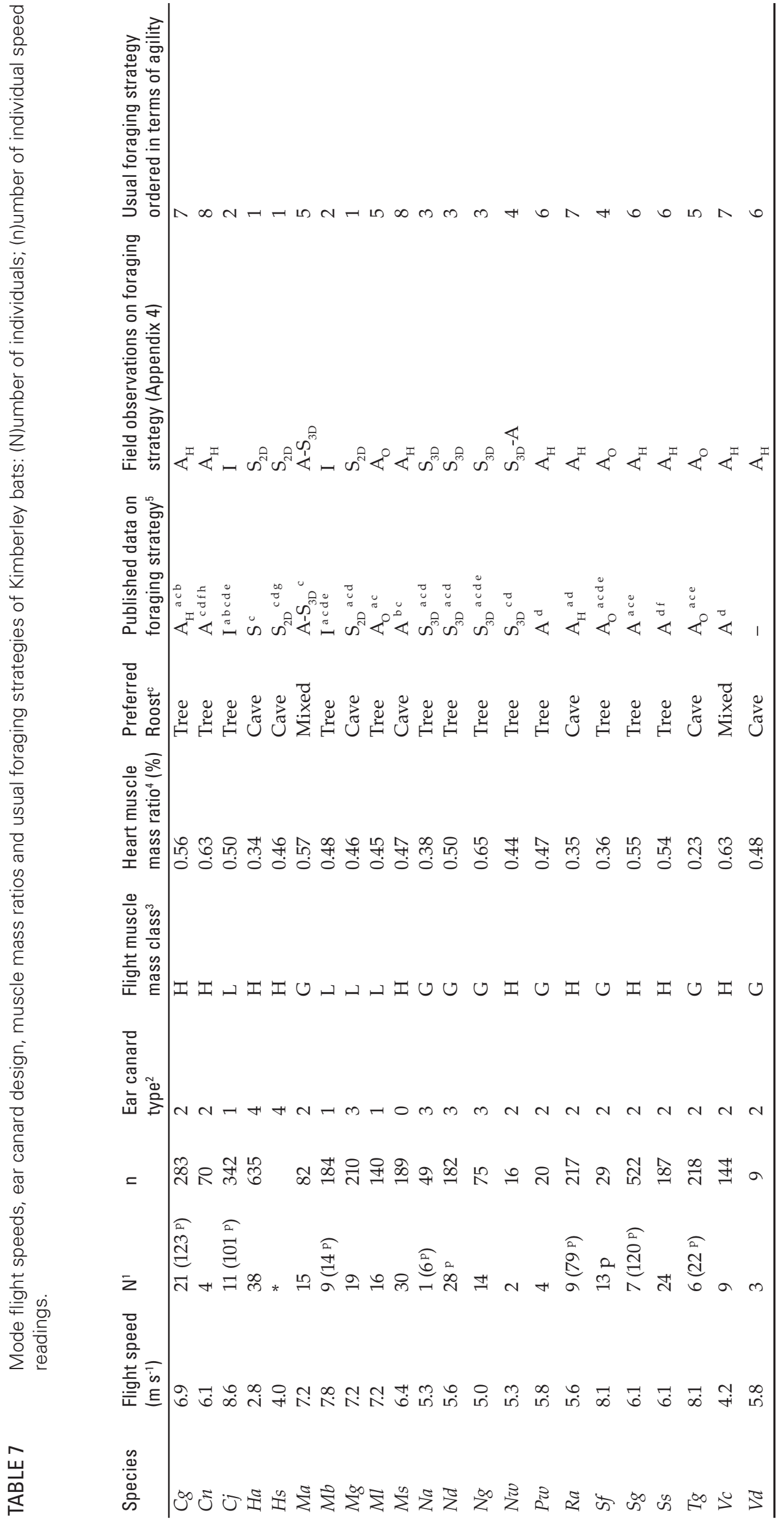


a

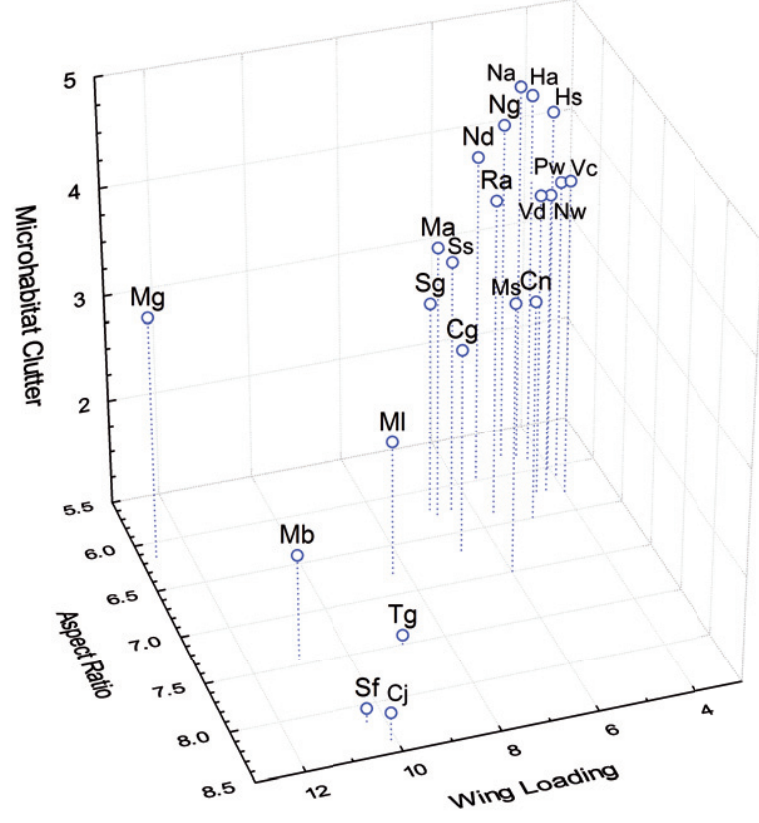

Multiple $\mathrm{R}\left(\right.$ Clutter $\left./ A R^{\star} W L\right)=0.94, P<0.000001$ b

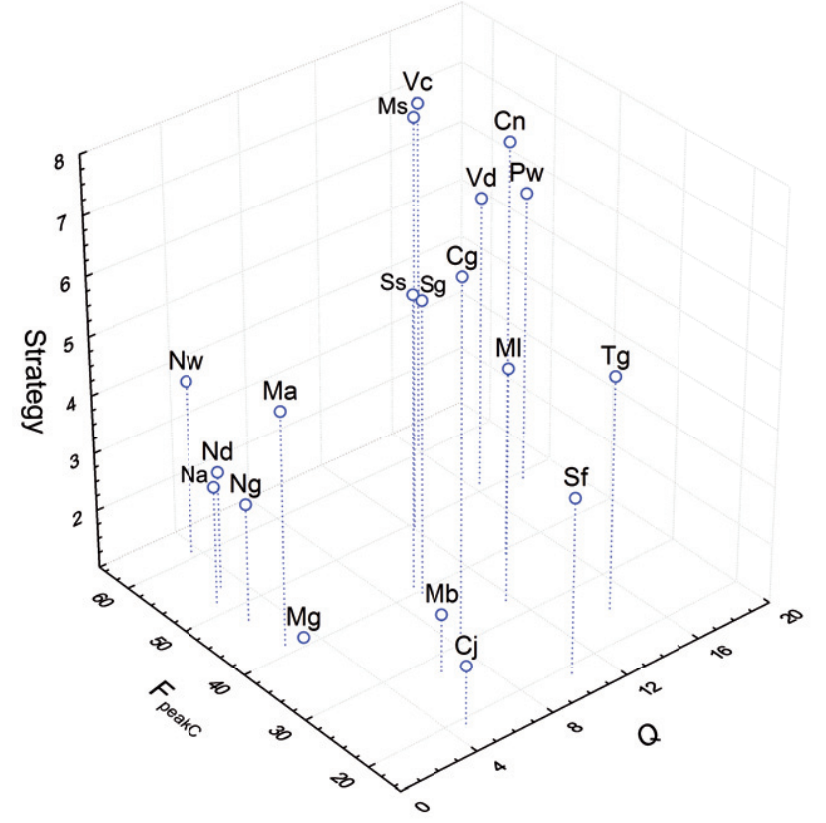

Multiple $\mathrm{R}\left(\right.$ Strategy $\left./ F p e a k C^{\star} Q\right)=0.78, P=0.0006$ (excluding $\mathrm{Ha}$, Hs and $\mathrm{Ra}$ )
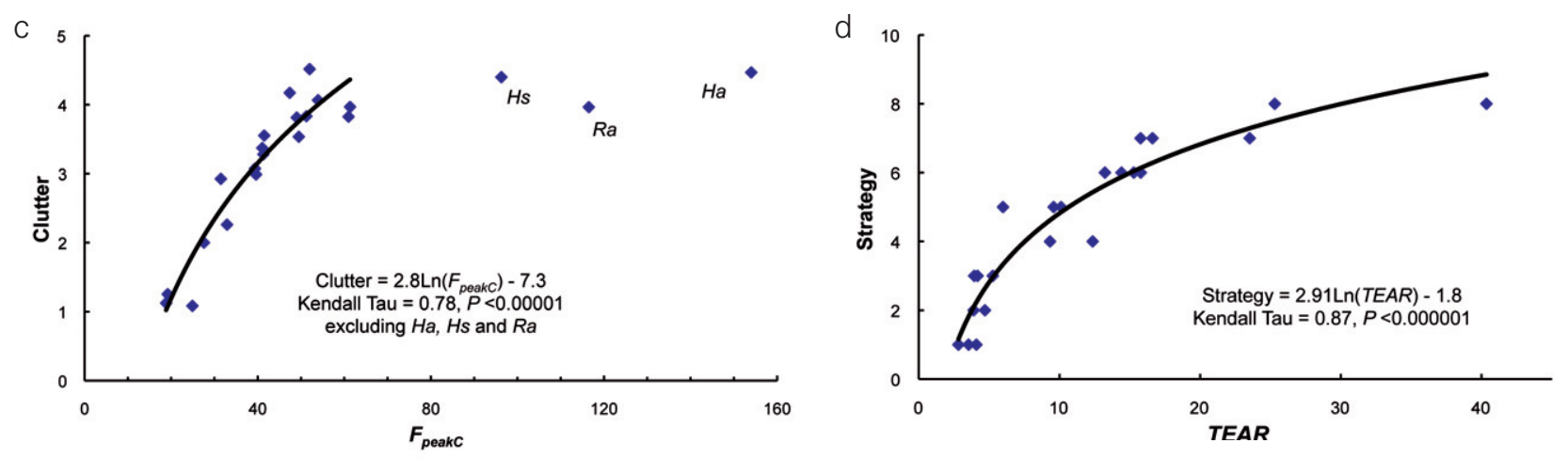

FIGURE 7

Relationships between airframe parameters, search-mode call variables and aspects of foraging niche: (a) microhabitat clutter $v$. aspect ratio and wing loading, (b) foraging strategy $v$. tail-ear area ratio (TEAR), (c) microhabitat clutter v. $F_{\text {peakC }}$ (d) foraging strategy v. $F_{\text {peakC }}$ and $Q$.

also show tight relationships with search-mode call variables: 'Clutter' to $F_{\text {peakc }}$ (Figure 7c) and 'Strategy' to the combination of $Q$ and $F_{\text {peak }}$ (Figure $7 \mathrm{~b}$ ).

\section{ORGANISATION OF SPECIES IN SPECTRAL SPACE}

The foraging microhabitat and strategy categories superimposed on Figures $4 \mathrm{a}$ and $4 \mathrm{~b}$ reveal that the two spectral characters array the FM bats according to differences in foraging niche, but not the CF species (the leaf-nosed bats $H$. ater, H. stenotis and $R$. aurantia; Figure 4c). Calls by 'interceptor' and 'surface' bats have moderate or low $Q$-values, respectively, compared to 'air superiority' strategists (Figure 7b), and species that usually forage in cluttered airspaces use higher frequencies than those operating in open microhabitats (Figure 7c).

From a community perspective, most species are arrayed discretely throughout the 'spectral' 
TABLE 8 Airframe variables of Kimberley bats: mean (SD).

\begin{tabular}{|c|c|c|c|c|}
\hline Species & $N$ & Aspect ratio & $\begin{array}{l}\text { Wing loading ( } \mathrm{Nm}^{-} \\
\left.{ }^{2}\right)\end{array}$ & $\begin{array}{l}\text { Tail-ear area ratio } \\
\text { (TEAR) }\end{array}$ \\
\hline $\mathrm{Cg}$ & 6 & $6.69(0.11)$ & $6.72(0.34)$ & $23.52(2.93)$ \\
\hline $\mathrm{Cn}$ & 12 & $6.49(0.16)$ & $4.94(0.41)$ & $25.30(7.97)$ \\
\hline$C j$ & 5 & $8.37(0.10)$ & $10.10(0.83)$ & $3.90(0.97)$ \\
\hline $\mathrm{Ha}$ & 13 & $5.87(0.14)$ & $4.30(0.44)$ & $2.82(0.39)^{a}$ \\
\hline Hs & 5 & $6.01(0.12)$ & $4.03(0.26)$ & $4.10(0.39)$ \\
\hline$M a$ & 4 & $6.27(0.23)$ & $6.76(0.81)$ & $10.12(0.73)$ \\
\hline$M b$ & 4 & $7.45(0.17)$ & $11.02(1.30)$ & $4.70(0.58)$ \\
\hline$M g$ & 4 & $6.15(0.18)$ & $12.68(1.49)$ & $3.54(0.79)$ \\
\hline$M l$ & 8 & $6.78(0.13)$ & $8.29(0.61)$ & $5.99(1.02)$ \\
\hline Ms & 10 & $6.99(0.19)$ & $5.98(0.51)$ & 40.35 (7.34) \\
\hline $\mathrm{Na}$ & 12 & $5.81(0.13)$ & $4.48(0.38)$ & $5.26(0.70)$ \\
\hline$N d$ & 6 & $5.96(0.21)$ & $5.55(0.33)$ & $4.18(0.37)$ \\
\hline $\mathrm{Ng}$ & 9 & $5.78(0.13)$ & $4.79(0.65)$ & $3.94(0.84)$ \\
\hline$N w$ & 8 & $6.23(0.11)$ & $4.34(0.26)$ & $9.33(1.32)$ \\
\hline$P w$ & 4 & $6.10(0.10)$ & $3.95(0.40)$ & $15.29(1.58)$ \\
\hline$R a$ & 4 & $6.36(0.17)$ & $5.64(0.30)$ & $16.62(3.67)$ \\
\hline$S f$ & 2 & $8.16(0.52)$ & $10.36(0.43)$ & $12.36(0.64)$ \\
\hline$S g$ & 8 & $6.21(0.26)$ & $6.84(0.98)$ & $14.41(2.93)$ \\
\hline Ss & 15 & $6.25(0.13)$ & $6.42(0.67)$ & $15.78(2.80)$ \\
\hline $\mathrm{Tg}$ & 8 & $7.49(0.38)$ & 8.88 (1.33) & 9.59 (1.12) \\
\hline$V c$ & 11 & $6.29(0.17)$ & $3.99(0.36)$ & $15.77(2.47)$ \\
\hline$V d$ & 6 & $6.23(0.25)$ & $4.54(0.37)$ & $13.23(2.52)$ \\
\hline
\end{tabular}

${ }^{a} N$ (number of individuals) $=6$

space and show partial or no overlaps (Figure 4). Nyctophilus daedalus and the large predator M. gigas are the exceptions, although $11 \%$ of $C$. nigrogriseus and S. greyii, $15 \%$ of C. nigrogriseus and S. sanborni, and $10 \%$ of $M$. schreibersii and $P$. westralis reference calls overlapped. In contrast, for the allopatric species pairs, $45 \%$ of $S$. greyii and S. sanborni, and $24 \%$ of $P$. westralis and $V$. douglasorum calls overlapped.

Family members were adjacent to one another in spectral space, and similar in their foraging niches (Figure 4). The only exception was M. schreibersii (the only Miniopteridae), which was positioned between vespertilionids. While congenerics were neighbours, not all spectrally similar species were congeners (C. gouldii cf. M. loriae; P. westralis cf. V. douglasorum).

\section{ACOUSTIC SURVEY OF ISLAND BATS}

In Figure 8, the reference calls plotted in Figure 4 are overlayed with unknown calls (as small dots) from sequences recorded at landward and mangrove sites on the Northern Kimberley islands.
As explained in the Methods, unknown calls that plotted on the periphery of a reference call cluster were identified only if they were in continuous sequence with calls that fell within the cluster; those that fell into an area of overlap with another species were identified only if they were in continuous sequence with calls that fell elsewhere in the cluster. Saccolaimus flaviventris and T. georgianus sequences sometimes included one or two 2nd harmonic calls that were in the same frequency band as C. gouldii and M. schreibersii calls, respectively, but with distinctively CF-like shapes in time domain and high $Q$ values. Examples for T. georgianus are included in Figure 8. On the basis that we have never recorded a T. georgianus reference call in the 12 or the $36 \mathrm{kHz}$ range, we conclude that the frequency of its strongest harmonic is about $24 \mathrm{kHz}$ (range 23-27).

The leaf-nosed bats showed wide variation in both $Q$ and $F_{\text {peak }}$ compared to other species (Table 5). This variation could be reduced by excluding weak calls, i.e. calls that appeared diffuse or noisy in spectral view, compared to adjacent calls in 
a

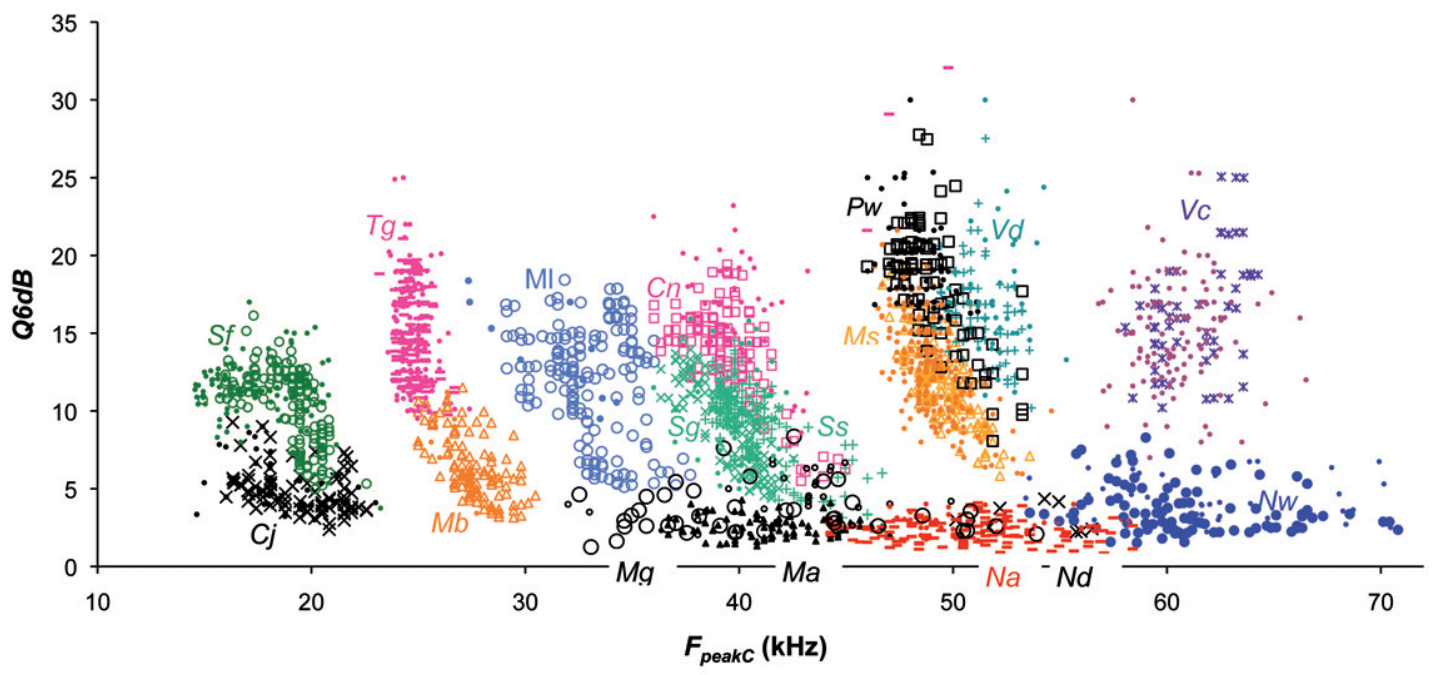

b

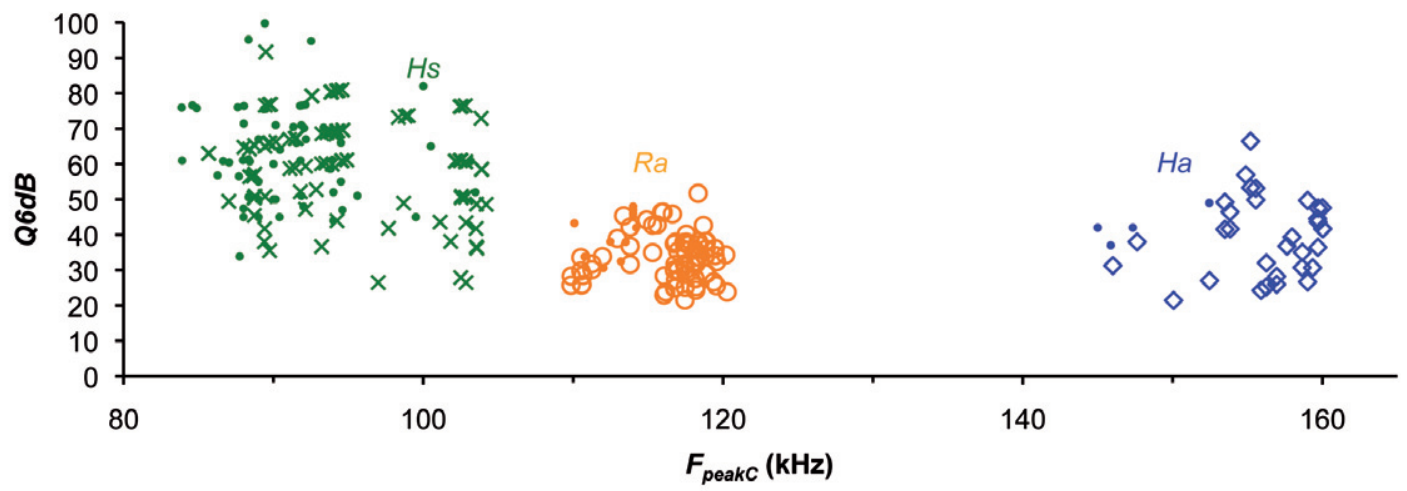

FIGURE 8 Scatterplot of strongest harmonic $F_{\text {peak }}$ versus $Q$ of 'unknown' sequences of search-mode echolocation calls (small dots in the relevant colour) overlaid onto reference calls for identification purposes. To provide an indication of wider variation, good quality calls from some sequences are plotted irrespective of whether they fell into an overlap zone or were peripheral to a species cluster; such calls were identified from calls in the same sequence that plotted unambiguously. (a) Landward and mangrove species with calls $<80 \mathrm{kHz}$, combined. M. gigas determinations (small hollow dots) were distinguished using the additional call attributes described in text: duration, complex structure and/or irregular spacing). (b) Leaf-nosed bats.

the same sequence. Weak calls usually included dropouts, mid-call changes in frequency and/or lacked their FM components. Individual weak calls in these sequences sometimes returned readings as low as $72 \mathrm{kHz}$ for H. stenotis, and $105 \mathrm{kHz}$ for $R$. aurantia, that we treated as artefacts of the recording equipment representing inharmonic partials that were not integer multiples of the fundamental frequency (first harmonic). Even after they were excluded, $H$. stenotis populations showed up to a 10 $\mathrm{kHz}$ range in $F_{\text {peakc }}$ sequence-to-sequence (Figure 9). This figure also reveals systematic variation between populations; populations on islands along central and northern parts of the coast $\left(<16^{\circ} \mathrm{S}\right)$ used calls $c a .10 \mathrm{kHz}$ lower than their southern and mainland counterparts.

Almost all sequences and most of the individual search-mode calls we recorded from landward sites were identifiable unless: (1) the recording was weak (atmospheric attenuation) or visibly distorted by echoes or over-saturation, or (2) the recording site was more than $50 \mathrm{~m}$ but less than $500 \mathrm{~m}$ from a mangrove stand. With the same restrictions, the equivalent result was obtained for recordings from mangrove sites; unknown sequences could be identified unambiguously. Capture data at or near recording sites confirmed many of the identifications (e.g. V. douglasorum on Storr, $M$. schreibersii on Coronation, $N$. arnhemensis on SW Osborn, H. stenotis on Boongaree). On the basis that virtually all clear sequences by 20 of the Northern Kimberley's 21 echolocating bat species were identified, we concluded that spectral parameters provided a viable survey tool. 


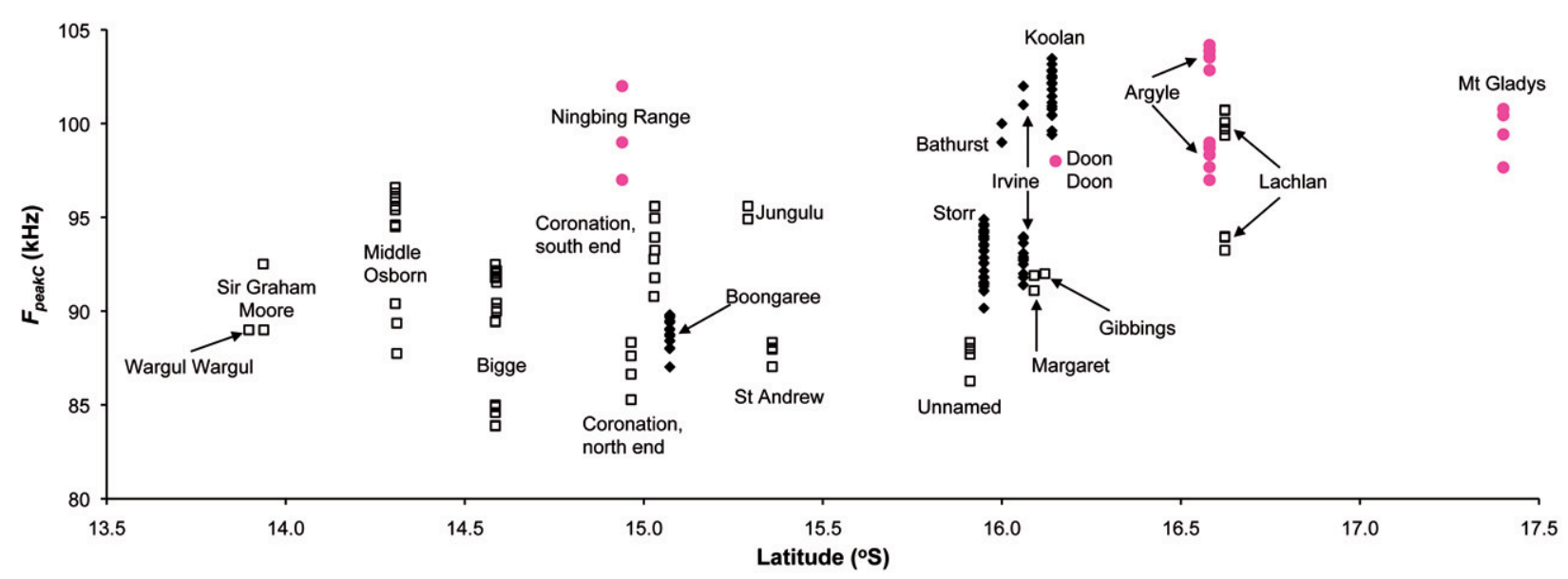

FIGURE $9 \quad F_{\text {peakC }}$ plotted against latitude ( $\left.{ }^{\circ} \mathrm{S}\right)$ for individual calls from sequences by free-flying $\mathrm{H}$. stenotis recorded at different Western Australian localities. Reference calls are indicated by solid diamonds (Appendix 1); pink circles are calls from mainland sites, including Argyle Ridge (16³6'54'S

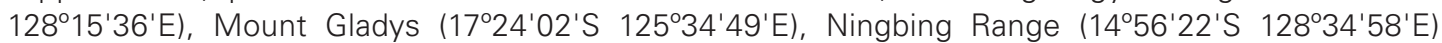
and Doon Doon (16 $\left.09^{\prime} S 128^{\circ} 09^{\prime} E\right)$; calls from sequences identified acoustically are hollow squares (Appendix 6).

The results of the acoustic survey are summarised in Appendix 6, which lists the species identified from each recording made on each island sampled. These data are combined with previous species records held by the WAM as well as species captured in mist nets during our field survey (vouchers are now lodged in the WAM) to produce lists of the bats known from each island (Table 9). Excluding the three fruit/nectar-eating bats, a total of 20 species are now known from the islands (average $7.8 \pm 0.6$ S.E.), including all but one of the species known from the adjacent Northern Kimberley mainland (C. gouldii, see Table 4), and $M$. loriae, a new record for the Northern Kimberley. ICE and Chao2 procedures in EstimateS both produced an estimate of 20 species from the 30 Northern Kimberley islands sampled. The field survey result was $100 \%$ of the estimation, and the accumulation curves were asymptotic.

\section{SPECIES DISTRIBUTIONS AND CONSERVATION STATUS}

Table 9 shows that:

1. Chalinolobus gouldii was not recorded on the islands despite its loud echolocation calls and sampling programs in both the wet and dry seasons (Appendix 8).

2. We detected both $H$. ater and $R$. aurantia calls on seven islands even though the Anabat detector range is $<3 \mathrm{~m}$ for these species, and despite the sparse sampling (mode $=8.0 \mathrm{~h}$ of recording per island, and 2 sites). Suitable foraging and roosting habitats are common on most
Northern Kimberley islands of more than 500 ha, so both species probably occur on most of the islands we sampled (Appendix 2).

3. Macroderma gigas also appears to be widespread and common on the islands; we observed it on five of the islands surveyed and detected its calls on six others despite the sparse sampling and the low intensity of its in-flight calls (bat detector range is $<3 \mathrm{~m}$ for $M$. gigas).

4. Nyctophilus daedalus is known from only one of the 30 islands surveyed, but its apparent rarity may be an artefact of its low intensity calls (detectable only to distances of 3-4 m with Anabat), their similarity to $N$. arnhemensis, and its narrow habitat associations (e.g. McKenzie and Bullen 2009).

5. Vespadelus douglasorum, a species endemic to the Kimberley, was detected on seven islands, and has been captured on two of these. These are the only island populations known for this species.

6. Mormopterus loriae, a mangrove specialist in WA, was detected in the Northern Kimberley for the first time. Despite its loud echolocation calls, and our thorough sampling programs during both wet and dry seasons, it was detected on only three islands, all on the south-western periphery of the bioregion adjacent to Dampierland. These are the only island populations known in WA, but appear to be absent during the dry season (it was recorded in November, February, April and May, but not June, July and October - see 


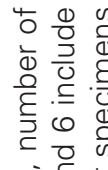

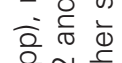

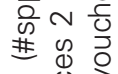

D)

든 응

क.

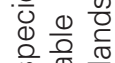

कि $\frac{0}{10} \frac{\pi}{20}$

(ब)

की

os 0

言造递

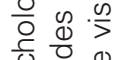

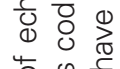

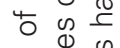

은 $\frac{0}{0} \frac{5}{0}$

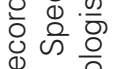

일 응

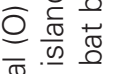

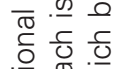

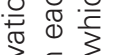

离

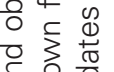

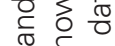

ज) $\frac{\square}{\square}$

离部兽

它

के $\frac{\infty}{0} \cdot \frac{x}{\bar{c}}$

बi के

등용

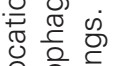

응 운흥

ब.

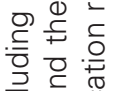

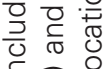

iิ

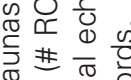

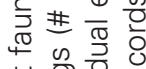

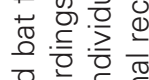

든.

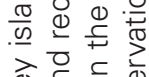

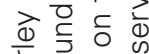

这

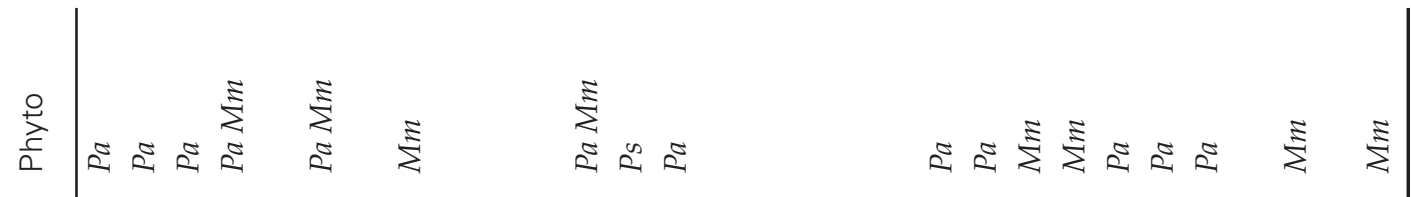
$\#$
0
0
0
0

응

\#

I

s

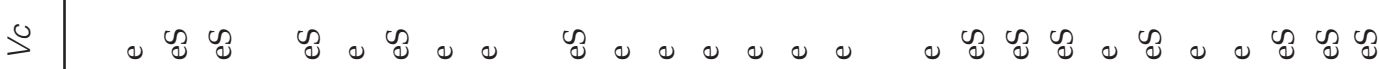

\&

s

के

के

10

$\begin{array}{llllllll}0 & 0 & 0 & 0 & 0 & 0 & 0 & 0 \\ 0 & 0 & 0 & 0 & 0 & & 0\end{array}$

3

3

$\sum^{3}$

$\stackrel{8}{z}$

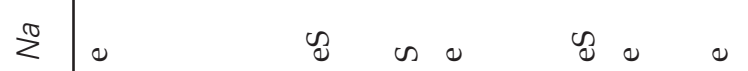

$\sum^{\infty}$

in 0

$\bar{z}$

$\Sigma$

$\sum$ D.

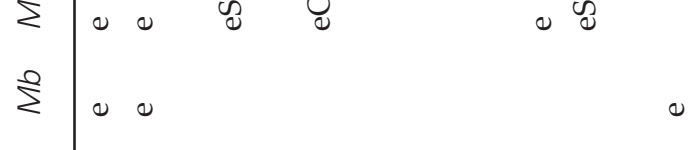

$\circ 00$

$\sum^{\pi} 0$

$\stackrel{5}{1}$

赵 \& 0 \&

0

E 0 क क ०

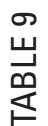

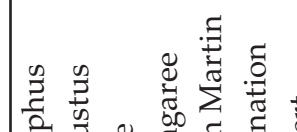

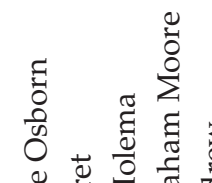
ㅇ. 0 \&

$\mathcal{2}$




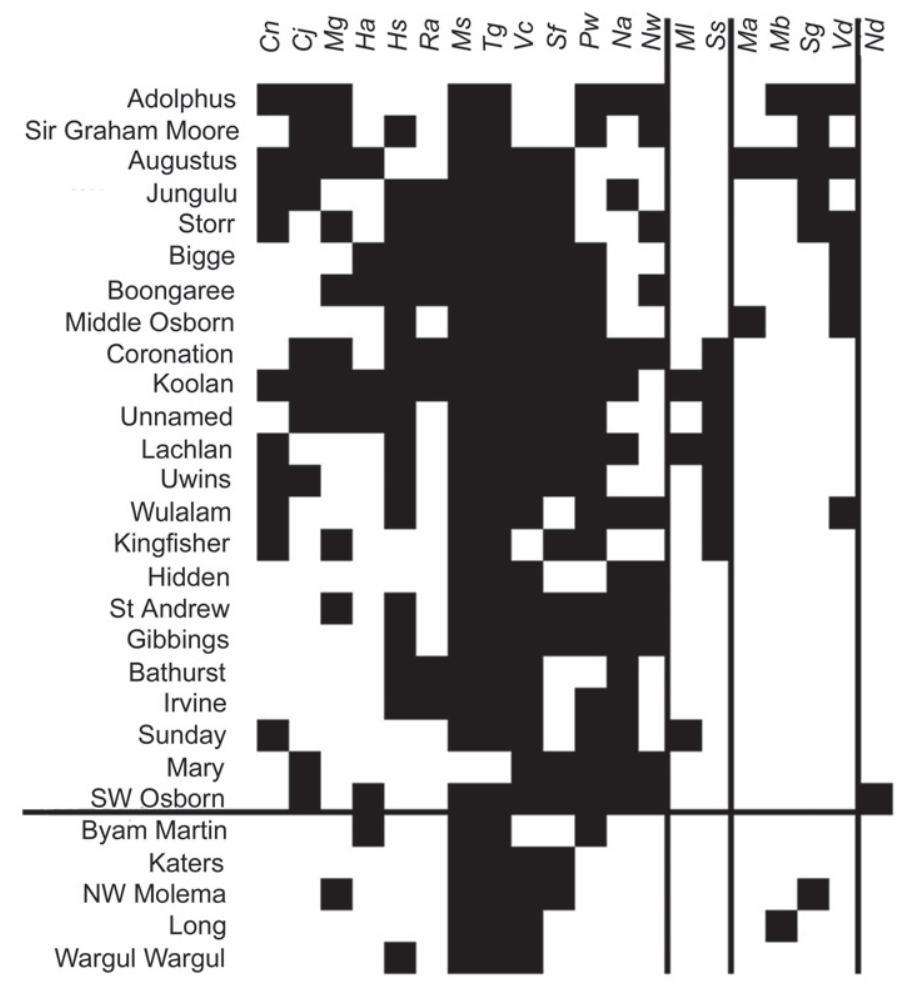

FIGURE $10 \quad$ Island $x$ species matrix re-ordered according to the classification analyses (islands in terms of composition and species in terms of their co-occurrences).

Appendix 6).

7. Populations of N. walkeri were also detected on islands for the first time.

8. While H. stenotis and N. walkeri were detected only at landward sites during the island survey, two of these sites were within $20 \mathrm{~m}$ of mangroves ( $H$. stenotis: Coronation recording \#25 and Middle Osborn \#57; N. walkeri: Wulalam \#89 and Gibbings \#91 - Appendix 2), so further field survey work may show that they belong to the mangrove community as well.

\section{SPECIES COMPOSITION AND HABITAT ASSOCIATIONS ON THE ISLANDS}

Figure 10 displays the island data matrix reordered according to the classification analyses: species in terms of their co-occurrences and islands in terms of their species composition.

When species attributes (Table 3, Appendix 7a) were plotted as vectors into the scatterplot derived by ordinating species according to their co-occurrences on islands (Figure 11), two were orthogonal to one another (3-D divergence angle $=87^{\circ}$ ), implying independence, and strongly correlated with the observed co-occurrence pattern ('mangrove': $\mathrm{R}^{2}=0.69,0.0 \%$ of randomisations exceeded this correlation value; 'riparian': $\mathrm{R}^{2}=0.52$, $0.6 \%$ ). These correlations were unlikely to be an analysis artefact because multi-dimensional scaling the species dissimilarity matrix to three dimensions did not result in high 'stress' (<0.09).

When island attribute values (Table 3, Appendix $7 \mathrm{~b})$ were plotted as vectors into the scatterplot derived by ordinating islands according to their species composition, four widely divergent vectors were correlated with the island compositional similarity pattern: (1) 'cave country': $R^{2}=0.48$, $0.0 \%$ of randomisations exceeded this value; (2) 'isothermality': $\mathrm{R}^{2}=0.38,0.5 \%$; (3) 'mangrove proximity': $\mathrm{R}^{2}=0.35,1.2 \%$; and (4) 'sampling effort': $\mathrm{R}^{2}=0.27,4.3 \%$. Three-dimensional divergence angles between these vectors were $>45^{\circ}$ in all cases (average $=67^{\circ}$ ), implying independent relationships. However, reducing the island dissimilarity matrix to three dimensions resulted in appreciable 'stress' (0.18), so correlation values may be inexact.

Nestedness was overt in the island data matrix ( $T=20.4, P \ll 0.0001$, Atmar and Patterson 1993, 1995; $\mathrm{T}=18.2, P<0.0001$, Rodriguez-Girones and Santamaria 2006) with, as the ordination analyses indicated, most landward and mangrove community members being detected on islands with cave country as well as well-developed mangrove stands and riparian sites, unless survey effort was low. The emergence of 'sampling effort' as a factor influencing composition suggests that island species lists are still incomplete. A correlation between similarity in island species 


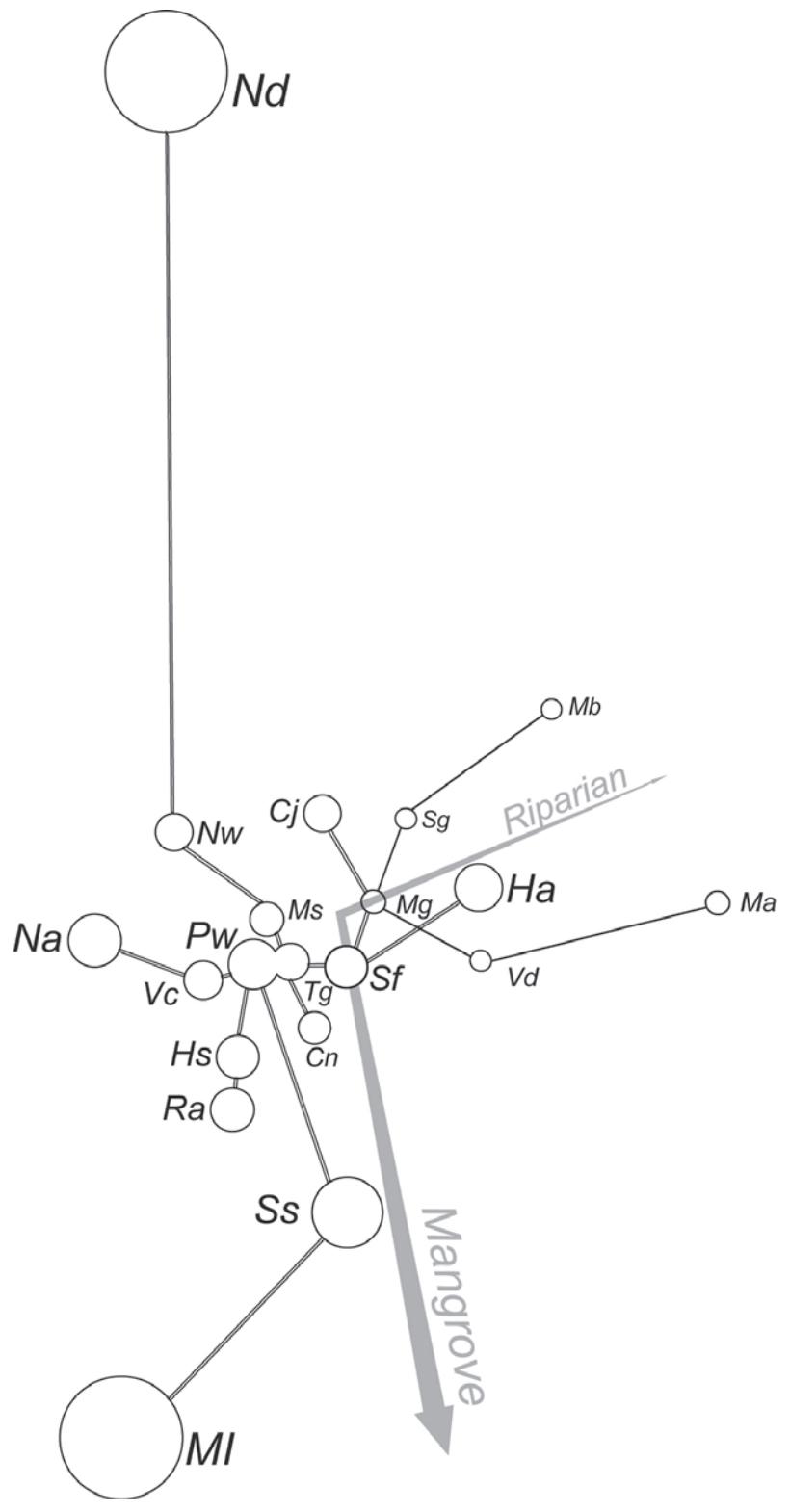

FIGURE 11 Three-dimensional ordination of the bats according to their island cooccurrences (stress < 0.09), with a Minimum Spanning Tree superimposed. The third dimension is indicated by circle diameters. The two vectors plotted into the ordination space indicate species fidelity to riparian habitats and to mangrove (or landward) environments (Table 3). Species codes are listed in Table 1.

composition (Czekanowski) and their geographical distance apart was detectable $(0.19, P=0.011)$, so partial mantel tests were used to reassess the correlations between island species composition and each of the four island attributes (above) while geographic distance between islands was held constant. The correlations with 'cave country'
(0.30, $P=0.001)$, 'mangrove proximity' $(0.24,0.002)$, 'isothermality' $(0.19,0.020)$, but not 'sampling effort' $(0.04,0.296)$, were independent of geographical distance between islands.

\section{DISCUSSION}

\section{NORTHERN KIMBERLEY FAUNA}

Strictly, 21 species of zoophagic bat occur in the Northern Kimberley, but one of these is known only from islands on the bioregion's south-western periphery ( $M$. loriae) and another appears to be absent from its near-coastal areas, including the islands (C. gouldii - Tables 4 and 9). This gap in the geographic range of $C$. gouldii is consistent with its absence from coastal areas elsewhere in tropical Australia that have similarly high year-round humidity (i.e. Arnhemland coast and Cape York Peninsula: Milne et al. 2006; Dixon and Lumsden 2008).

Our analysis revealed two compositionally distinct communities in the Kimberley, one occupying landward environments and the other mangroves. Equivalent bat communities occupy the landward and mangrove environments of the semi-arid Pilbara bioregion, further south in tropical Western Australia (McKenzie and Bullen 2009). These two communities were not revealed by an equivalent analysis of 35 sites scattered through mesic regions of the Northern Territory, just east of the Kimberley, because mangrove sites were not sampled by Milne et al. (2005b). However, consistent with our results, Milne's analysis did not reveal compositionally discrete communities in the landward environments, just compositional gradients related to the proximity of cavernous and structurally complex riparian habitats.

Clues to the origin of the two Kimberley bat communities are overt in the Pleistocene climatic history of Australia's north-western coastline where, unlike north-eastern Australia (see also Wyrwoll et al. 2007), mangroves appear to have been the only highly productive, closed-canopy vegetation that retained its extent and integrity through cool dry periods associated with glacial maxima (Nix and Kalma 1972; Webb et al. 1984; McKenzie and Rolfe 1986; De Deckker et al. 1987; Walker and Chen 1987; Barlow and Hyland 1988). Recent data confirm the traditional idea of aridity associated with glacial maxima, and reveal that shorter-term wet-dry fluctuations were relatively subdued (K.-H. Wyrwoll, pers. comm.). This palaeoclimatic difference between northeastern and north-western Australia explains the virtual absence of endemic rainforest plants in the Kimberley (just one species, Hybiscus perabuls) compared to the rich suite of rainforest endemics 
in Queensland (e.g. Gillison 1987; Kenneally et al. 1991). While mangrove refugia were not an option available to rainforest plants, their importance for persistence of rainforest vertebrates in north-western Australia during the Pleistocene is reflected in contemporary phylogenetic differences between the two regions. A variety of the birds and bats associated with rainforest, riparian and mangrove environments in north-eastern Australia are represented in the Kimberley (and Northern Territory) by distinct species, sub-species and colour-morphs that are either confined to mangroves, or are more dependent on them than their eastern counterparts (Ford 1982; Johnstone 1990; McKenzie et al. 1991; Morton et al. 1995; Eldridge et al. 2011). Examples include bats such as P. westralis, M. loriae cobourgiana, S. sanborni and N. arnhemensis, and birds such as the Chestnut Rail, Mangrove Golden Whistler, Mangrove Flyeater, Torresian Imperial Pigeon and Shining Flycatcher.

\section{RELEVANCE OF CALL SPECTRAL CHARACTERISTICS TO FORAGING NICHE}

From a review of literature on acoustic imaging by bats, Simmons (1989) concluded that (1) the representation of echo and target features in the bat's brain closely follows the structure of the bat's sonar calls, (2) the perceived target images are formed by the neural convergence of auditory temporal as well as auditory spectral processes, and (3) differences in call structure between species are thought to contribute to resource partitioning among sympatric species through niche differentiation (e.g. Heller and Helversen 1989; Neuweiler 1990). This acoustic partitioning was subsequently confirmed analytically (e.g. Neuweiler 1989; Fullard et al. 1991; McKenzie and Bullen 2003, 2009) and experimentally (Siemers and Schnitzler 2004; Triblehorn and Yager 2005) for both temporal (time-frequency) and spectral variables. Here, we assess the functional relevance of two spectral variables, $F_{\text {peak }}$ and $Q$, to aspects of bat foraging niche and to the frequency tuning characteristics peculiar to bat auditory neurones (Covey 2005).

To explain why the $Q$ of the strongest harmonic might discriminate species that have different foraging strategies but use calls of similar $F_{\text {peakc }}$ (Figure 4), we need to consider the functional implications of $Q$ and $F_{\text {peak }}$ in frequency modulated (FM) calls of low duty-cycle. High frequency echolocation can provide detailed imagery but at the expense of range, so most species detect prey at a distance by concentrating the energy in their brief search-mode calls at the lower end of the frequency sweep (Simmons and Stein 1980; Kingston et al. 1999). The 'shallow sweep', low frequency calls emitted in search mode by molossids and emballonurids foraging in open airspaces are typical examples.

Detection-range can be maximised by further concentrating the call-energy into an extremely narrow bandwidth (a high sharpness quotient, $Q$ ). Noting that 'call-energy' in our data relate more to the accumulation of cycles than to cycle amplitude, Figure 4 confirms that many Kimberley bats use 'high- $Q$ ' search-mode calls, as do their counterparts in faunas further south in Western Australia (e.g. McKenzie and Bullen 2009). However, high- $Q$ calls provide less information on shape, orientation and flight-path than an equivalent call with more complexity in the peak of the strongest harmonic (Moss and Zagaeski 1994; Jensen et al. 2001). Given that the FM-bats that emit high- $Q$ calls are the air superiority strategists (able to perform agile manoeuvres, Figure $7 d$ ), they can delay characterising and tracking a target until it is close enough for the available power to be (1) emitted at a higher frequency to improve resolution, and (2) dispersed across a wider range of frequencies to provide details on target shape, orientation and flight-path. As a result, the search mode calls used by air superiority strategists, such as the emballonurids and Vespertilioninae (sub-family), decrease in $Q$ as $F_{\text {peak }}$ increases (Figure 4). The only exception is $V$. caurinus. Relevant statistics are summarised in Table 10. If these changes in call structure were merely attenuation or emission (side-lobe) artefacts, reflecting differences in the bat's position and orientation relative to the microphone (e.g. Fenton 1995), each of these species would show proportions of both high- and low- $Q$ calls across their $F_{\text {peak }}$ range. Plasticity in species call frequency and bandwidth in response to various levels of clutter is well documented (e.g. Wund 2006; Mora et al. 2011).

In contrast, the molossids are aerial interceptors, relying on speed (7 to $\left.8 \mathrm{~m} \mathrm{sec}^{-1}\right)$ rather than agility to catch prey (Table 7), so they need to characterise and track airborne prey from the moment of detection (e.g. Fenton et al. 1995; Holderied and von Helversen 2003; Surlykke and Kalko 2008). To do this, the $F_{\text {peakc }}$ of the strongest harmonic in molossid search-mode calls needs to be complex as well as intense, which explains the more moderate $Q$-values and more modest variation with $F_{\text {peakc }}$ observed for the large molossids in Figure $4 \stackrel{4 \text { peak } C}{(C}$. jobensis and $M$. beccarii). The differences between molossids and emballonurids were not induced by the proximity of obstructions because these bats were all flying in open microhabitats at the time their call sequences were recorded (Table 6). A comparison of molossid and emballonurid audiograms and pinna features confirm that molossids are adapted to characterise and track airborne prey from a greater distance than are 
TABLE $10 \quad$ Kendall's Tau Correlations between species' $F_{\text {peakc }}$ and $Q$ values for normal, in-flight calls by Kimberley bats (from Figure 4). Leaf-nosed bats are listed at the bottom of the table.

\begin{tabular}{llllll} 
Species & Family & $\begin{array}{l}\text { Usual Foraging } \\
\text { Strategy }\end{array}$ & SD $Q^{\mathrm{c}}$ & Tau & P-level \\
\hline$C j$ & $\mathrm{M}$ & $\mathrm{I}$ & 1.4 & -0.28 & 0.000 \\
$M b$ & $\mathrm{M}$ & $\mathrm{I}$ & 2.1 & -0.46 & 0.000 \\
$M l$ & $\mathrm{M}$ & $\mathrm{A}_{\mathrm{O}}$ & 3.6 & -0.15 & 0.002 \\
$S f$ & $\mathrm{E}$ & $\mathrm{A}_{\mathrm{O}}$ & 2.4 & -0.43 & 0.000 \\
$T g$ & $\mathrm{E}$ & $\mathrm{A}_{\mathrm{O}}$ & 2.9 & -0.13 & 0.020 \\
$M s$ & $\mathrm{Mi}$ & $\mathrm{A}_{\mathrm{H}}$ & 2.7 & -0.54 & 0.000 \\
$S g$ & $\mathrm{~V}$ & $\mathrm{~A}_{\mathrm{H}}$ & 2.5 & -0.57 & 0.000 \\
$S s$ & $\mathrm{~V}$ & $\mathrm{~A}_{\mathrm{H}}$ & 2.7 & -0.42 & 0.000 \\
$P w$ & $\mathrm{~V}$ & $\mathrm{~A}_{\mathrm{H}}$ & 3.8 & -0.35 & 0.000 \\
$C n$ & $\mathrm{~V}$ & $\mathrm{~A}_{\mathrm{H}}$ & 2.9 & -0.30 & 0.000 \\
$C g$ & $\mathrm{~V}$ & $\mathrm{~A}_{\mathrm{H}}$ & 1.9 & -0.29 & 0.000 \\
$V d$ & $\mathrm{~V}$ & $\mathrm{~A}_{\mathrm{H}}$ & 2.9 & -0.19 & 0.011 \\
$V c$ & $\mathrm{~V}$ & $\mathrm{~A}_{\mathrm{H}}$ & 3.7 & 0.28 & 0.003 \\
$M a$ & $\mathrm{~V}$ & $\mathrm{~A}_{-} \mathrm{S}_{3 \mathrm{D}}$ & 0.7 & -0.06 & 0.436 \\
$N w$ & $\mathrm{~N}$ & $\mathrm{~S}_{3 \mathrm{D}}-\mathrm{A}$ & 1.6 & -0.14 & 0.045 \\
$N g$ & $\mathrm{~N}$ & $\mathrm{~S}_{3 \mathrm{D}}$ & 0.8 & 0.16 & 0.104 \\
$N a$ & $\mathrm{~N}$ & $\mathrm{~S}_{3 \mathrm{D}}$ & 0.8 & -0.08 & 0.179 \\
$N d$ & $\mathrm{~N}$ & $\mathrm{~S}_{3 \mathrm{D}}$ & 0.9 & 0.15 & 0.203 \\
$M g$ & $\mathrm{Se}$ & $\mathrm{S}_{2 \mathrm{D}}$ & 1.5 & -0.02 & 0.875 \\
\hline$R a$ & $\mathrm{H}$ & $\mathrm{A}_{\mathrm{H}}$ & 6.6 & 0.01 & 0.853 \\
$H s$ & $\mathrm{H}$ & $\mathrm{S}_{2 \mathrm{D}}$ & 13.1 & -0.05 & 0.405 \\
$H a$ & $\mathrm{H}$ & $\mathrm{S}_{2 \mathrm{D}}$ & 11.4 & 0.04 & 0.709 \\
\hline
\end{tabular}

${ }^{\text {a }}$ codes from Table 1

${ }^{\mathrm{b}}$ from Table 7

${ }^{c} \mathrm{SD}=$ standard deviation

emballonurids (Obrist et al. 1993).

The observed agility (Table 7) and wide range of $Q$ values measured from search-mode calls by the tiny molossid, $M$. loriae (Figure $4 \mathrm{~b}$ ), are consistent with the dual-mode airframe of WA Mormopterus spp (Bullen and McKenzie 2002b; McKenzie and Bullen 2009). Mormopterus loriae can deploy its airframe for either 'air-superiority' foraging, as discussed above, or for high-speed 'interception' during which high- $Q$ calls are appropriate. This dual operating mode is consistent with the distinct $F-Q$ alignments overt in M. loriae (Figure $4 b$ ), and may also explain why it was the least specific Kimberley bat in its use of foraging microhabitats (Table 6).

The 'surface' strategists (M. gigas and Nyctophilus spp), all of which hunt at relatively low speeds in cluttered airspaces (slow hawking, ambushing) and onto surfaces (gleaning), use calls that have a complex profile in which the energy is dispersed across a wide range of frequencies (low- $Q$ ), rather than tightly focussed in a narrow band. Their 45-70
$\mathrm{kHz}$ calls provide the detailed imagery needed to navigate clutter and distinguish prey against clutter; spreading the call energy across a range of frequencies enables these so-called 'whispering bats' to avoid over-saturating the imagery with reflections from close objects (e.g. Kingston et al. 1999), prior to any range-related auditory gain adjustments (e.g. Kick and Simmons 1984). In combination, the appropriate airframe parameter (TEAR $=9.3 \mathrm{cp} .4$ to 5 for the other 'surface' species) and our empirical observations on foraging behaviour indicate that $N$. walkeri is the most agile of the 'surface' species in the Kimberley (Table 7), consistent with its higher average $Q$ values $(3.7 \mathrm{cp}$. 2.6 to 3.5 for the other FM-'surface' species; Table 5).

Irrespective of their foraging strategy, the FM species that hunt in or against clutter using high frequency calls ( $>45 \mathrm{kHz}-M$. macropus, V. caurinus, M. gigas, Nyctophilus spp) did not show the inverse call-to-call relationship between $Q$ and $F_{\text {peak }}$ that was seen in bats of less cluttered air spaces (Figure 4, Table 10). While high frequency provides the 
detailed imagery needed to search cluttered situations, there is an increasingly severe range penalty imposed by atmospheric attenuation, which would become a critical issue for these species (and especially for the air superiority strategist, $V$. caurinus) because they use moderate flight speeds of around $5 \mathrm{~m} \mathrm{~s}^{-1}$ in these cluttered air spaces (e.g. Holderied and von Helversen 2003). Thus, the lack of a strong relationship between $F_{\text {peakc }}$ and $Q$ in these species is functionally appropriate.

Clearly, the 'spectral' plots (Figure 4) can be treated as representations of resource allocation for FM bats. Their search mode calls showed clear, functionally appropriate relationships with foraging niche that, in turn, reflected the relevant airframe performance and control variables (Bullen and McKenzie 2001, 2007, 2009). Species call frequencies were appropriate to their foraging microhabitat (see also Simmons 1989; Kingston et al. 1999; McKenzie and Bullen 2003; Wund 2006; Surlykke and Kalko 2008), and their $Q$ and $F_{\text {peakc }}$ combinations to their foraging strategy (Figures 4 and 7). For instance, the high Q-value of $C$. nigrogriseus calls compared to $S$. greyii (Figure 4a) is consistent with its airframe's greater ability to generate and sustain lateral forces (TEAR $=25.3$ v. 14.4, Table 8) and its higher aerobic capacity (heart muscle-mass ratio $=0.63$ v. 0.54 , Table 7$)$, thus its higher agility ( 8 v. 6, Table 7). In terms of the available foraging niche space, the absence of $M$. loriae from all but the southwestern periphery of the Northern Kimberley's mangroves, and of C. gouldii from the bioregion's near-coastal environments suggests that habitat filtering of species with particular phenotypes (sensu Pausas and Verdu 2010) is also structuring these communities. At an even broader scale, the influence of habitat filtering was also apparent in Dampierland (Tables 4 and 11) where V. douglasorum replaces its allopatric counterpart $V$. finlaysoni, and T. australis, a migratory molossid, achieves the northern limit of its seasonal climatic envelope (Kitchener et al. 1987; Bullen and McKenzie 2005, respectively).

The spectral differences overt in Figure 4 are consistent with the evolutionary divergence of families towards different foraging strategies air superiority in the case of the emballonurids and vespertilionids, air interception in the case of the molossids, and 'surface' strategies in the case of the megadermatid and nyctophilinids (Table 10). However, the phylogenetic signal is not deterministic: while species are dispersed throughout the spectral space with partial or no overlaps in communities, members of the same family are often as spectrally different from one another as they are from unrelated species in the same community. The imprint of phylogenetic niche conservatism, in which most species are at least as ecologically similar as would be expected from their phylogenetic relationships (Losos 2008), is overt in Figure 4, with congeners always neighbours (e.g. N. arnhemensis, N. daedalus and $N$. walkeri; $V$. caurinus and $V$. douglasorum) even though ecologically similar species do not always belong to the same family (e.g. M. schreibersii and P. westralis; M. loriae and C. gouldii).

Although the airframe-niche relationships of leaf-nosed bats are consistent with those of the FM bats (Figures 7a and 7d; Bullen and McKenzie 2007, 2009), their call parameters are not (see also Kingston et al. 2000). For instance, their characteristically high- $Q$ calls (Figure 4c) do not necessarily indicate a highly agile foraging strategy. Leaf-nosed bats emit constant frequency calls and rely on Doppler-shifts impressed on echoes by the target insect's wing-beats, rather than the pulseecho sonar of 'FM' bats, so the implications of call parameters for aspects of foraging strategy such as flight speed (Holderied and von Helversen 2003), acoustic gaze (Ghose and Moss 2006) and image resolution against clutter (e.g. Lazure and Fenton 2011) are likely to be very different.

Experimental data suggest that the auditory image from each call is built through the neural convergence of auditory spectral as well as auditory temporal processing (Simmons 1989; Moss and Surlykke 2001; Triblehorn and Yager 2005). In this context, Krumbholz and Schmidt (1999), (corroborated by Genzel and Wiegrebe 2008, p. 13), concluded that "...in most cases [FM-]bats recruit a spectral profile rather than a pitch analysis (time domain) for echo imaging." A recent review of neuroanatomical specialisations in bat cochlear and lower brainstem auditory pathways identified characteristic patterns of organisation for different families of bats, the structure of their echolocation calls, and the specific ecological niches they occupy (Covey 2005). The causal relevance of $Q$ as an ecological variable relates to the auditory neurone frequency tuning characteristics peculiar to bats (Covey 2005), particularly the high proportion of units across all divisions of the cochlear nucleus that are sharply tuned to the fundamental frequencies of the call (Marsh et al. 2006).

\section{SPECTRAL CHARACTERS AS A SURVEY TOOL}

We could identify 20 of the 21 species (96\%) known from the Northern Kimberley from their search-mode echolocation call sequences, a useful survey technique that compares favourably with other call identification methods, even those using neural network analyses. Examples include studies by Adams et al. (2010) that identified up to $75 \%$ of a fauna comprising 18 species, Preatoni et al. (2005) up to $74 \%$ of 20 species, and 
TABLE 11 Structural diversity of echolocating bat faunas in coastal bioregions of tropical Western Australia, listing species belonging to each foraging strategy, a measure of overall productivity (annual average rainfall), occurrence of productive landscape mosaics, and availability of physiological refuges (updated from McKenzie and Bullen 2009). Species codes from Table 1.

\begin{tabular}{|c|c|c|c|c|c|}
\hline Usual Foraging Strategy & $\begin{array}{c}\text { Northern } \\
\text { Kimberley }\end{array}$ & $\begin{array}{c}\text { Victoria- } \\
\text { Bonaparte }\end{array}$ & Dampierland & Pilbara & Carnarvon \\
\hline Interceptor (I) & $C j M b$ & $C j M b$ & $\begin{array}{l}\mathrm{Cj} M b \\
{ }^{\mathrm{a}} \mathrm{Ta}\end{array}$ & $\begin{array}{c}\mathrm{CjMb} \\
\mathrm{Ta}\end{array}$ & $\begin{array}{c}\mathrm{CjMb} \\
\mathrm{Ta}\end{array}$ \\
\hline Air superiority open $\left(\mathrm{A}_{\mathrm{O}}\right)$ & $\operatorname{Tg} S f$ & $\operatorname{Tg} S f$ & $\begin{array}{l}\mathrm{Tg} S f \\
M l\end{array}$ & $\begin{array}{c}\mathrm{Tg} / \mathrm{Th} S f \\
M l\end{array}$ & $\begin{array}{c}\text { Th Sf } \\
\text { Ml }\end{array}$ \\
\hline Surface $3 \mathrm{D}\left(\mathrm{S}_{3 \mathrm{D}}\right)$ & $\mathrm{Nd} \mathrm{Na}$ & $\begin{array}{l}\mathrm{Nd} \mathrm{Na} \\
{ }^{\mathrm{b}} \mathrm{Ng}\end{array}$ & $\begin{array}{l}\mathrm{Nd} \mathrm{Na} \\
{ }^{\mathrm{b}} \mathrm{Ng}\end{array}$ & $\begin{array}{l}\mathrm{Nd} \mathrm{Na} \\
{ }^{\mathrm{b}} \mathrm{Ng}\end{array}$ & $\begin{array}{l}\mathrm{Na} \\
{ }^{\mathrm{b}} \mathrm{Ng}\end{array}$ \\
\hline $\mathrm{S}_{3 \mathrm{D}}-\mathrm{A}$ & $M a N w$ & $M a N w$ & & & \\
\hline $\begin{array}{l}\text { Air superiority highly } \\
\text { agile }\left(A_{H}\right)\end{array}$ & $\begin{array}{c}C g S g \\
V c R a \\
C n M s \\
\text { Ss } P w \\
\quad V d\end{array}$ & $\begin{array}{c}C g S g \\
V c R a \\
C n M s \\
S s P w \\
V d\end{array}$ & $\begin{array}{l}\mathrm{Cg} S g \\
V c R a \\
C n M s \\
S s P w \\
V d /{ }^{a} V f\end{array}$ & $\begin{array}{c}\mathrm{Cg} \mathrm{Sg} \\
\mathrm{Ra} \\
{ }^{\mathrm{c}} \mathrm{Cm} \\
\mathrm{Vf}\end{array}$ & $\underset{V f}{C g S g}$ \\
\hline Surface $2 \mathrm{D}\left(\mathrm{S}_{2 \mathrm{D}}\right)$ & $\begin{array}{c}\mathrm{Mg} \\
\mathrm{HaHs}\end{array}$ & $\begin{array}{c}\mathrm{Mg} \\
\mathrm{Ha} \mathrm{Hs}\end{array}$ & $\begin{array}{l}\mathrm{Mg} \\
\mathrm{Ha}\end{array}$ & $M g$ & \\
\hline Total & 20 & 21 & 19 & 16 & 11 \\
\hline
\end{tabular}

\begin{tabular}{llllll} 
Productivity $^{d}$ & \multicolumn{1}{l}{} \\
\hline Rainfall $(\mathrm{mm})$ & 970 & 870 & 550 & 310 & 240 \\
Mangroves & $\mathrm{Y}$ & $\mathrm{Y}$ & $\mathrm{Y}$ & $\mathrm{Y}$ & $\mathrm{Y}$ \\
Cavernous ranges & $\mathrm{Y}$ & $\mathrm{Y}$ & $\mathrm{Y}$ & $\mathrm{Y}$ & $\mathrm{S}$ \\
Riparian systems & $\mathrm{Y}$ & $\mathrm{Y}$ & $\mathrm{Y}$ & $\mathrm{Y}$ & $\mathrm{S}$ \\
\hline
\end{tabular}

a See point (2) under the heading 'Kimberley bat communities' in Methods.

${ }^{b}$ Includes N. g. geoffroyi Thomas, 1913 and N. g. pallescens Thomas, 1913.

${ }^{\mathrm{c}} \mathrm{Cm}=$ Chalinolobus morio (Gray, 1841).

${ }^{\text {d }} \mathrm{Y}=$ widespread; $\mathrm{S}=$ sparse; 'Riparian systems' $=$ complex riparian woodlands with permanent pools.

Parsons and Jones (2000) who identified up to $87 \%$, albeit in a relatively small temperate fauna comprising 14 species. The only constraints we encountered were: (1) the need to pre-select the calls used for identification on criteria related to recording quality, although note that the program Song Scope (http://www.wildlifeacoustics.com/ products/analysis-software) uses FFT analysis (as in this paper) in conjunction with voice-recognition technology to locate 'reference call signatures' in full wave recordings of bird and bat calls, and (2) the broad overlap in spectral characters observed between $N$. arnhemensis and $N$. daedalus in the landward community (Figure 4). The reason for this sympatry between two such spectrally similar congeners in the Kimberley (but not in the Pilbara) is unknown, unless Kimberley N. arnhemensis has expanded its realised foraging niche to encompass the acoustic niche of $N$. geoffroyi, the latter being absent from the Northern Kimberley (Figure 6). Nevertheless, $N$. daedalus has never been captured in the Kimberley mangroves despite comprehensive 
sampling (spanning more than two decades and searching greater than 30 mangrove stands representing all sections of the Kimberley coast) during which several hundred $N$. arnhemensis were mist netted (e.g. McKenzie and Rolfe 1986; WAM collections; authors' unpublished data).

As with the microhabitat and flight speed data presented herein (Tables 6 and 7), species call frequency and $Q$ values (Table 5) were consistent with their populations elsewhere in WA (McKenzie and Bullen 2009). The average call frequencies were even comparable to 'characteristic frequency' data from the Northern Territory (Milne 2002) for all but 6 of the 20 species shared by these two regions: $H$. stenotis $(+7.7 \mathrm{kHz}$ in Northern Territory), $M$. beccarii (-3.3), $N$. arnhemensis (-4.9), N. daedalus (-4.5), N. walkeri (-6.3) and P. westralis (-2.4). Although comparisons between 'peak' and 'characteristic' measures are problematic, the discrepancy apparent in our $H$. stenotis data prompted a more detailed appraisal (Figure 9) that revealed c. $10 \mathrm{kHz}$ variation both between and within islands. While the Kimberley mainland values were consistent with those reported from the Northern Territory, there was geographically systematic variation between populations on the Kimberley islands, north to south (Kendall Tau $=-0.46, P<0.0001$, see Figure 9). The southern islands have lower average humidity than do those further north, so our data conform to the inverse relationship between colony mean frequency and environmental humidity reported by Guillen et al. (1999) for Hipposideros ruber in the Gulf of Guinea (but see Armstrong and Kerry 2011). However, a variety of other factors may be involved such as flight-direction doppler shift effects, morphological variation (e.g. Yoshino et al. 2006) and insular divergence (Russo et al. 2007).

Recordings of S. flaviventris and T. georgianus sometimes included harmonic calls much higher than the 'reference' frequency normally used by these species in search mode (strongest harmonic at c. 18 and $25 \mathrm{kHz}$, respectively), as has been noted for emballonurids from elsewhere (e.g. Obrist et al. 1993; McKenzie and Bullen 2009). Most of these were calls interspersed among the normal calls in sequences. In most cases, no other species of echolocating bat were present.

\section{SAMPLING EFFORT}

The assemblage analysis herein is based on 2.5 $\mathrm{h}$ recording sessions that commenced at dusk, the period of peak activity for most microbat species (Law et al. 1998; Kuenzi and Morrison 2003; Milne et al. 2005a). Although a minimum of two nights of recording was carried out per island, only two or three sites were sampled on most islands, and only $15(54 \%)$ of the 28 islands used in the analysis were sampled in both the wet and dry seasons. Richards
(2001) recommended $3 \mathrm{~h}$ of recording from dusk to detect $90 \%$ of species present at a site, whereas Duffy et al. (2000) recommended $5 \mathrm{~h}$, and Fisher et al. (2009) recommended multiple detectors and nights per site as well as several sites per survey area (= island in the context of our study). Although it was spatially autocorrelated, the emergence of sampling effort as a potential influence on composition of the island faunas supports the effort thresholds recommended by Fisher et al. (2009); for large, diverse, inshore islands such as Bigge, richer species lists would be expected with additional recording sessions at more sites, and if all sites had been sampled in at least two seasons.

\section{LOCAL ENVIRONMENTAL INFLUENCES ON COMPOSITION}

A number of other studies have concluded that distance to coastline, to ranges with caves/crevices, and/or to a riparian zone are important factors explaining local patterns in the composition of microbat assemblages (Crome and Richards 1988; Williams and Dickman 2004; Milne et al. 2005b, McKenzie and Bullen 2009).

The coastal factor differentiated the distinctive bat community found in Kimberley mangroves, and interaction between the cavernous country and the riparian development explained compositional differences between landward localities (Figure 2). Clearly, the environmental factors that had explanatory power for compositional patterns in the Pilbara bat fauna (McKenzie and Bullen 2009) could also explain patterns exposed by the Kimberley mainland analysis. Especially for the landward species, caves or crevices provide obligate day-roosts for a range of species, including nine that occur in the Kimberley (e.g. Armstrong 2001; Van Dyck and Strahan 2008 - see Appendix 7a). Deep cave-roosts offer opportunity to species whose energy budget is dominated by the cost of their metabolic rate during foraging flight (e.g. $R$. aurantia, T. georgianus and $H$. ater, Table 7); their characteristically small heart mass fractions (low aerobic capacity) imply a remaining energy budget that is delicately balanced in the more variable conditions of roosting environments outside caves (Bullen and McKenzie 2009).

Well-developed riparian zones provide the most complex and productive vegetation structures found in the landward environments of semi-arid and sub-humid regions such as the Kimberley. Since bats partition airspace according to clutterlevels (e.g. McKenzie and Rolfe 1986; Schnitzler and Kalko 1998; Bullen and McKenzie 2001), it is not surprising that high microbat species diversity has been associated with freshwater bodies such as perennial rivers elsewhere, and that some species are confined to these habitats (e.g. Cross 1988; 
Law et al. 1998; Young and Ford 2000; Seidman and Zabel 2001). Myotis macropus, M. beccarii, $V$. douglasorum, $N$. daedalus, $N$. arnhemensis and $N$. walkeri are the species in the Kimberley's landward community that show this particular habitat association (e.g. Churchill 2008; Van Dyck and Strahan 2008).

Despite their disparate foraging strategies, several of these species have specialised (1) aerodynamic cleanliness characteristics (ear-canard designs and other airflow control features, e.g. M. beccarii and $M$. macropus; see Bullen and McKenzie 2007), (2) heart muscle-mass ratios (N. arnhemensis and possibly $S$. flaviventris given its high energy foraging strategy - see also Bullen and McKenzie 2009), and/or (3) flight muscle-mass ratios (e.g. $V$. douglasorum - see Bullen and McKenzie 2004), that require productive foraging habitats. For instance, $V$. douglasorum, as well as the mangrove specialists $M$. loriae and $P$. westralis, are confined to very productive environments because they have relatively small flight muscle fractions for their agility (Table 7). On the other hand, $N$. daedalus incurs high energy costs in hovering and manoeuvring at low speeds while gleaning in clutter because of its airframe's relatively high wing loading $\left(5.6 \mathrm{v} .4 .8 \mathrm{~N} \mathrm{~m}^{-2}\right.$ for its less habitat-confined counterpart N. geoffroyi). Riparian areas provide greater abundances of insects than lightly wooded habitats, which has been correlated with higher bat feeding rates (Thomas 1988). Young and Ford (2000) reported that in semi-arid western Queensland, bat species richness and abundance was greatest in riparian woodland and open forest adjacent to water (97\% of harp trap captures) and explained this result in terms of increasing insect diversity and abundance measured in the structurally diverse vegetation of the riparian areas. Furthermore, bat activity along intermittent streams in California was related to their size, being least along small ephemeral examples, especially when the channels were dry (Seidman and Zabel 2001). Well-developed riparian areas also provide roost sites and areas for drinking (Cross 1986, 1988; Tidemann and Flavel 1987). The basis of the high productivity associated with mangrove ecosystems has been reviewed by Holguin et al. (2001).

The diversity productivity hypothesis predicts positive relationships between productivity and community diversity (richness, evenness and the degree of difference between species), particularly in the context of strong interspecific competition (e.g. Rosenzweig and Abramski 1993; Srivastrava and Lawton 1998; Nijs and Roy 2000). In terms of their structural complexity, the regional bat faunas of Western Australia's tropical north conform to this hypothesis, with the most arid bioregions having species-poor faunas dominated by fast-flying species of open airspaces, rather than surface and air superiority strategists that hunt in more cluttered microhabitats (Table 11, also see McKenzie et al. 2002; McKenzie and Bullen 2009). Our Kimberley study confirms that the additional species found in the more mesic of these bioregions are confined to productive landscape mosaics such as riparian zones (e.g. M. macropus, $N$. walkeri, V. douglasorum) and mangroves (M. loriae, $P$. westralis and S. sanborni), or depend on physiologically benign day-roosts in caves and rock-crevices (e.g. $H$. ater, M. schreibersii and T. georgianus).

This productivity relationship might explain why our island analysis exposed 'isothermality' as an additional factor likely to influence species composition. Isothermality has a strong positive correlation with annual rainfall (Tau $=0.60, P<$ 0.001 ), a rough surrogate for productivity in these landscapes.

\section{DETERMINANTS OF COMMUNITY STRUCTURE}

Given the ecological relevance of the spectral variables, the discrete spacing of species across the spectral plots implies that Kimberley bat communities are organised deterministically, according to specialisations related to resource partitioning. This interpretation is consistent with the results of numerous meta-analyses of community structure carried out by Gotelli and McCabe (2002), that assessed a variety of plant, invertebrate and vertebrate assemblages, including bats (but not bat communities that are phytophagic [Meyer and Kalko 2008] or include facultative omnivores [Humphrey et al. 1983]). Niche-assembly models of metacommunity organisation have been reported previously for guilds and faunas of echolocating (zoophagic) bats (McKenzie and Rolfe 1986; Kingston et al. 2000; McKenzie and Bullen 2009), although the first two of these studies relied on measures of flight performance, rather than echolocation, as surrogates of realised foraging niche. The auditory and airframe structures used as predictors of foraging niche in this paper reflect processes operating over evolutionary time-periods and at broad geographical scales. In these terms, as we pointed out earlier, consistent auditory and airframe relationships are apparent even at familylevel. Of course, at smaller temporal and geographic scales, i.e. in individual landscape mosaics, species immigration and emigration generate fluctuating patterns in assemblage composition (e.g. Leibold et al. 2004; Fischer and Lindenmayer 2005; Jenkins 2006; Fischer et al. 2009). We conclude that Kimberley bat communities illustrate the role of historical (Late Pleistocene) biogeographic events, competitive niche differentiation, phylogenetic structure and, perhaps, environmental filtering in driving species distributions in a large-scale 
zoophagic bat metacommunity (Leibold et al. 2010).

On their own, however, metacommunity processes are insufficient to explain the structure of bat assemblages on the Northern Kimberley islands because nestedness in assemblage species composition that related to environmental factors was exposed by the habitat analysis, implying the influence of local environmental controls (see Mouquet and Loreau 2002; Urban 2004; Armstrong 2005). Several species were absent from islands without (or remote from) well-developed riparian habitats (e.g. M. gigas, S. greyii, M. macropus and $V$. douglasorum) while others were absent from islands lacking cavernous habitats (e.g. T. georgianus and $M$. schreibersii) or mangroves (S. sanborni and $P$. westralis). Meyer and Kalko (2008) reported a similar association between nestedness and environmental factors, including isolation, for bat assemblages on land-bridge islands in Panama.

Nestedness in species composition was not restricted to the Kimberley's landward and mangrove communities; it was also overt among faunas of the adjacent regions when they were arrayed using rainfall as an approximate measure of regional productivity (Table 11). Where the nestedness was disrupted, the species turnover involved a congeneric replacement (e.g. C. nigrogriseus by $C$. morio in the Pilbara region). As we noted earlier, equivalent replacements involving closely related allopatric species discriminated the two Kimberley communities: landward species such as $V$. douglasorum and $S$. greyii, are replaced in the mangroves by their ecological counterparts $P$. westralis and S. sanborni, respectively. Given the tight relationship between foraging ecology and phylogeny in Western Australian communities of zoophagic bats (e.g. McKenzie and Bullen 2009), we suggest that metacommunity as well as habitat interactions are important determinants of organisation in Western Australian bat assemblages at local and regional scales.

\section{ECOLOGICAL APPLICATION}

Our results imply that two spectral variables can be used to characterise free flying bats in terms of their foraging niche without distorting the outcome by disrupting their normal activities. These spectral variables may allow the organisation of other bat communities to be reliably and quickly related to environmental factors, including disturbance heterogeneity (sensu Urban 2004), even in communities of unknown species composition. This opportunity depends on species airframe, foraging niche, auditory neurology and echolocation call spectral characteristics being as tightly integrated as our results and relevant literature indicate, and on species being arrayed sequentially along the same resource axis. In the Kimberley, for instance, all were obligate insectivores/predators rather than facultative omnivores.

\section{CONSERVATION}

Armstrong (2005) argued that metapopulation and habitat paradigms have to be integrated to understand broad-scale declines in species, and to provide sound management advice. Our results are consistent with this view, revealing that metacommunity and habitat paradigms are both required to explain community composition in Kimberley bats at local and regional scales, and we can identify several factors relevant to planning for their conservation. As previously found by Frick et al. (2008) for zoophagic bats occupying islands in the Gulf of California, many Kimberley species rely on particular habitats for foraging and/or roosting, although small islands are species-poor unless close to the coastline suggesting that incidence on the islands is affected by area as well as isolation. This incidence pattern could be recognised despite the variable sampling effort because some relatively small off-shore end-of-chain islands that included cavernous, mangrove and riparian habitats (e.g. Irvine) were species-poor despite being intensively sampled even compared to large inshore islands such as Augustus, Boongaree and Koolan (Appendix 7b). Any resource development liable to affect the islands should be accompanied by non-intrusive monitoring of microbats; loss of complexity in riparian vegetation, reduced permanence of pools, loss of mangrove stands and loss of suitable cave roosts, are all likely to reduce occupancy by various species. These are examples of the other factors listed by Armstrong (2005) and others (references cited above) as more local and ephemeral controls on assemblage composition, including movements due to fluctuations in conditions locally such as seasonal effects and, as pointed out by Urban (2004), disturbance heterogeneity. The call library provided in this paper will allow monitoring to be implemented inexpensively.

In regulating nocturnal insect numbers, bat communities provide an important ecosystem service (e.g. Whittaker 1993), an integral part of the intricate network of processes that maintain biological diversity on these islands. For microbats belonging to the landward community, we need to ensure that islands with well-developed riparian sites in cavernous country are included in the managed system of conservation lands (e.g. Augustus, Boongaree, Adolphus, Coronation and South-West Osborn). For the mangrove bat community, at least two islands with well developed mangrove stands should be included in these conservation lands (e.g. Lachlan and Coronation). 
Kimberley bats have not yet suffered the extinctions experienced by the region's other (nonvolant) indigenous mammals (McKenzie et al. 2006; Burbidge et al. 2008). We found no evidence that microbat species have been extirpated from parts of the Kimberley; even the species with highenergy strategies that rely on specialised habitats persist in all bioregions where appropriate habitats are present (e.g. S. sanborni and V. douglasorum). Nevertheless, a smart reserve system is required to preserve these intact, interesting microbat communities.

\section{ACKNOWLEDGEMENTS}

We thank Wes Caton, M.A. Cowan, Tricia Handasyde, P.G. Kendrick, L.A. Gibson, M.H. McKenzie, R.A. Palmer, D.J. Pearson, Rod O'Donnell, J.K. Rolfe, T.A. Smith, A.N. Start and R.J. Teale for assisting with field sampling, D.B. McKenzie for the loan of the video camera, Pluton Resources for access to data collected by Biota Environmental Sciences Pty Ltd from Gibbings, Irvine and Bathurst islands, L.A. Gibson and M.R. Williams for advice on the mantel tests, and two anonymous referees for helpful comments on the manuscript. The project involved a research agreement with the Kimberley Land Council for the Balanggarra, Bardi-Jawi, Dambimangari, Mayala and Uunguu native title claim groups. M.A. Cowan and J.K. Rolfe helped with Figures 1 and 2, respectively, and N. Jolakoski prepared Figure 11. Funding for the fieldwork was provided by the WA Department of Environment and Conservation and Natural Heritage Trust.

\section{REFERENCES}

Adams, M.D., Law, B.S. and Gibson, M.S. (2010). Reliable automation of bat call identification for eastern New South Wales, Australia, using classification trees and AnaScheme software. Acta Chiropterologia 12: 231-245.

Armstrong, D.P. (2005). Integrating the metapopulation and habitat paradigms for understanding broad-scale declines of species. Conservation Biology 19: 1402-1410.

Armstrong, K.N. (2001). The distribution and roost habitat of the orange leaf-nosed bat, Rhinonicteris aurantius, in the Pilbara region of Western Australia. Wildlife Research 28: 95-104.

Armstrong, K.N. (2011). The current status of bats in Western Australia (pp 257-269). In: Law, B., Eby, P., Lunney, D. and Lumsden, L. (eds), The biology and conservation of Australasian bats. Royal Zoological Society of New South Wales: Mosman, Australia.

Armstrong, K.N. and Kerry, L.J. (2011). Modelling the prey detection performance of Rhinonicteris aurantia (Chiroptera: Hipposideridae) in different atmospheric conditions discounts the notional role of relative humidity in adaptive evolution. Journal of Theoretical Biology 278: 44-54.

Atmar, W. and Patterson, B.D. (1993). The measure of order and disorder in the distribution of species in fragmented habitat. Oecologia 96: 373-382.

Atmar, W. and Patterson, B.D. (1995). The nestedness temperature calculator: a visual basic program, including 294 presence-absence matrices. AICS Research, Inc.: University Park, New Mexico, U.S.A. and the Field Museum: Chicago.

Austin, M.P. (1991). Vegetation theory in relation to costefficient survey (pp 17-22). In: Margules, C.R. and Austin, M.P. (eds), Nature conservation: cost effective biological surveys and data analysis. CSIRO Division of Wildlife and Ecology: Canberra.

Austin, M.P. and McKenzie, N.J. (1988). Data analysis (pp 210-232). In: Gunn, R.H., Beattie, J.A., Reid, R.E. and van der Graaff, R.H.M. (eds), Australian soil and land survey handbook: guidelines for conducting surveys. Inkata Press: Melbourne and Sydney.

Barlow, B.A. and Hyland, P.P.M. (1988). The origins of the flora of Australia's wet tropics (pp 1-17). In: Kitching, R. (ed.), Ecology of Australia's wet tropics. Proceedings of the Ecological Society of Australia 15. Surrey Beatty and Sons: New South Wales.

Belbin, L. (1980). TWOSTEP: a program incorporating asymmetric comparisons that uses two steps to produce a dissimilarity matrix. CSIRO Division of Land Use Research Technical Memorandum 80/9. CSIRO: Canberra.

Belbin, L. (1995). PATN Technical Reference. CSIRO Division of Wildlife and Ecology, Canberra.

Buchler, E.R. (1976). A chemiluminescent tag for tracking bats and other small nocturnal animals. Journal of Mammalogy 57: 173-176.

Bullen, R.D. and McKenzie, N.L. (2001). Bat airframe design - flight performance, stability and control in relation to foraging ecology. Australian Journal of Zoology 49: 235-261.

Bullen, R.D. and McKenzie, N.L. (2002a). Differentiating Western Australian Nyctophilus (Chiroptera: Vespertilionidae) echolocation calls. Australian Mammalogy 23: 89-93.

Bullen, R.D. and McKenzie, N.L. (2002b). Scaling bat wing-beat frequency and amplitude. Journal of Experimental Biology 205: 2615-2626.

Bullen, R.D. and McKenzie, N.L. (2004). Bat flight muscle mass: implications for foraging strategy. Australian Journal of Zoology 52: 605-622.

Bullen, R.D. and McKenzie, N.L. (2005). Seasonal range variation of Tadarida australis (Chiroptera: Molossidae) in Western Australia: the impact of enthalpy. Australian Journal of Zoology 53: 145-156.

Bullen, R.D. and McKenzie, N.L. (2007). Bat wing airfoil and planform structures relating to aerodynamic cleanliness. Australian Journal of Zoology 55: 237-247.

Bullen, R.D. and McKenzie, N.L. (2009). Aerodynamic cleanliness in bats. Australian Journal of Zoology 56: 1-16.

Bullen, R.D., McKenzie, N.L., Bullen, K.E. and Williams, M.R. (2009). Bat heart mass: correlation with foraging niche and roost preference. Australian Journal of Zoology 57: 399-408.

Burbidge, A.A., McKenzie, N.L., Brennan, K.E.C., Woinarski, J.C.Z., Dickman, C.R., Baynes, A., Gordon, G., Menkhorst, P.W. and Robinson, A.C. (2008). Conservation status and biogeography of Australia's terrestrial mammals. Australian Journal of Zoology 56: 411-422.

Casseday, J.H. and Covey, E. (1992). Frequency tuning 
properties of neurones in the inferior colliculus of an FM bat. The Journal of Comparative Neurology 319: 34-50.

Chao, A. (1987). Estimating the population size for capture-recapture data with un-equal catchability. Biometrics 43: 783-791.

Churchill, S. (2008). Australian bats. 2nd Edition. Allen and Unwin: New South Wales, Australia.

Churchill, S.K., Milne, D.J. and Kitchener, D.J. (2008). Pygmy Long-eared Bat Nyctophilus walkeri Thomas 1892 (pp 529-530). In: Van Dyck, S. and Strahan, R. (eds), The mammals of Australia. Reed New Holland: Sydney.

Clarke, K.R. (1993). Non-parametric multivariate analyses of changes in community structure. Australian Journal of Ecology 6: 163-174.

Clarke, K.R. and Green, R.H. (1988). Statistical design and analysis for a 'biological effects' study. Marine Ecology Progress Series 46: 213-226.

Colwell, R.K. (2006). EstimateS. Statistical estimation of species richness and shared species from samples Version 8.0. http:/ / viceroy.eeb.uconn.edu/estimates.

Covey, E. (2005). Neurobiological specialisations in echolocating bats. The Anatomical Record Part A 287A: 1103-1116.

Crome, F.H.J. and Richards, G.C. (1988). Bats and gaps: microchiropteran community structure in a Queensland rain forest. Ecology 69: 1960-1969.

Cross, S.P. (1986). Bats (pp 279-519). In: Cooperider, A.Y., Boyd, R.J. and Stuart, H.R. (eds), Inventory and monitoring of wildlife habitat. United States Department of Interior, Bureau of Land Management Service Centre, Colorado, U.S.A.

Cross, S.P. (1988). Riparian systems and small mammals and bats (pp 93-112). In: Raedeke, K.J. (ed.), Streamside management: riparian wildlife and forestry interactions. University of Washington Institute of Forest Resources Contribution 59: 1-277. Washington: U.S.A.

De Deckker, P., Kershaw, A.P. and Williams, M.A.J. (1987). Past environmental analogues (pp 473-488). In: Pearman, G.I. (ed.), Greenhouse: planning for climate change. CSIRO Division of Atmospheric Research: Melbourne.

Dickman, C.R. and Crowther, M.S. (2008). Science and the environment (pp 23-42). In: Calver, M.C., Lymbery, A., McComb, J. and Bamford, M. (eds), Environmental biology. Cambridge University Press: Cambridge, U.K.

Diniz-Filho J.A. F., Bini, L.M. and Hawkins, B.A. (2003). Spatial autocorrelation and red herrings in geographical ecology. Global Ecology and Biogeography 12: 53-64.

Dixon, J.M. and Lumsden, L.F. (2008). Gould's Wattled Bat Chalinolobus gouldii (Gray, 1841) (pp 533-534). In: Van Dyck, S. and Strahan, R. (eds), The mammals of Australia. Reed New Holland: Sydney.

Duffy, A.M., Lumsden, L., Caddle, C.R., Chick, R.R. and Newell, G.R. (2000). The efficacy of Anabat ultrasonic detectors and harp traps for surveying microchiropterans in south-eastern Australia. Acta Chiropterologica 2: 127-144.

Eldridge, M.D., Potter, S. and Cooper, S.J.B. (2011). Biogeographic barriers in north-western Australia: an overview and standardisation of nomenclature. Australian Journal of Zoology 59: 270-272.

Environment Australia (2000). Revision of the interim biogeographic regionalisation of Australia (IBRA) and development of version 5.1. Environment Australia: Canberra.

Fenton, M.B. (1982). Echolocation calls and patterns of hunting and habitat use of bats. Australian Journal of Zoology 30: 417-425.

Fenton, M.B. (1995). Natural history and biosonar signals (pp 37-86). In: Popper, A.N. and Fay, R.R. (eds), Hearing by bats. Springer-Verlag: New York.

Fenton, M.B., Audet, D., Obrist, M.K. and Rydell, J. (1995). Signal strength, timing and self-deafening: the evolution of echolocation in bats. Paleobiology 21: 229-242.

Fischer, J., Stott, J., Law, B.S., Adams, M. and Forrester, R.I. (2009). Designing effective habitat studies: quantifying multiple sources of variability in bat activity. Acta Chiropterologica 11: 127-137.

Fischer, J. and Lindenmayer, D.B. (2005). Perfectly nested or significantly nested - an important difference for conservation management. Oikos 109: 485-495.

Ford, J. (1982). Origin, evolution and speciation of birds specialised to mangroves in Australia. Еmu 82: 12-23.

Frick, W. F., Hayes, J. P. and Heady III, P. A. (2008). Patterns of island occupancy in bats: influences of area and isolation. Global Ecology and Biogeography 17: 622-632.

Friend, G.R., Morris, K.D. and McKenzie, N.L. (1991). The mammal fauna of Kimberley rainforests (pp 45-61). In: McKenzie, N.L., Johnston, R.B. and Kendrick, P.G. (eds), Kimberley rainforests of Australia. Surrey Beatty and Sons: Chipping-Norton, Australia.

Fullard, J., Koehler, K., Surlykke, A. and McKenzie, N.L. (1991). Echolocation ecology and flight morphology of insectivorous bats (Chiroptera) in south-western Australia. Australian Journal of Zoology 39: 427-438.

Gannon, W.L., Sherwin, R.E. and Haymond, S. (2003). On the importance of articulating assumptions when conducting acoustic studies of habitat use by bats. Wildife Society Bulletin 31: 45-61.

Genzel, D. and Wiegrebe, L. (2008). Time variant spectral peak and notch detection in echolocation-call sequences in bats. Journal of Experimental Biology 211: 9-14.

Ghose and Moss (2006). Steering by hearing: a bat's acoustic gaze is linked to its flight motor output by a delayed, adaptive linear law. The Journal of Neuroscience 26: 1704-1710.

Gibson, L.A. and McKenzie, N.L. (2012). Identification of biodiversity assets of selected Kimberley islands: background and implementation. Records of the Western Australian Museum, Supplement 81: 1-14.

Gillison, A.N. (1987). The 'dry' rainforests of Terra Australis. In: The rainforest legacy. Special Australian Heritage Publication No. 7(1): 305-321. Australian Heritage Commission: Canberra.

Gotelli, N.J. and McCabe, D.J. (2002). Species cooccurrence: a meta-analysis of J. M. Diamond's assembly rules model. Ecology 83: 2091-2096.

Grodzinski, U., Spiegel, O., Korine, C. and Holderied, M.W. (2009). Context dependant flight speed: evidence for energetically optimal flight speed in the bat Pipistrellus kuhlii. Journal of Animal Ecology 78: 540-548.

Guillen, A., Juste, B. and Ibanez, C. (1999). Variation in the frequency of the echolocation calls of Hipposideros ruber in the Gulf of Guinea: an exploration of the 
adaptive meaning of the constant frequency value in rhinolophid CF calls. Journal of Evolutionary Biology 13: 70-80.

Heller, K-G. and Helversen, O.V. (1989). Resource partitioning of sonar frequency bands in rhinolophoid bats. Oecologia 80: 178-186.

Hernández, L., Romero, A.G., Laundré, J.W., Lightfoot, D., Aragón, E. and López Portillo, J. (2005). Changes in rodent community structure in the Chihuahuan Desert México: comparisons between two habitats. Journal of Arid Environments 60: 239-257.

Holderied, M.W. and von Helversen, O. (2003). Echolocation range and wingbeat period match in aerial hawking bats. Proceedings of the Royal Society of London, Series B 270: 2293-2299.

Holguin, G., Vazques, P. and Bashen, Y. (2001). The role of sediment microorganisms in the productivity, conservation, and rehabilitation of mangrove ecosystems: an overview. Biology and Fertility of Soils 55: 265-278.

How, R., Schmitt, L., Teale, R. and Cowan, M. (2006). Appraising vertebrate diversity of Bonaparte Islands, Kimberley, Western Australia. Western Australian Naturalist 25: 92-110.

Humphrey, S.R., Bonaccourso, F.J. and Zinn, T.L. (1983). Guild structure of surface-gleaning bats in Panama. Ecology 64: 284-294.

Jenkins, D.G. (2006). In search of quorum effects in metacommunity structure: species co-occurrence analyses. Ecology 87: 1523-1531.

Jensen, M.E., Miller, L..A. and Rydall, J. (2001). Detection of prey on cluttered environments by the northern bat Eptesicus nilssonii. Journal of Experimental Biology 204: 199-208.

Johnstone, R.E. (1990). Mangrove and mangrove birds of Western Australia. Records of the Western Australian Museum Supplement 32: 1-120.

Kalko, E.K.V. and Schnitzler, H.U. (1993). Plasticity in echolocation signals of European pipistrelle bats in search flight: implications for habitat-use and prey detection. Behavioural Ecology and Sociobiology 33: 415-428.

Kalko, E.K.V. and Schnitzler, H.U. (1998). How echolocating bats approach and acquire food (pp 197-204). In: Kunz, T.H. and Racey, P.A (eds), Bat biology and conservation. Smithsonian Institution Press: Washington, D.C.

Kenneally, K.F., Keighery, G.J. and Hyland, B.P.M. (1991). Floristics and phytogeography of Kimberley rainforests (pp 93-131). In: McKenzie, N.L., Johnston, R.B. and Kendrick, P.G. (eds), Kimberley rainforests of Australia. Surrey Beatty and Sons: Chipping-Norton, Australia.

Kick, S.A. and Simmons, J.A. (1984). Automatic gain control in the bat's sonar receiver and the neuroethology of echolocation. The Journal of Neuroscience 4: 2725-2737.

Kingston, T.G., Jones, G., Akbar, Z. and Kunz, T.H. (1999). Echolocation signal call design in Kerivoulinae and Murininae (Chiroptera: Vespertilionidae) from Malaysia. Journal of Zoology (London) 249: 359-374.

Kingston, T.G., Jones, G., Zubaid, A. and Kunz, T.H. (2000). Resource partitioning in rhinolophoid bats revisited. Oecologia 124: 332-342.
Kitchener, D.J. and Caputi, N. (1985). Systematic revision of Australian Scotenax and Scotorepens (Chiroptera: Vespertilionidae), with remarks on relationships to other Nycticeiini. Records of the Western Australian Museum 12: 85-146.

Kitchener, D.J., Jones, B. and Caputi, N. (1987). Revision of Australian Eptesicus (Microchiroptera: Vespertilionidae). Records of the Western Australian Museum 13: 427-500.

Kitchener, D.J., Keller, L.E., Chapman, A., McKenzie, N.L., Start, A.N. and Kenneally, K.F. (1981). Observations on Mammals of the Mitchell Plateau area, Kimberley, Western Australia (pp 123-168). In: Biological survey of Mitchell Plateau and Admiralty Gulf, Kimberley, Western Australia. Western Australian Museum: Perth.

Krumbholz, K. and Schmidt, S. (1999). Perception of complex tones and its analogy to echo spectral analysis in the bat, Megaderma lyra. Journal of the Acoustical Society of America 105: 898-911.

Kuenzi, A.J. and Morrison, M.L. (2003). Temporal patterns of bat activity in southern Arizona. Journal of Wildlife Management 67: 52-64.

Kulzer, E., Nelsen, J.E., McKean, J.L. and Moehres, F.P. (1984). Prey-catching behaviour and echolocation in the Australian Ghost Bat (Macroderma gigas) (Microchiroptera: Megadermatidae). Australian Mammalogy 7: 37-50.

Lazure, L. and Fenton, M.B. (2011). High duty cycle echolocation and prey detection by bats. Journal of Experimental Biology 214: 1131-1137.

Laverghetta, T.S. (1981). Handbook of microwave testing. Artech, Dedham: Massachusetts, U.S.A.

Law, B., Anderson, J. and Chidel, M. (1998). A bat survey in state forests on the south-west slopes region of New South Wales with suggestions of improvements for future surveys. Australian Zoologist 30: 467-479.

Lee, S.M. and Chao, A. (1994). Estimating population size via sample coverage for closed capture-recapture models. Biometrics 50: 88-97.

Leibold, M.A., Holyoak, M., Mouquet, N, Amarasekare, P., Chase, J.M., Hoopes, M.F., Holt, R.D., Shurin, J.B., Law, R., Tilman, D., Loreau, M. and Gonzalez, A. (2004). The metacommunity concept: a framework for multi-scale community ecology. Ecology Letters 7: 601-613.

Leibold, M.A., Economo, E.P. and Peres-Neto, P. (2010). Metacommunity phylogenetics: separating the roles of environmental filters and historical biogeography. Ecology Letters 13: 1290-1299.

Losos, J.B. (2008). Phylogenetic niche conservatism, phylogenetic signal and the relationship between phylogenetic relatedness and ecological similarity among species. Ecological Letters 11: 995-1007.

Lumsden, L.F. and Bennett, A.F. (1995). Bats of a semi-arid environment in south-eastern Australia: biogeography, ecology and conservation. Wildlife Research 22: 217-240.

Lumsden, L.F., Churchill, S. and Schultz, M. (2005). Bat survey of the Ord River stage 2 M2 study area, Western Australia. Unpublished Report. Department of Sustainability and Environment: Heidelberg, Australia.

Marsh, R.A., Nataraj, K., Gans, D., Portfors, C.V., Wenstrup, J.J. (2006). Auditory responses of the cochlear nucleus of awake Mustached Bats: Precursors to spectral integration in the auditory midbrain. 
Journal of Neurophysiology 95: 88-105.

McKenzie, N.L. Chapman, A. and Youngson, W.K. (1975). Mammals of the Prince Regent River Reserve, Northwest Kimberley, W.A. (pp 69-74). In: Miles, J.M. and Burbidge, A.A. (eds) A biological survey of the Prince Regent River reserve, north-west Kimberley, Western Australia. Western Australian Wildlife Research Bulletin No. 3. Department of Fisheries and Wildlife: Perth.

McKenzie, N.L., Chapman. A., Youngson, W.K. and Burbidge, A.A. (1977). The Mammals of the Drysdale River National Park (pp 69-74). In: Kabay, E.D. and Burbidge, A.A. (eds), A biological survey of the Drysdale River National Park, North Kimberley, Western Australia. Western Australian Wildlife Research Bulletin No. 6. Department of Fisheries and Wildlife: Perth.

McKenzie, N.L., Burbidge, A.A., Chapman, A. and Youngson, W.K. (1978). Mammals (pp 22-28). In: Burbidge, A.A. and McKenzie, N.L. (eds), The islands of the north-west Kimberley, Western Australia. Western Australian Wildlife Research Bulletin No. 7. Department of Fisheries and Wildlife: Perth.

McKenzie, N.L. (1983). Mammals (pp 40-52). In: McKenzie, N.L. (ed.), Wildlife of the Dampier Peninsula, south-west Kimberley, Western Australia. Western Australian Wildlife Research Bulletin No. 11. Department of Fisheries and Wildlife: Perth.

McKenzie, N.L. and Rolfe, J.K. (1986). Structure of bat guilds in the Kimberley mangroves, Australia. Journal of Animal Ecology 55: 401-420.

McKenzie, N.L. and Start, A.N. (1989). Structure of bat guilds in mangroves: disturbance and determinism (pp 167-178). In: Morris, D.W., Abramski, Z., Fox, B.J. and Willig, M.R. (eds), Patterns in the structure of mammalian communities. Special Publication, Texas Technical University: Lubbock, U.S.A.

McKenzie, N.L., Belbin, L., Keighery, G.J. and Kenneally, K.F. (1991). Kimberley rainforest communities: patterns of species composition and Holocene biogeography (pp 423-452). In: McKenzie, N.L., Johnston, R.B. and Kendrick, P.G. (eds), Kimberley rainforests of Australia. Surrey Beatty and Sons: Chipping-Norton, Australia.

McKenzie, N.L., Fontanini, L., Lindus, N.V. and Williams, M.R. (1995). Biological survey of Koolan Island, Western Australia. 2. Zoological notes. Records of the Western Australian Museum 17: 249-266.

McKenzie, N.L. and Muir, W.P. (2000). Bats of the southern Carnarvon Basin, Western Australia. Records of the Western Australian Museum Supplement 61: 465-477.

McKenzie, N.L., Start, A.N. and Bullen, R.D. (2002). Foraging ecology and organization of a desert bat fauna. Australian Journal of Zoology 50: 529-548.

McKenzie, N.L. and Bullen, R.D. (2003). Identifying Little Sandy Desert bat species from their echolocation calls. Australian Mammalogy 25: 73-80.

McKenzie, N.L., Burbidge, A.A., Baynes, A., Brereton, R., Dickman, C.R., Gibson, L.A., Gordon, G., Menkhorst, R.W., Robinson, A.C., Williams, M.R. and Woinarski, J.C.Z. (2006). Analysis of factors implicated in the recent decline of Australia's mammalian fauna. Journal of Biogeography 34: 597-611.

McKenzie, N.L. and Bullen, R.D. (2009). The echolocation calls, habitat relationships, foraging niches and communities of Pilbara microbats. Records of the Western Australian Museum, Supplement 78: 123-155.

McMahon, J.P., Hutchinson, M.F., Nix, H.A. and Ord, K.D. (1995). ANUCLIM users guide. Version 1. Centre for Resource and Environmental Studies, Australian National University: Canberra.

McNab, B.K. (1980) Food-habits, energetics, and the population biology of mammals. American Naturalist 116: 106-124.

Meyer, C.F.J. and Kalko, E.K.V. (2008). Bat assemblages on neotropical land-bridge islands: nested subsets and null model analyses of species co-occurrence patterns. Diversity and Distribution 14: 644-654.

Meyer, C.F.J., Aguiar, L.M.S., Aguirre, L.F., Baumgarten, J., Clarke, F.M., Cosson, J-F., Villegas, S.E., Fahr, J., Faria, D., Furey, N., Henry, M., Hodgekison, R., Jenkins, R.K.B., Jung, K.G., Kingston, T., Kunz, T.H., Gonzalez, M.C.M., Moya, I., Patterson, B.D., Pons, J-M., Racey, P.A., Rex, K., Sampaio, E.M., Solari, S., Stoner, K.E., Voight, C.C., von Staden, D., Weise, C.D. and Kalko, E.K.V. (2011). Accounting for detectability improves estimates of species richness in tropical bat surveys. Journal of Applied Ecology doi: 10.1111/j.13652664.2011.01976.x

Meynard, C.N. and Quinn, J.F. (2007). Predicting species distributions: a critical comparison of the most common statistical models using artificial species. Journal of Biogeography 34: 1455-1469.

Milne, D.J. (2002). Key to the bat calls of the top end of the Northern Territory. Technical Report No. 71. Parks and Wildlife Commission: Darwin.

Milne, D.J., Fisher, A., Rainey, I. and Pavey, C.R. (2005a). Temporal patterns of bats in the top end of the Northern Territory, Australia. Journal of Mammalogy 86: 909-920.

Milne, D.J., Armstrong, A., Fisher, A., Flores, T. and Pavey, C.R. (2005b). Structure and environmental relationships of insectivorous bat assemblages in tropical Australian savannas. Austral Ecology 30: 914-927.

Milne, D.J., Fisher, A. and Pavey, C.R. (2006). Models of the habitat associations and distributions of insectivorous bats of the Top End of the Northern Territory, Australia. Biological Conservation 130: 370385.

Mora, E.C., Ibanez, C., Macias, S., Juste, J., Lopez, I. and Torres, L. (2011). Plasticity in the echolocation inventory of Mormopterus minutus (Chiroptera, Molossidae). Acta Chiropterologica 13: 179-187.

Morton, S.R., Short, J. and Barker, R.D. (1995). Refugia for biological diversity in arid and semi-arid Australia. Biodiversity Series Paper No 4, Biodiversity Unit. Department of Environment, Sports and Territories: Canberra, ACT.

Moss, C.F. and Surlykke, A. (2001). Auditory scene analysis by echolocation in bats. Journal of the Acoustical Society of America 110: 2207-2226.

Moss, C.F. and Zagaeski, M. (1994). Acoustic information available to bats using frequency-modulated sound for the perception of insect prey. Journal of the Acoustic Society of America 95: 2745-2756.

Mouquet, N. and Loreau, M. (2002). Coexistence in metacommunities: the regional similarity hypothesis. The American Naturalist 159: 420-426.

Neuweiler, G. (1989). Foraging ecology and audition in 
echolocating bats. Trends in Ecology and Evolution 4: 160-166.

Neuweiler, G. (1990). Auditory adaptations for prey capture in echolocating bats. Physiological Review 70: 615-641.

Nias, R.C., Burbidge, A.A., Ball, D. and Pressey, R.L. (2010). Island arks: the need for an Australian national biosecurity initiative. Ecological Management and Restoration 11: 166-167.

Nijs, I. and Roy, J. (2000). How important are species richness, species evenness and interspecific differences to productivity? A mathematical model. Oikos 88: 57-66.

Nix, H.A. and Kalma, J.D. (1972). Climate as a dominant control in the biogeography of Northern Australia and New Guinea (pp 61-93). In: Walker, D. (ed.), Bridge and barrier: the natural and cultural history of Torres Strait. Research School of Pacific Studies Publication B6/3, Australian National University: Canberra.

Norberg, U.M. and Rayner, J.M.V. (1987). Ecological morphology and flight in bats (Mammalia: Chiroptera): wing adaptations, flight performance, foraging strategy and echolocation. Philosophical Transactions of the Zoological Society of London B316, 335-427.

Obrist, M.K., Fenton, M.B., Eger, J.L. and Schlegel, P.A. (1993). What ears do for bats: a comparative study of pinna sound pressure transformation in chiroptera. Journal of Experimental Biology 180: 119-152.

Oksanen, L. (2001). Logic of experiments in ecology: is pseudoreplication a pseudoissue? Oikos 94: 27-38.

OZCAM (2011). Online zoological collections of Australian museums. http://www.biomaps.net.au/ ozcam2

Pausas, J.G. and Verdu, (2010). The jungle of methods for evaluating phenotypic and phylogenetic structure in communities. Bioscience 60: 614-625.

Parsons, S. and Jones, G. (2000). Acoustic identification of twelve species of echolocating bat by discriminant function analysis and artificial neural networks. Journal of Experimental Biology 203: 2641-2656.

Parsons, S., Boonman, A.M. and Obrist, M.K. (2000). Advantages and disadvantages of techniques for transforming and analysing Chiropteran echolocation calls. Journal of Mammalogy 81: 927-938.

Parsons, S. and Szewczak, J.M. (2009). Detecting, recording and analysing the vocalisations of bats (pp 91-111). In: Kunz, T.H. and Parsons, S. (eds), Ecological and behavioural methods for the study of bats 2nd edition. The John Hopkins University Press: Baltimore, U.S.A.

Preatoni, D.G., Nodari, M., Chirichella, R., Tosi, G., Wauters, L.A. and Martinoli, A. (2005). Identifying bats from time-expanded recordings of search calls: comparing classification methods. Journal of Wildlife Management 69: 1601-1614.

Presley, S.J., Higgins, C.L., Lopez-Gonzalez, C. and Stevens, R.D. (2009). Elements of metacommunity structure of Paraguayan bats: multiple gradients require analysis of multiple ordination axes. Oecologia 160: 781-793.

Prosser, C.L. and Brown, F. (1961). Comparative animal physiology. W.B. Saunders: Philadelphia, U.S.A.

Richards, G.C. (2001). Towards defining adequate bat survey methodology: why electronic call detection is essential throughout the night. Bat Society Newsletter 16: $24-28$.

Rodríguez-Gironés, M.A. and Santamaría, L. (2006). A new algorithm to calculate the nestedness temperature of presence-absence matrices. Journal of Biogeography 33: 924-935.

Rosenberg, M.S. and Anderson, C.D. (2011). PASSaGE: pattern analysis, spatial statistics and geographic exegesis. Version 2. Methods in Ecology and Evolution 2: 229-232.

Rosenzweig, M.L. and Abramski, Z. (1993). How are diversity and productivity related (pp 52-65)? In: Ricklefs, R.E. and Schluter, D. (eds), Species diversity in ecological communities: historical and geographical perspectives. University of Chicago Press: Chicago.

Russo, D., Mucedda, M., Bello, M., Biscardi, S., Pidinchedda, E. and Jones, G. (2007). Divergent echolocation call frequencies in insular rhinolophids (Chiroptera): a case of character displacement? Journal of Biogeography 24: 2129-2138.

Schnitzler, H.U. and Kalko, E.K.V. (1998). How echolocating bats search and find food (pp 183-196). In: Kunz, T.H. and Racey, P.A. (eds), Bat biology and conservation. Smithsonian Institution Press: Washington, D.C.

Schnitzler, H.U., Kalko, E.K.V. and Surlykke, A. (1987). The echolocation and hunting behaviour of the bat, Pipistrellus kuhli. Journal of Comparative Physiology A161: 267-274.

Seidman, V.M. and Zabel, C.J. (2001). Bat activity along intermittent streams in northwestern California. Journal of Mammalogy 82: 738-747.

Siemers, B.M. and Schnitzler, H.U. (2004). Echolocation signals reflect niche differentiation in five sympatric congeneric bat species. Nature 429: 657-661.

Simmons, J.A. (1989). A view of the world through the bat's ear: the formation of acoustic images in echolocation. Cognition 33: 155-199.

Simmons, J.A. and Stein, R.A. (1980). Acoustic imaging in bat sonar: echolocation signals and the evolution of echolocation. Journal of Comparative Physiology A135: 61-84.

Sneath, P.H.A. and Sokal, R.R. (1973). Numerical taxonomy. The principles and practice of numerical classification. W.H. Freeman, San Francisco.

Speakman, J.R. and Thomas D.W. (2003). Physiology ecology and energetics of bats (pp 430-490). In: Kunz, T.H. and Fenton M.B. (eds), Bat ecology. University of Chicago Press: Chicago.

Spicer, J.I. and Gaston, K. (1999). Physiological diversity and its ecological implications. Blackwell Science: Oxford, UK.

Srivastrava, D.S. and Lawton J.H. (1998). Why more productive sites have more species: an experimental test of theory using tree-hole communities. American Naturalist 152: 510-529.

Surlykke, A. and Kalko, E.K.V. (2008). Echolocating bats cry out loud to detect their prey. PLOS ONE 3(4): e2036.

Thomas, D.W. (1988). The distribution of bats in different ages of Douglas-fir forests. Journal of Wildlife Management 52: 619-626.

Tidemann, C.R. and Flavel, S.C. (1987). Factors affecting choice of diurnal roost sites by tree-hole bats (Microchiroptera) in south-eastern Australia. 
Australian Wildlife Research 14: 459-473.

Triblehorn, J.D. and Yager, D.D. (2005). Acoustic interactions between insects and bats: a model for the interplay of neural and ecological specializations (pp 77-1040). In: Barbosa, P. and Castellanos, I. (eds), Ecology of predator-prey interactions. Oxford University Press: UK.

Torenbeek, E. (1976). Synthesis of subsonic airplane design. Delft University Press: The Netherlands.

Urban, M.C. (2004). Disturbance heterogeneity determines freshwater metacommunity structure. Ecology 85: 2971-2978.

Van Dyck, S. and Strahan, R. (eds) (2008). The mammals of Australia. Reed New Holland: Sydney.

Walker, D. \& Chen, Y. (1987). Palynological light on tropical rainforest dynamics. Quaternary Science Review 6: 77-92.

Webb, L.T., Tracey, J.G. and Williams, W.T. (1984). A floristic framework of Australian rainforests. Australian Journal of Ecology 9: 169-198.

Whittaker, J.O. (1993). Bats, beetles and bugs: more big brown bats mean less agricultural pests. Bats 11: 23.

Williams, A.J. and Dickman, C.R. (2004). The ecology of insectivorous bats in the Simpson Desert, Central
Australia: habitat use. Australian Mammalogy 26: 205-214.

Wund, M.A. (2006). Variation in the echolocation calls of Little Brown Bats (Myotis lucifugus) in response to different habitats. American Midland Naturalist 156: 99-108.

Wyrwoll, K-H., Zhengyu, L., Chen, G., Kutzbach, J.E. and Liu, X. (2007). Sensitivity of the Australian summer monsoon to tilt and precession forcing. Quaternary Science Reviews 26: 3043-3057.

Yoshino, H., Matsumura, S., Kinjo, K Tamura, H., Ota, H. and Izawa, M. (2006). Geographical variation in echolocation call and body size of the Okinawan Least Horseshoe Bat, Rhinolophus pumilus (Mammalia: Rhinolophidae), on Okinawa-jima Island, Ryukyu Archipelago, Japan. Zoological Science 23: 661-667.

Young, R.A. and Ford, G.I. (2000). Bat fauna of a semiarid environment in central western Queensland, Australia. Wildlife Research 27: 203-215.

MANUSCRIPT RECEIVED OCTOBER 2011; ACCEPTED MARCH 2012. 


\section{APPENDICES (ELECTRONIC)}

Appendix $1 \quad$ Locations and dates of echolocation reference recordings used to develop the species call library. Species codes are explained in Table 1.

Appendix $2 \quad$ Island sampling site locations, environmental attributes (defined in Methods) and echolocation recording systems (1 = Anabat-minidisc MZ-N510 (mono-mode), 2 = Anabat-LS10, 3 = Anabat-Sony WMD6C, 4 = Song Meter SM2BATmono Wildlife Acoustics Inc. USA). ${ }^{a}$ The terms 'pool' and 'creek' refer to fresh water).

Appendix $3 \quad$ Comparison of 116 clean search-mode calls (total of 13 species overall) recorded simultaneously using Anabat and D940 frequency-division bat detectors feeding into the left and right channels of an Olympus LS10 digital stereo recorder. Call quality abbreviations ( $v$ = very; sym = symmetrical frequency peak; see Figure 2 in McKenzie and Bullen 2009). Species codes are provided in Table 1.

Appendix $4 \quad$ Field observations on flight behaviours and foraging strategies of Kimberley bats. Species codes are explained in Table 1.

Appendix $5 \quad$ Airframe measurements for Kimberley bats: mean (SD). Variable definitions are from Bullen and McKenzie (2001): $N=$ number of individuals, $m=$ mass, $b_{R E F}=$ reference wing span, $S_{R E F}=$ reference wing area, $S_{H T}=$ horizontal tail area, $I_{H T}=$ horizontal tail arm, $I_{=}=$ear arm, $S=$ ear area. Underlined values are derived from 6 individuals. ${ }^{*}=$ Tail membrane fully extended. Species codes are explained in Table 1.

Appendix 6 Acoustic recordings from each island, including the duration (minutes) and species identified from each recording. Other relevant data are provided in Appendix 2. Species codes are explained in Table 1.

Appendix 7 Species and island attribute values (see Table 3). Species codes are explained in Table 1.

Appendix 8 Dates of visits to islands by bat biologists, and resulting voucher specimens and sighting records. Dates enclosed in brackets are sampling visits that did not entail ultrasound recording.

Appendix $9 \quad$ An external character that distinguishes Scotorepens sanborni from S. greyii in the Kimberley. 